\title{
Macrocyclization in the Design of Organic n-Type Electronic Materials
}

Melissa Ball ${ }^{\dagger 1}$, Yu Zhong ${ }^{\dagger 1}$, Brandon Fowler ${ }^{1}$, Boyuan Zhang ${ }^{1}$, Panpan Li ${ }^{1,2}$, Grisha Etkin ${ }^{1}$, Daniel W. Paley $^{1}$, John Decatur ${ }^{1}$, Ankur K. Dalsania ${ }^{1}$, Hexing Li ${ }^{2}$, Shengxiong Xiao*2, Fay Ng*1, Michael L. Steigerwald ${ }^{* 1}$, Colin Nuckolls*1,2

Affiliations:

${ }^{1}$ Department of Chemistry, Columbia University, New York, New York 10027, United States

${ }^{2}$ The Education Ministry Key Lab of Resource Chemistry, Shanghai Key Laboratory of Rare Earth Functional Materials, Optoelectronic Nano Materials and Devices Institute, Department of Chemistry, Shanghai Normal University, Shanghai, China 200234

Email addresses of corresponding authors: senksong@msn.com, fwn2@columbia.edu, mls2064@columbia.edu, and cn37@columbia.edu

Table of Contents

$\begin{array}{lr}\text { I. Figures and Tables Referenced in the Manuscript } & \text { S-2 }\end{array}$

$\begin{array}{ll}\text { II. General Experimental Information } & \text { S-6 }\end{array}$

$\begin{array}{ll}\text { III. Synthetic Procedures and Characterization Data } & \text { S-8 }\end{array}$

IV. ${ }^{1} \mathrm{H}$ NMR and ${ }^{13} \mathrm{C}$ NMR Spectra $\quad$ S-26

V. Density Functional Theory (DFT) Calculations S-53

$\begin{array}{lr}\text { VII. References } & \text { S-60 }\end{array}$ 


\section{Figures and Tables Referenced in the Manuscript}
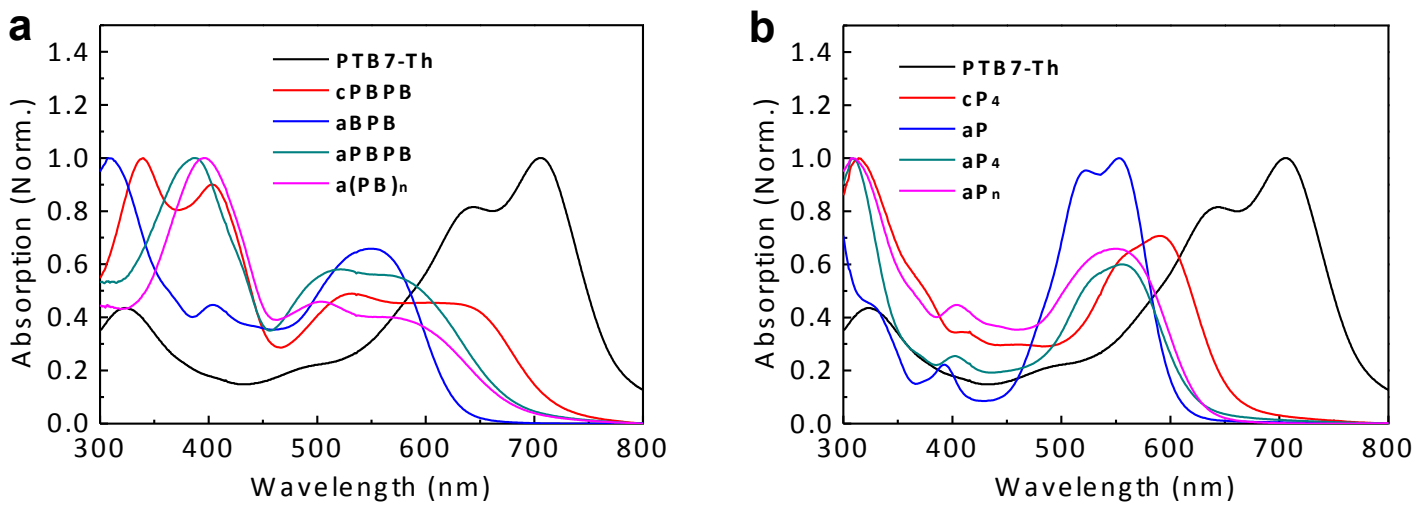

Figure S1. UV-vis absorption spectra measured in films: (a) for cPBPB, aBPB, aPBPB and $\mathbf{a}(\mathbf{P B})_{\mathbf{n}}(\mathrm{b})$ for $\mathbf{C P}_{\mathbf{4}}$, $\mathbf{a P}, \mathbf{a P}_{4}$, and $\mathbf{a} \mathbf{P}_{\mathbf{n}}$ normalized to each absorption maxima, where absorption $\max =1$.
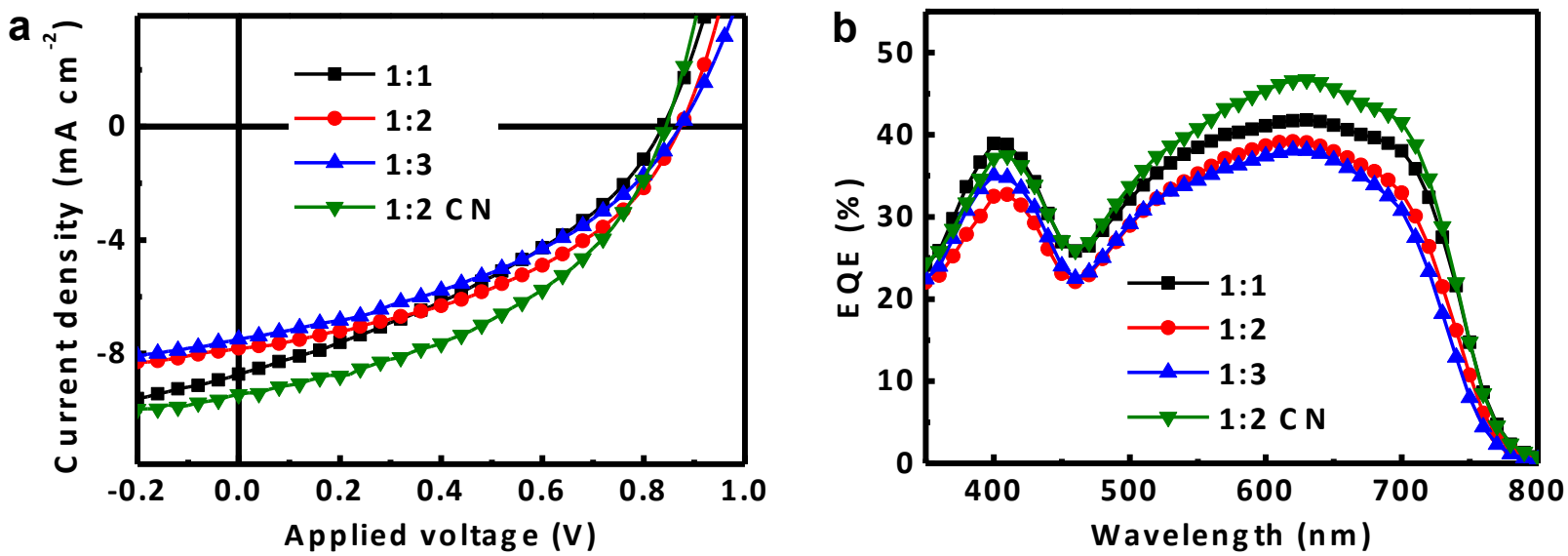

Figure S2. Device performance of PTB7-Th:cPBPB solar cells. (a) Current density versus voltage $(J-V)$ characteristics of PTB7-Th:cPBPB solar cells with different blend ratios (PTB7-Th to cPBPB) and $1 \%$ v/v CN. (b) EQE spectra of corresponding PTB7-Th:cPBPB solar cells.

Table S1. Summary of device parameters of best PTB7-Th:cPBPB solar cells with different conditions. Average PCE values were calculated from six devices for each condition; the highest PCE values are shown in parentheses.

\begin{tabular}{|c|c|c|c|c|}
\hline Mass ratio & $J_{s c}\left(\mathrm{mAcm}^{-2}\right)$ & $V_{o c}(\mathbf{V})$ & FF & PCE (\%) \\
\hline $1: 1$ & $8.5 \pm 0.3$ & $0.83 \pm 0.01$ & $0.36 \pm 0.01$ & $2.5 \pm 0.1(2.6)$ \\
\hline $1: 2$ & $7.6 \pm 0.2$ & $0.87 \pm 0.01$ & $0.43 \pm 0.01$ & $2.8 \pm 0.1(2.9)$ \\
\hline $1: 3$ & $7.4 \pm 0.1$ & $0.87 \pm 0.01$ & $0.40 \pm 0.01$ & $2.5 \pm 0.1(2.6)$ \\
\hline $1: 2$ with CN & $9.2 \pm 0.3$ & $0.84 \pm 0.01$ & $0.44 \pm 0.01$ & $3.3 \pm 0.2(3.5)$ \\
\hline
\end{tabular}



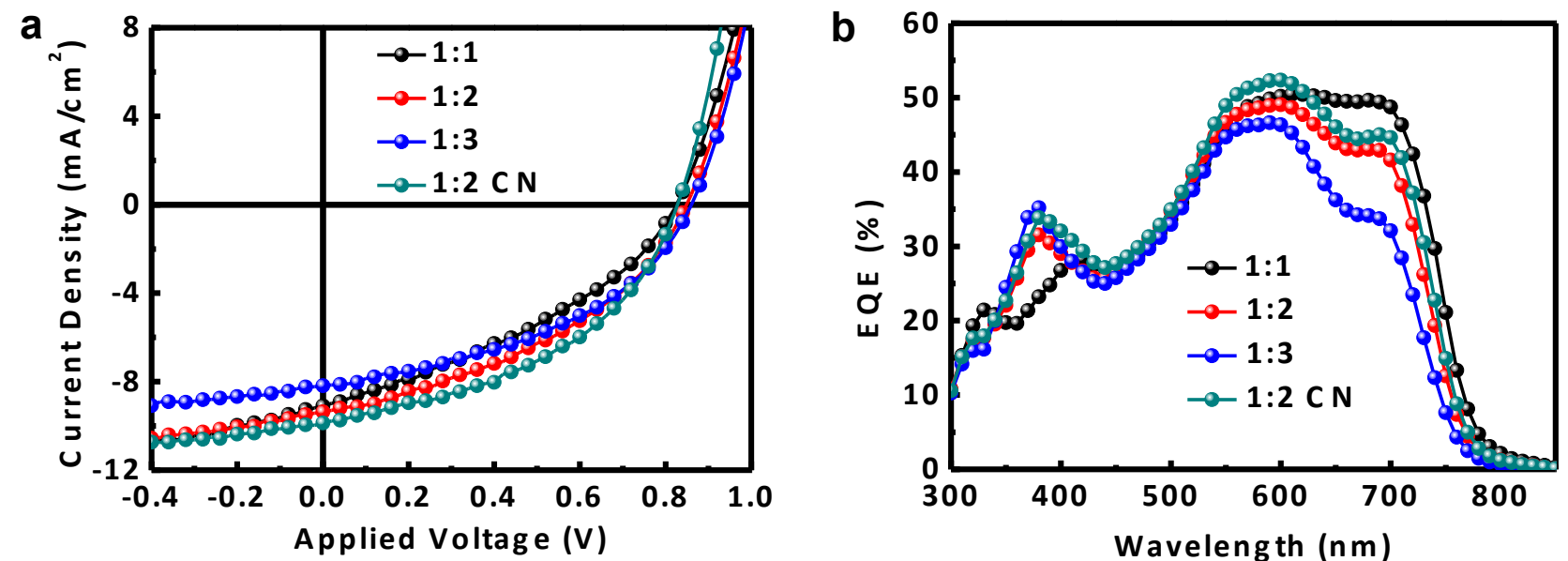

Figure S3. Device performance of PTB7-Th:CP 4 solar cells. (a) Current density versus voltage $(J-V)$ characteristics of PTB7-Th: $\mathbf{C P}_{4}$ solar cells with different blend ratios (PTB7-Th to $\mathbf{c P}_{\mathbf{4}}$ ) and $1 \% \mathrm{v} / \mathrm{v}$ CN. (b) EQE spectra of corresponding PTB7-Th:CP 4 solar cells.

Table S2. Summary of device parameters of best PTB7-Th:CP 4 solar cells with different conditions. Average PCE values were calculated from six devices for each condition; the highest PCE values are shown in parentheses.

\begin{tabular}{|c|c|c|c|c|}
\hline Mass ratio & $J_{s c}\left(\mathrm{mAcm}^{-2}\right)$ & $V_{o c}(\mathbf{V})$ & FF & PCE (\%) \\
\hline $1: 1$ & $8.6 \pm 0.3$ & $0.82 \pm 0.01$ & $0.37 \pm 0.01$ & $2.6 \pm 0.2(2.8)$ \\
\hline $1: 2$ & $8.8 \pm 0.2$ & $0.85 \pm 0.01$ & $0.41 \pm 0.01$ & $3.0 \pm 0.1(3.2)$ \\
\hline $1: 3$ & $7.6 \pm 0.2$ & $0.86 \pm 0.01$ & $0.43 \pm 0.01$ & $2.8 \pm 0.2(3.0)$ \\
\hline $1: 2$ with CN & $9.7 \pm 0.2$ & $0.83 \pm 0.01$ & $0.44 \pm 0.01$ & $3.5 \pm 0.1(3.6)$ \\
\hline
\end{tabular}



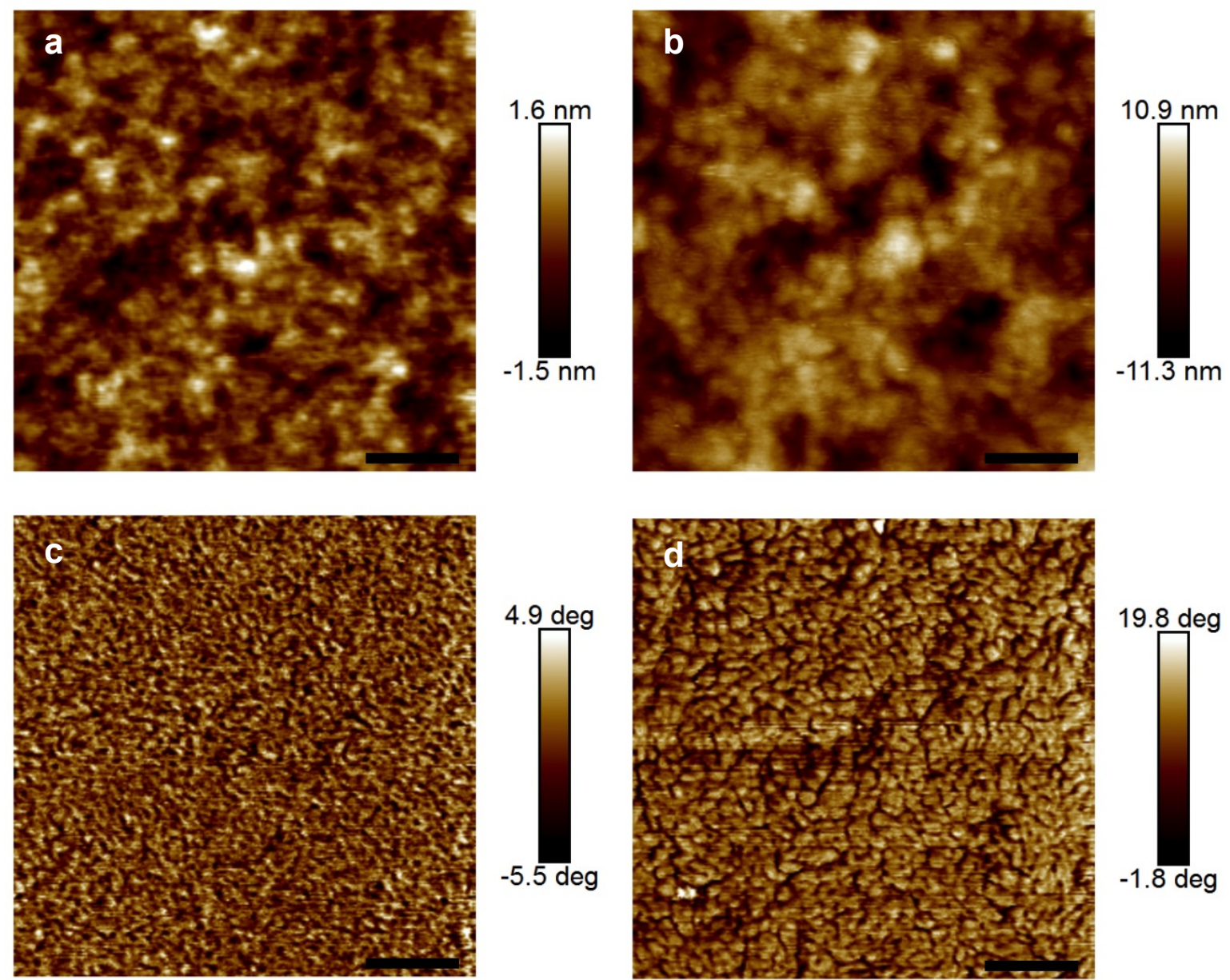

Figure S4. AFM height images of PTB7-Th:cPBPB films at a donor:acceptor ratio of 1:2 (a) without CN and (b) with $1 \% \mathrm{CN}$. AFM phase images of PTB7-Th:CPBPB films at a donor:acceptor ratio of 1:2 (c) without CN and (d) with $1 \% \mathrm{CN}$. The scale bar is $200 \mathrm{~nm}$. Both of the active layers have very smooth surface, with root-mean-square roughness (RMS) of $0.5 \mathrm{~nm}$ and $2.6 \mathrm{~nm}$ for films both with/without $1 \% \mathrm{CN}$, respectively. When turning to the phase images, we observed fibrous domains in the active layer without $\mathrm{CN}$. However, this feature is too fine to be quantified under the instrument limit $(\sim 8 \mathrm{~nm})$. In contrast, the active layer with the $1 \% \mathrm{CN}$ additive possesses clear phase separation as shown in $\mathrm{d}$. The average domain size is estimated to be $20-40 \mathrm{~nm}$. Here CN plays a critical role in phase aggregation, which is essential to the device performance. 
$\mathbf{a}$
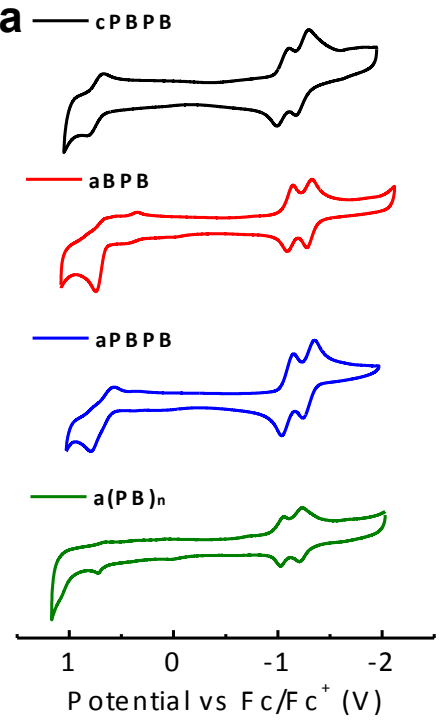

b

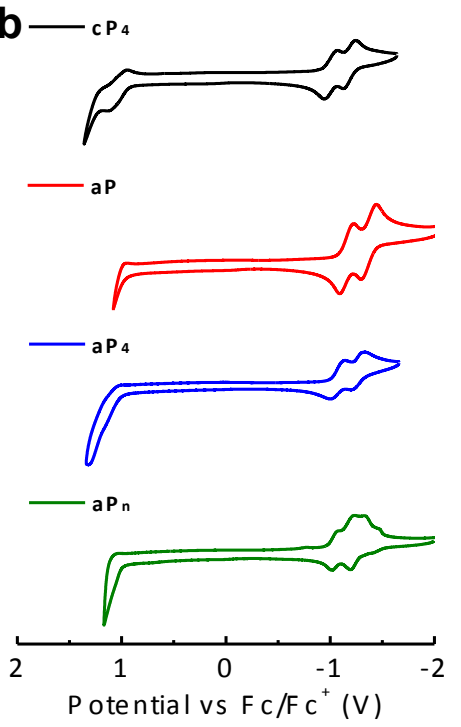

Figure S5. Cyclic voltammograms (a) for cPBPB, aBPB, aPBPB and $\mathbf{a}(\mathbf{P B})_{\mathbf{n}}(\mathrm{b})$ for $\mathbf{c P}_{\mathbf{4}}, \mathbf{a P}$, $\mathbf{a P} \mathbf{P}_{4}$, and $\mathbf{a P} \mathbf{P}_{\mathbf{n}}$.
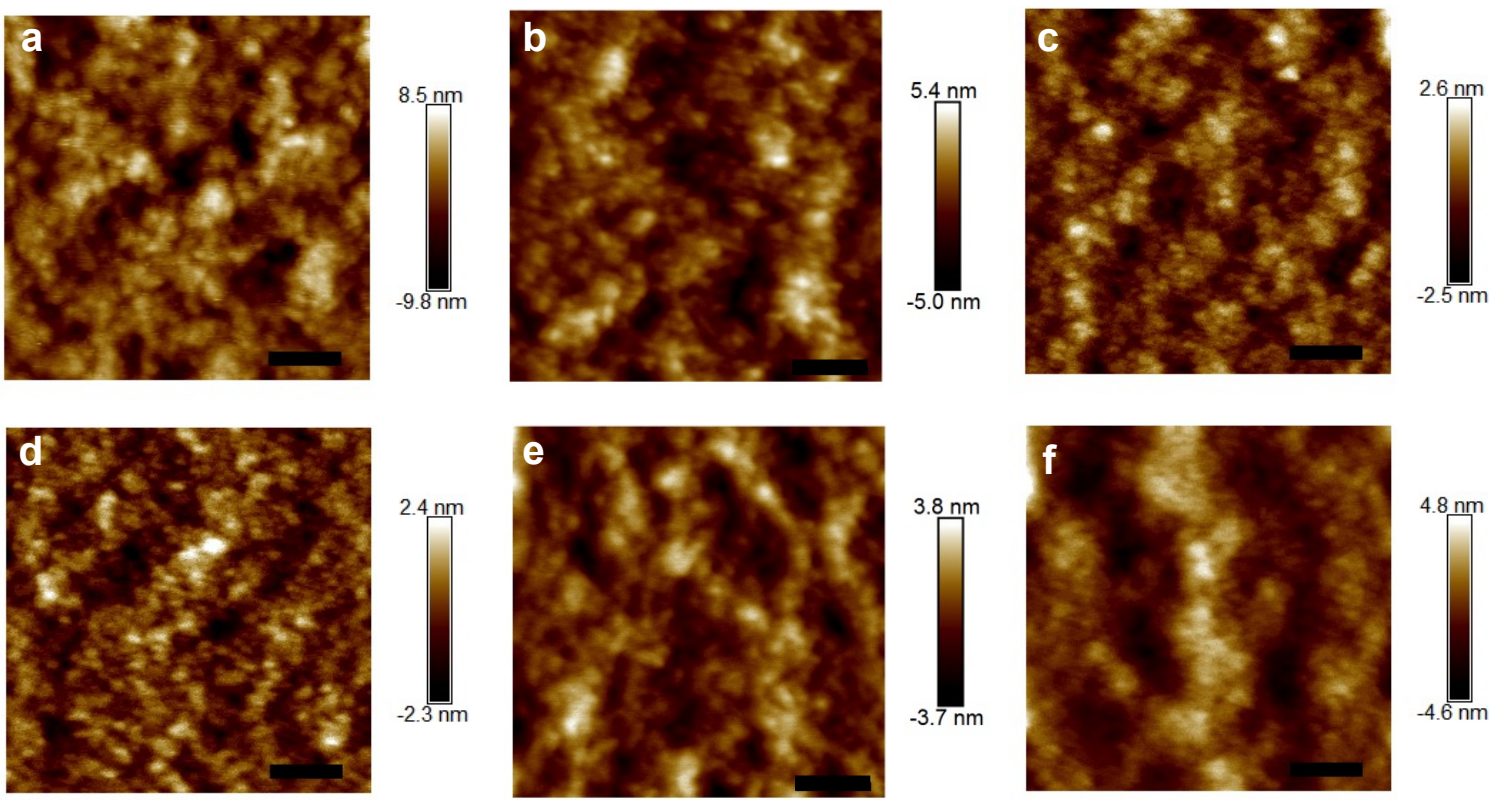

Figure S6. AFM height images of bulkjunction films for (a) CPBPB, (b) aBPB, (c) a(PB) n, (d) $\mathbf{c P}_{\mathbf{4}}$, (e) aP, and (f) $\mathbf{a P}_{\mathrm{n}}$. The mass ratio of donor-to-acceptor is fixed at 1:2.1\% CN additive was used. The scale bar is $200 \mathrm{~nm}$. 


\section{General Experimental Information}

Synthesis. All reactions were performed in oven-dried or flame-dried round bottom flasks unless otherwise noted. The flasks were fitted with rubber septa and reactions were conducted under a positive pressure of nitrogen unless otherwise noted. Anhydrous and anaerobic solvents were obtained from a Glass Contour solvent system consisting of a Schlenk manifold with purification columns packed with activated alumina and supported copper catalyst. Reaction monitoring by thin layer chromatography (TLC) was performed on J.T. Baker Baker-flex Silica Gel IB2-F (25 mm x $75 \mathrm{~mm})$ TLC plates. TLC visualization was accomplished by visible observation and irradiation with a UV lamp.

Reagents. Commercial reagents were used without further purification. $\mathrm{Pt}(\mathrm{COD}) \mathrm{Cl}_{2}$ was purchased from Strem Chemicals, and all other reagents were purchased from Sigma-Aldrich.

Purificaton. Automated flash chromatography was performed using a Teledyne Isco Combiflash Rf200 and Redisep Rf Silica columns. Preparative high performance liquid chromatography (HPLC) was performed on a Waters Prep150 instrument equipped with a UV-vis detector, an automated fraction collector, and a Nacalai Tesque COSMOSIL Buckyprep column (20 mm I.D. x $250 \mathrm{~mm}, 5 \mu \mathrm{m}$ ).

Spectrometers. ${ }^{1} \mathrm{H}$ NMR spectra were recorded on a Bruker $500 \mathrm{MHz}$ or $400 \mathrm{MHz}$ spectrometer. ${ }^{13} \mathrm{C}$ NMR spectra were recorded on a Bruker $125 \mathrm{MHz}$ or $100 \mathrm{MHz}$ spectrometer with complete proton decoupling. NMR spectra were recorded at $300 \mathrm{~K}$ unless otherwise noted. Chemical shifts for protons are reported in parts per million (ppm) downfield from tetramethylsilane (TMS) and are referenced to residual protium in the said NMR solvent. Chemical shifts for carbon are reported in ppm downfield from TMS and are referenced to the carbon resonances of the indicated solvent. Data are represented as follows: chemical shift, multiplicity $(s=\operatorname{singlet}, d=$ doublet, $d d=$ doublet of doublets, $\mathrm{t}=$ triplet, $\mathrm{m}=$ multiplet), coupling constants in $\mathrm{Hz}$, and integration.

High-resolution mass spectrometry (HRMS) was performed on (1) a Waters XEVO G2-XS QTOF instrument equipped with a UPC ${ }^{2}$ SFC inlet, and electrospray (ESI) and atmospheric pressure chemical (APCI) ionization sources; or (2) a Bruker UltrafleXtreme MALDI TOF/TOF instrument using a dithranol matrix.

UV-vis absorption spectra were recorded on a Shimadzu UV-1800 spectrophotometer using a $1.0 \mathrm{~cm}$ quartz cell. Infrared (IR) spectra were recorded on a Perkin Elmer Spectrum400 FTIR spectrometer using a PIKE ATR attachment.

GPC analysis was done on an Agilent Technologies 1200 Infinity Series GPC fitted with a refractive index detector and a UV-visible detector. All samples were eluted at $1.0 \mathrm{~mL} / \mathrm{min}$ through two Agilent Technologies PLgel $5 \mu \mathrm{m}$ MIXED-D $300 \times 7.5 \mathrm{~mm}$ columns and monitored by their UV-vis signal. $M_{n}$ and $M_{w}$ were assigned based off of polystyrene standards.

Atomic force microscopy. AFM measurements were carried out in tapping mode on a Bruker Multi-Mode AFM at ambient conditions. A commercial silicon cantilever (RTESPA, MPP-11120-10, Bruker) was used in this study with a typical radius of curvature of $\sim 8 \mathrm{~nm}$ and a nominal spring constant of $\sim 40 \mathrm{Nm}^{-1}$.

Cyclic Voltammetry. Cyclic voltammograms (CVs) were recorded on a $\mathrm{CH} 166$ electrochemical workstation using an $\mathrm{Ag} / \mathrm{AgCl}$ electrode as the reference electrode at room temperature. Experiments were performed in $\mathrm{CH}_{2} \mathrm{Cl}_{2}$ with $\mathrm{NBu}_{4} \mathrm{PF}_{6}$ as the supporting electrolyte at a scan rate of $0.1 \mathrm{~V} / \mathrm{s}^{1}$

Thin film transistors. To create the devices, we first silanize the substrate (300 nm of $\mathrm{SiO}_{2}$ on a $\mathrm{Si}$ wafer) with octadecyltrichlorosilane (OTS). Au is deposited onto the substrate as bottom-contact source and drain electrodes $(40 \mathrm{~nm})$ with a width of $105 \mu \mathrm{m}$ and length of $20 \mu \mathrm{m}$. Next, we spin-cast organic films onto the surface at 1,000 r.p.m. for $1 \mathrm{~min}$, to form transistors using the silicon wafer as the global back gate for the device. Finally, the samples were annealed under inert atmosphere at $160^{\circ} \mathrm{C}$ for 10 minutes to optimize device performance except that the a-P4 film was annealed at $120^{\circ} \mathrm{C}$. The thin film transistors were tested on the Agilent $4155 \mathrm{C}$ semiconductor parameter analyzer.

Solar cell fabrication. PTB7-Th was purchased from 1-Material Inc. Synthesis of ZnO sol-gel precursor was described elsewhere. ${ }^{2}$ Zinc acetate dihydrate, ethanolamine, 2-methoxyethanol, DIO and all of the solvents were purchased from Sigma Aldrich. Pre-patterned ITO-coated glass with a sheet resistance of $\sim 15 \Omega \mathrm{sq}^{-1}$ was cleaned 
with detergent and ultrasonicated in deionized water, acetone and isopropanol for $30 \mathrm{~min}$, respectively. Subsequently, we treated the substrates by ultraviolet-ozone for $10 \mathrm{~min}$. The prepared $\mathrm{ZnO}$ precursor was spincast onto the ITO substrate at 3,000 r.p.m. for $1 \mathrm{~min}$, followed by annealing at $200{ }^{\circ} \mathrm{C}$ for $1 \mathrm{~h}$ in air, to form a thin film with approximate thickness of $20 \mathrm{~nm}$. Active layers were prepared by spin-coating a mixed solution containing polymer and acceptor in chlorobenzene at a total concentration of $25 \mathrm{mgml}^{-1}$. The thickness of the prepared active layers is about $100 \mathrm{~nm}$. Finally, a $7 \mathrm{~nm} \mathrm{MoO}$ layer was deposited first and then a $100-\mathrm{nm} \mathrm{Ag}$ electrode was subsequently deposited through a shadow mask by thermal evaporation under a vacuum about $1 \times 10^{-6}$ torr. The current density-voltage $(J-V)$ curves were measured by a Keithley $2635 \mathrm{~A}$ source measure unit. The photocurrent was measured under AM 1.5G illumination at $100 \mathrm{mWcm}^{-2}$ under a Newport solar Simulator. A KG5-Si reference cell traceable to Newport was used to calibrate light intensity. The effective device area was defined as $6.25 \mathrm{~mm}^{2}$ by an aperture mask. EQE measurements were performed using a QEXL system from PV Measurements Inc. 


\section{Synthetic Procedures and Characterization Data}

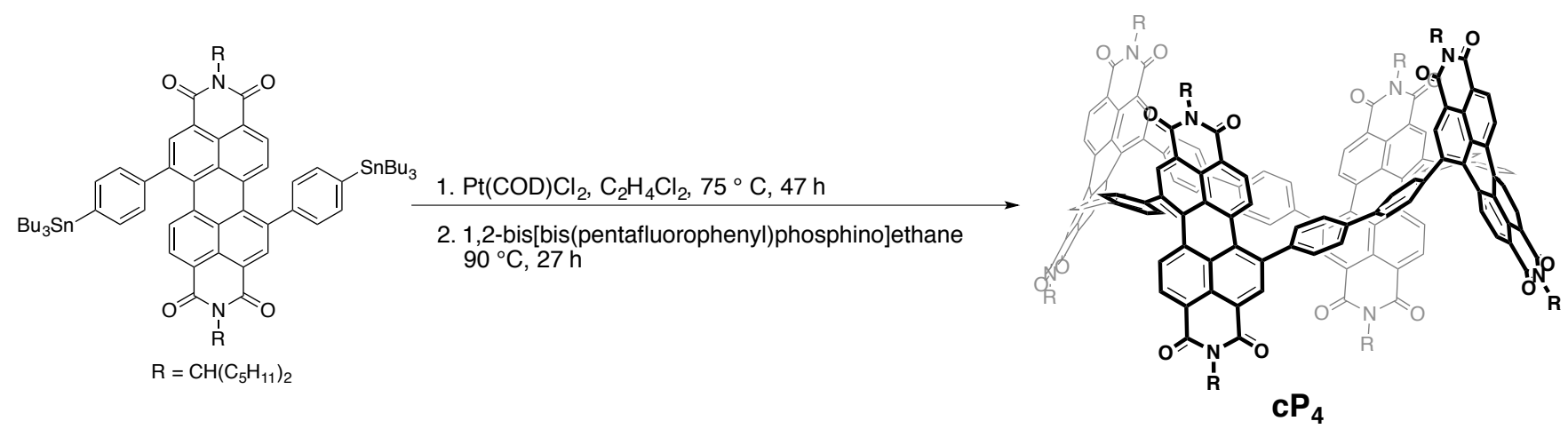

Synthesis of $\boldsymbol{c P}_{4}$. Regio-pure 1,7-Bis[4-(tributylstannyl)-phenyl]-PDI ,was synthesized by the published procedure, ${ }^{3}$ from regio-pure $N, N^{\prime}{ }^{\prime}$ di(6-undecyl)-1,7-dibromoperylene-3,4:9,10-tetracarboxylic diimide. The 1,6and 1,7-regioisomers of $N, N^{\prime}$-di(6-undecyl)-dibromoperylene-3,4:9,10-tetracarboxylic diimide were separated using prep HPLC on a COSMOSIL Buckyprep $20 \times 250 \mathrm{~mm}, 18.9 \mathrm{~mL} / \mathrm{min}$ and $12: 88 \mathrm{CH}_{2} \mathrm{Cl}_{2}$ :hexanes prior to the Suzuki coupling. Bis-stannane $\left(1.04 \mathrm{~g}, 0.727 \mathrm{mmol}, 1.00\right.$ equiv) and $\mathrm{Pt}(\mathrm{COD}) \mathrm{Cl}_{2}(0.272 \mathrm{~g}, 0.727 \mathrm{mmol}, 1.00$ equiv) were added to an oven-dried, 2-neck, 500-mL roundbottom flask with a stir bar. 1,2-Dichloroethane (300 $\mathrm{mL}$ ) was added, and the mixture was sparged with $\mathrm{N}_{2}$ for 30 min at ambient temperature. Under positive pressure of $\mathrm{N}_{2}$, the flask was placed in an oil bath at $75^{\circ} \mathrm{C}$ with stirring for $47 \mathrm{~h}$. The mixture was allowed to cool to ambient temperature before adding 1,2-bis[bis(pentafluorophenyl)phosphino]ethane (2.76 g, $3.63 \mathrm{mmol}, 5.00$ equiv). The mixture was stirred at room temperature for $30 \mathrm{~min}$, fitted with a reflux condenser, and placed in an oil bath at 90 ${ }^{\circ} \mathrm{C}$ for $27 \mathrm{~h}$. The mixture was allowed to cool to room temperature then concentrated under reduced pressure. The crude mixture was loaded onto a silica column (120 g Redisep Rf Silica) and made more pure by a gradient elution from 9:1 $\mathrm{CH}_{2} \mathrm{Cl}_{2} /$ hexanes to $\mathrm{CH}_{2} \mathrm{Cl}_{2}$ to $9: 1 \mathrm{CH}_{2} \mathrm{Cl}_{2} / \mathrm{MeOH}$ at $85 \mathrm{~mL} / \mathrm{min}$. Fractions containing $\mathbf{c P}_{\mathbf{4}}$ were identified by MALDI-TOF MS and were collected and concentrated. These fractions were further purified by preparative HPLC on a COSMOSIL Buckyprep column $(20 \times 250 \mathrm{~mm})$ with an eluent of $12 \% \mathrm{CH}_{2} \mathrm{Cl}_{2} /$ hexanes $(\mathrm{v} / \mathrm{v})$ at a flow rate of $18.9 \mathrm{~mL} / \mathrm{min}$. The pure fractions were concentrated to give $\mathbf{C P}_{\mathbf{4}}$ as a dark purple solid $(0.0530 \mathrm{~g}$, $0.0150 \mathrm{mmol}, 8 \%$ yield). ${ }^{1} \mathrm{H}$ NMR $\left(500 \mathrm{MHz}, \mathrm{C}_{2} \mathrm{D}_{2} \mathrm{Cl}_{4}, 413 \mathrm{~K}\right) \delta 8.62(\mathrm{~s}, 8 \mathrm{H}), 8.39(\mathrm{~d}, \mathrm{~J}=8.0 \mathrm{~Hz}, 8 \mathrm{H}), 8.32(\mathrm{~d}, \mathrm{~J}=$ $8.0 \mathrm{~Hz}, 8 \mathrm{H}), 7.75(\mathrm{~d}, \mathrm{~J}=8.4 \mathrm{~Hz}, 16 \mathrm{H}), 7.64(\mathrm{br} d, \mathrm{~J}=7.7 \mathrm{~Hz}, 16 \mathrm{H}), 5.21-5.13(\mathrm{~m}, 8 \mathrm{H}), 2.30-2.18(\mathrm{~m}, 16 \mathrm{H})$, $2.00-1.89(\mathrm{~m}, 16 \mathrm{H}), 1.44-1.29(\mathrm{~m}, 96 \mathrm{H}), 0.89(\mathrm{t}, \mathrm{J}=7.0 \mathrm{~Hz}, 48 \mathrm{H}) .{ }^{13} \mathrm{C} \mathbf{N M R}\left(125 \mathrm{MHz}, \mathrm{C}_{2} \mathrm{D}_{2} \mathrm{Cl}_{4}, 383 \mathrm{~K}\right) \delta$ 163.82, 163.57, 141.33, 140.40, 134.93, 134.52, 132.57, 130.13, 129.89, 129.52, 129.35, 128.46 (br), 127.45, 122.64, 122.30, 54.74, 32.34, 31.44, 26.38, 22.13, 13.53. IR $\left(\mathrm{cm}^{-1}\right)$ 2955, 2927, 2860, 1695, 1657, 1595, 1585, 
1456, 1407, 1324, 1238, 1180, 1127, 1096, 1003, 812. HRMS (MALDI-) calculated $\mathrm{m} / \mathrm{z}$ for $\left[\mathrm{C}_{232} \mathrm{H}_{240} \mathrm{~N}_{8} \mathrm{O}_{16}\right]^{-}$ 3393.821, found 3393.715.

Broadening of peaks (br) at this temperature likely results from slow rotation of the benzene rings. 


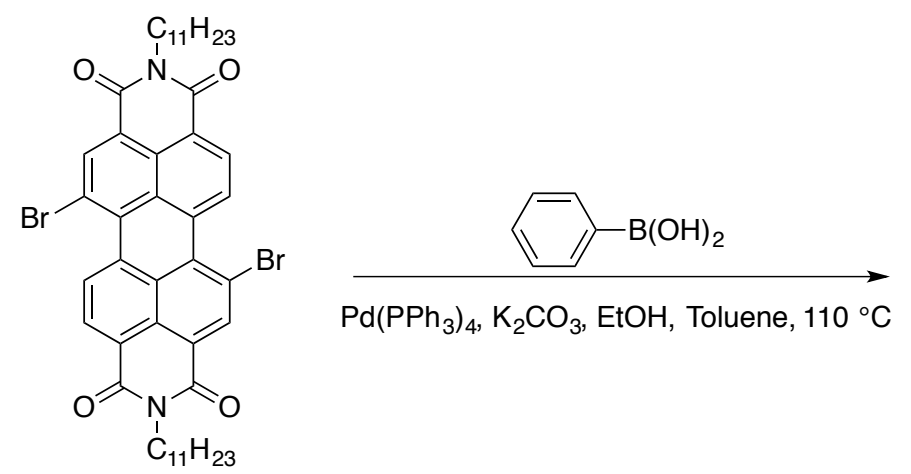

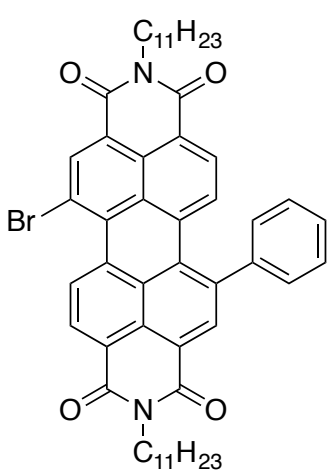

SI-1

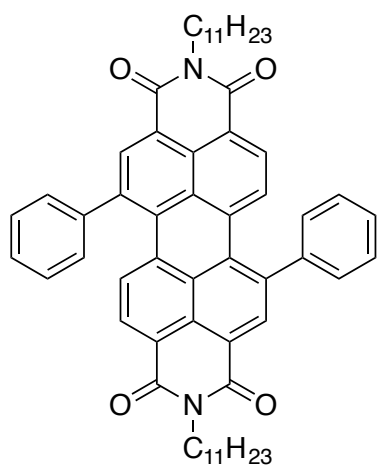

aP

Synthesis of SI-1 and aP. The 1,6- and 1,7-regioisomers of $N, N^{\prime}$-di(6-undecyl)-dibromoperylene-3,4:9,10tetracarboxylic diimide were separated using prep HPLC on a COSMOSIL Buckyprep $20 \times 250 \mathrm{~mm}, 18.9 \mathrm{~mL} / \mathrm{min}$ and 12:88 $\mathrm{CH}_{2} \mathrm{Cl}_{2}$ :hexanes. $N, N^{\prime}$-Di(6-undecyl)-1,7-dibromoperylene-3,4:9,10-tetracarboxylic diimide $(0.600 \mathrm{~g}$, $0.703 \mathrm{mmol}, 1.00$ equiv), phenyl boronic acid $\left(0.0430 \mathrm{~g}, 0.352 \mathrm{mmol}, 0.500\right.$ equiv), aqueous $\mathrm{K}_{2} \mathrm{CO}_{3}(2 \mathrm{M}, 6.00$ $\mathrm{mL}), \mathrm{EtOH}(1.20 \mathrm{~mL})$ and toluene $(18.0 \mathrm{~mL})$ were added to a two-neck $100-\mathrm{mL}$ round bottom flask equipped with a stir bar. The mixture was sparged with $\mathrm{N}_{2}$ for thirty minutes. While under $\mathrm{N}_{2}$, tetrakis(triphenylphosphine)palladium(0) $(0.0810 \mathrm{~g}, 0.0703 \mathrm{mmol}, 0.100$ equiv) was added. The mixture was further sparged for ten minutes before being fitted with a condenser and placed in a $100{ }^{\circ} \mathrm{C}$ oil bath under $\mathrm{N}_{2}$, stirring for twenty-four hours. The crude mixture was extracted with ethyl acetate and brine, concentrated and purified by column chromatography (40 g Redisep Rf Silica) using a gradient from $0 \%$ to $100 \% \mathrm{CH}_{2} \mathrm{Cl}_{2} /$ hexanes at $40 \mathrm{~mL} / \mathrm{min}$. Further purification by prep HPLC (COSMOSIL Buckyprep $20 \times 250 \mathrm{~mm}, 18.9 \mathrm{~mL} / \mathrm{min}$ and 3:93 $\mathrm{CH}_{2} \mathrm{Cl}_{2}$ :hexanes) yielded SI-1 (0.0930 g, $\left.0.109 \mathrm{mmol}, 16 \%\right)$ and aP $(0.0290 \mathrm{~g}, 0.0341,5.0 \%)$ SI-1: ${ }^{1} \mathbf{H}$ NMR $(400$ $\left.\mathrm{MHz}, \mathrm{CDCl}_{3}\right) \delta 9.54(\mathrm{~d}, \mathrm{~J}=8.2 \mathrm{~Hz}, 1 \mathrm{H}), 8.90(\mathrm{br}, 1 \mathrm{H}), 8.66(\mathrm{br}, 2 \mathrm{H}), 8.11(\mathrm{br}, 1 \mathrm{H}), 7.80(\mathrm{~d}, \mathrm{~J}=8.2 \mathrm{~Hz}, 1 \mathrm{H}), 7.49$ (br, 5H), $5.24-5.16(\mathrm{~m}, 1 \mathrm{H}), 5.12(\mathrm{br}, 1 \mathrm{H}), 2.30-2.17(\mathrm{~m}, 4 \mathrm{H}), 1.88-1.79(\mathrm{~m}, 4 \mathrm{H}), 1.26(\mathrm{br}, 24 \mathrm{H}), 0.85(\mathrm{br}$, 12H). ${ }^{13} \mathrm{C}$ NMR $\left(100 \mathrm{MHz}, \mathrm{CDCl}_{3}\right) \delta 164.61,164.26,163.53,162.54,141.96,141.43,138.48,137.83,135.74$, 135.07, 133.91, 133.70, 133.63, 131.62, 130.37, 130.30, 130.18, 129.99, 129.77, 129.58, 129.28, 128.99, 128.80, $128.67,128.24,127.70,127.41,123.87,123.16,122.45,121.76,120.29,54.87,54.76,32.34,32.26,31.75$, 31.72, 26.58, 22.57, 22.54, 14.04. IR $\left(\mathrm{cm}^{-1}\right)$ 2955, 2925, 2857, 1698, 1657, 1596, 1587, 1456, 1447, 1403, 1326, 1239, $1184,914,812,734$. HRMS $(\mathrm{APCl}+)$ calculated $\mathrm{m} / \mathrm{z}$ for $\left[\mathrm{C}_{52} \mathrm{H}_{57} \mathrm{~N}_{2} \mathrm{O}_{4} \mathrm{Br}+\mathrm{H}\right]^{+}$853.3580, found 853.3572. aP: ${ }^{1}$ H NMR $\left(400 \mathrm{MHz}, \mathrm{CDCl}_{3}\right) \delta 8.62(\mathrm{br}, 2 \mathrm{H}), 8.12(\mathrm{br}, 2 \mathrm{H}), 7.82(\mathrm{~d}, \mathrm{~J}=8.2 \mathrm{~Hz}, 2 \mathrm{H}), 7.59-7.55(\mathrm{~m}, 4 \mathrm{H}), 7.54-7.45$ (m, 6H), $5.15(b r, 2 H), 2.29-2.16(m, 4 H), 1.88-1.76(m, 4 H), 1.37-1.18(m, 24 H), 0.83(t, J=6.6 \mathrm{~Hz}, 12 \mathrm{H})$ 
${ }^{13} \mathrm{C}$ NMR $\left(100 \mathrm{MHz}, \mathrm{CDCl}_{3}\right) \delta 164.70,163.63,142.23,141.08,135.78,135.10,134.81,132.49,130.22,130.16$ $129.91,129.23,129.17,129.03,128.59,127.90,122.87,122.53,122.13,121.77,54.65,32.32,31.75,26.59$, 22.55, 14.04. IR $\left(\mathrm{cm}^{-1}\right)$ 2956, 2925, 2860, 1695, 1657, 1598, 1585, 1409, 1325, 1242, 910, 814. HRMS (APCI-) calculated $\mathrm{m} / \mathrm{z}$ for $\left[\mathrm{C}_{58} \mathrm{H}_{62} \mathrm{~N}_{2} \mathrm{O}_{4}\right]^{-} 850.4710$, found 850.4704

Broadening (br) of peaks in the ${ }^{1} \mathrm{H}$ NMR spectrum is due to rotational isomers about the imide side chains. ${ }^{3,4}$ Multiple peaks for the same carbon in the ${ }^{13} \mathrm{C}$ NMR spectrum reflect rotational isomers about the imide side chains that have been seen previously. ${ }^{3,4}$
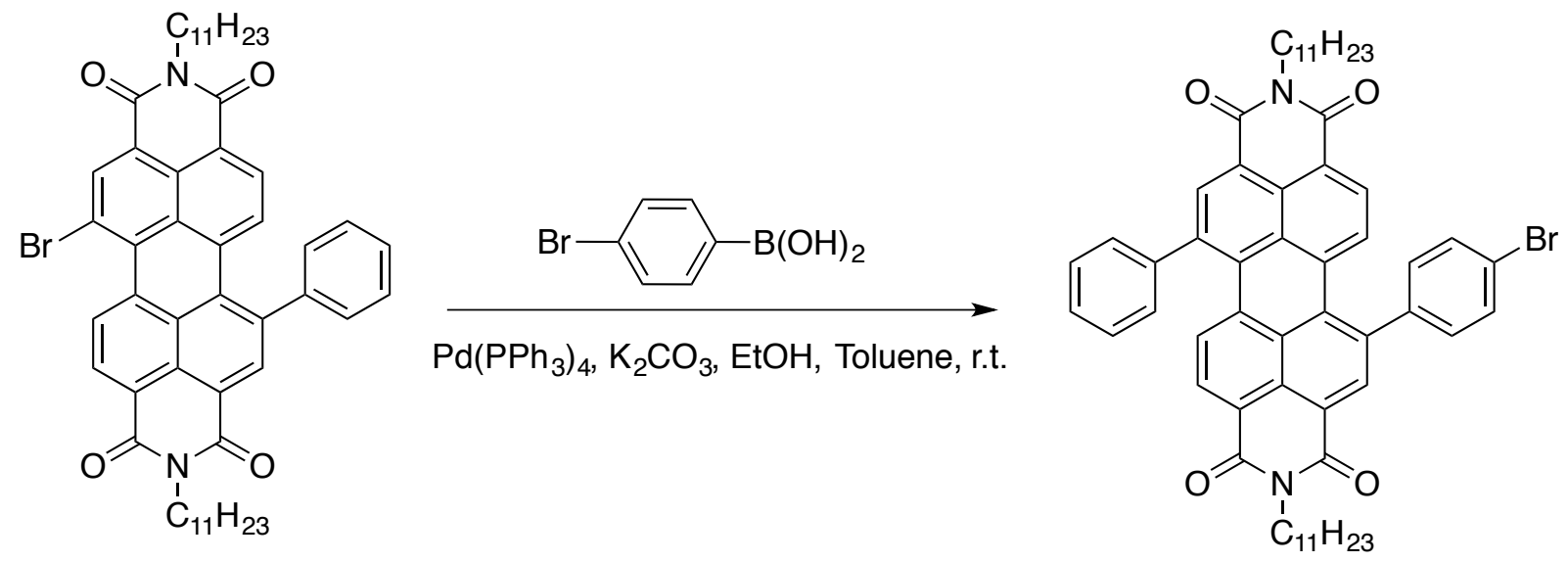

SI-2

Synthesis of SI-2. SI-1 (0.120 g, $0.141 \mathrm{mmol}, 1.00$ equiv), 4-bromophenylboronic acid $(0.0850 \mathrm{~g}, 0.422 \mathrm{mmol}$, 3.00 equiv), aqueous $\mathrm{K}_{2} \mathrm{CO}_{3}(2 \mathrm{M}, 1.20 \mathrm{~mL})$, EtOH $(0.240 \mathrm{~mL})$ and toluene $(3.60 \mathrm{~mL})$ were added to $20 \mathrm{~mL}$ scintillation vial equipped with a stir bar. The mixture was sparged with $\mathrm{N}_{2}$ for thirty minutes. While under $\mathrm{N}_{2}$, tetrakis(triphenylphosphine)palladium(0) $(0.0160 \mathrm{~g}, 0.0104 \mathrm{mmol}, 0.100$ equiv) was added. The mixture was further sparged for ten minutes and stirred overnight at room temperature. The crude mixture was extracted with ethyl acetate and brine, concentrated and purified by column chromatography (40 g Redisep Rf Silica) using a gradient from $0 \%$ to $100 \% \mathrm{CH}_{2} \mathrm{Cl}_{2} /$ hexanes at $40 \mathrm{~mL} / \mathrm{min}$. Impure fractions were further purified by prep HPLC (COSMOSIL Buckyprep $20 \times 250 \mathrm{~mm}, 18.9 \mathrm{~mL} / \mathrm{min}$ and 7:93 $\mathrm{CH}_{2} \mathrm{Cl}_{2}$ :hexanes) to yield a total $0.0700 \mathrm{~g}(0.0750$ mmol, 54\%) of SI-2. ${ }^{1} \mathrm{H}$ NMR (400 MHz, $\left.\mathrm{C}_{2} \mathrm{D}_{2} \mathrm{Cl}_{4}, 390 \mathrm{~K}\right) \delta 8.65(\mathrm{~s}, 1 \mathrm{H}), 8.60(\mathrm{~s}, 1 \mathrm{H}), 8.24(\mathrm{~d}, \mathrm{~J}=8.2 \mathrm{~Hz}, 1 \mathrm{H}), 8.18$ $(\mathrm{d}, \mathrm{J}=8.2 \mathrm{~Hz}, 1 \mathrm{H}), 7.92(\mathrm{~d}, \mathrm{~J}=8.1 \mathrm{~Hz}, 2 \mathrm{H}), 7.74(\mathrm{~d}, \mathrm{~J}=8.4 \mathrm{~Hz}, 2 \mathrm{H}), 7.65-7.51(\mathrm{~m}, 7 \mathrm{H}), 5.23-5.14(\mathrm{~m}, 2 \mathrm{H})$, $2.32-2.24(\mathrm{~m}, 4 \mathrm{H}), 1.98-1.93(\mathrm{~m}, 4 \mathrm{H}), 1.38(\mathrm{br}, 24 \mathrm{H}), 0.93(\mathrm{br}, 12 \mathrm{H}) .{ }^{13} \mathbf{C}$ NMR $\left(100 \mathrm{MHz}, \mathrm{C}_{2} \mathrm{D}_{2} \mathrm{Cl}_{4}, 390 \mathrm{~K}\right)$ $\delta 163.98,163.92,163.88,142.54,141.56,141.36,139.62,135.32,134.90,134.83,134.54,133.46,132.51$ 
132.34, 130.79, 130.22, 130.19, 130.10, 129.63, 129.44, 129.34, 129.04, 128.70, 128.19, 128.15, 123.17, 123.14, 123.08, 123.01, 122.75, 55.43, 32.67, 31.74, 26.68, 22.42, 13.80. IR $\left(\mathrm{cm}^{-1}\right)$ 2955, 2926, 2860, 1697, 1658, 1597, 1587, 1459, 1408, 1325, 1241, 1185, 813. HRMS (APCl+) calculated $m / z$ for $\left[\mathrm{C}_{58} \mathrm{H}_{61} \mathrm{~N}_{2} \mathrm{O}_{4} \mathrm{Br}+\mathrm{H}\right]^{+} 929.3893$, found 929.3885 . 


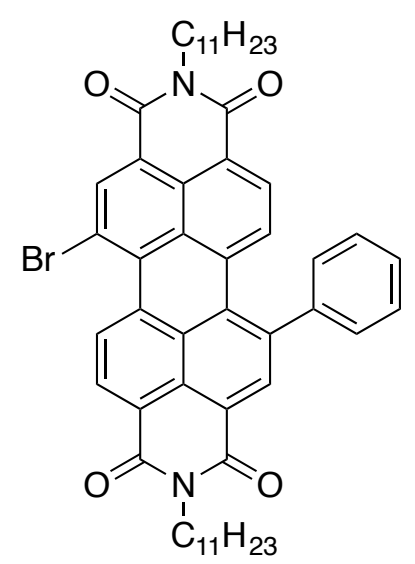

SI-1

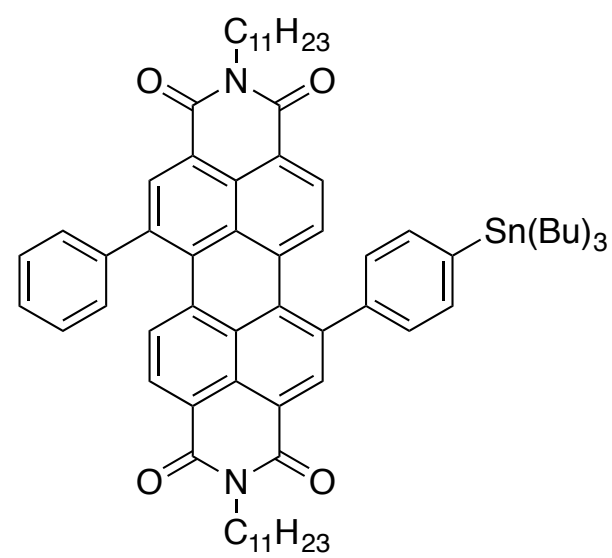

SI-3

Synthesis of SI-3. SI-1 (0.0930 g, $0.109 \mathrm{mmol}, 1.00$ equiv), 1,4-bis(tributylstannyl)benzene $(0.0600 \mathrm{~mL}, 0.0720$ mmol, 2.50 equiv) and THF $(90.0 \mathrm{~mL})$ were added to a $20 \mathrm{~mL}$ scintillation vial equipped with a stir bar. The mixture was sparged with $\mathrm{N}_{2}$ for thirty minutes. While under $\mathrm{N}_{2}$, tris(dibenzylideneacetone)dipalladium (0.0100 g, $0.0109 \mathrm{mmol}, 0.100$ equiv) and tri(2-furyl)phosphine $(0.0110 \mathrm{~g}, 0.0436 \mathrm{mmol}, 0.400$ equiv) were added. The mixture was further sparged for ten minutes before being placed in a $55^{\circ} \mathrm{C}$ oil bath and stirred overnight. The crude mixture was condensed and purified by column chromatography (40 g Redisep Rf Silica) using a gradient from $0 \%$ to $100 \% \mathrm{CH}_{2} \mathrm{Cl}_{2} /$ hexanes at $40 \mathrm{~mL} / \mathrm{min}$ to yield $\mathbf{S I}-3\left(0.0770 \mathrm{~g}, 0.0680 \mathrm{mmol}, 62 \%\right.$ yield). ${ }^{1} \mathbf{H}$ NMR (500 $\left.\mathrm{MHz}, \mathrm{CDCl}_{3}\right) \delta 8.62(\mathrm{br}, 2 \mathrm{H}), 8.11(\mathrm{br}, 2 \mathrm{H}), 7.88(\mathrm{~d}, \mathrm{~J}=8.5 \mathrm{~Hz}, 1 \mathrm{H}), 7.81(\mathrm{~d}, \mathrm{~J}=6.3 \mathrm{~Hz}, 1 \mathrm{H}), 7.63-7.54^{\star}(\mathrm{m}, \mathrm{J}=$ $7.1 \mathrm{~Hz}, 4 \mathrm{H}), 7.52-7.48(\mathrm{~m}, 5 \mathrm{H}), 5.15(\mathrm{br}, 2 \mathrm{H}), 2.25-2.21(\mathrm{~m}, 4 \mathrm{H}), 1.82(\mathrm{br}, 4 \mathrm{H}), 1.66-1.54^{\star}(\mathrm{m}, 6 \mathrm{H}), 1.43-$ $1.35(\mathrm{~m}, 6 \mathrm{H}), 1.26(\mathrm{br}, 24 \mathrm{H}), 1.18-1.09^{\star}(\mathrm{m}, 6 \mathrm{H}), 0.94(\mathrm{t}, \mathrm{J}=7.3 \mathrm{~Hz}, 9 \mathrm{H}), 0.83(\mathrm{br} \mathrm{t}, \mathrm{J}=6.6 \mathrm{~Hz}, 12 \mathrm{H}) .{ }^{13} \mathrm{C}$ NMR $\left(125 \mathrm{MHz}, \mathrm{CDCl}_{3}\right) \delta 164.77,163.66,143.14,142.28,141.68,141.33,141.00,138.19,138.08,135.87,135.41$ $135.16,134.91,134.76,132.57,132.40,130.20,130.17,130.15,129.97,129.84,129.26,129.06,128.58,128.28$, $127.92,127.87,122.83,122.50,122.14,121.77,54.63,32.34,31.77,29.14^{\star}, 27.37^{\star}, 26.60,26.59,22.56,14.05$, 13.73, 9.75*. IR $\left(\mathrm{cm}^{-1}\right)$ 2956, 2925, 2855, 1697, 1657, 1598, 1586, 1459, 1447, 1408, 1325, 1264, 1239, 863, 814, 739. HRMS $(\mathrm{APCl}+)$ calculated $m / z$ for $\left[\mathrm{C}_{70} \mathrm{H}_{88} \mathrm{~N}_{2} \mathrm{O}_{4} \mathrm{Sn}+\mathrm{H}\right]^{+} 1141.5844$, found 1141.5859 .

Broadening (br) of peaks in the ${ }^{1} \mathrm{H}$ NMR spectrum is due to rotational isomers about the imide side chains. ${ }^{3,4}$ ${ }^{*}$ Tin satellite peaks visible.

Multiple peaks for the same carbon in the ${ }^{13} \mathrm{C}$ NMR spectrum reflect rotational isomers about the imide side chains that have been seen previously. ${ }^{3,4}$ 


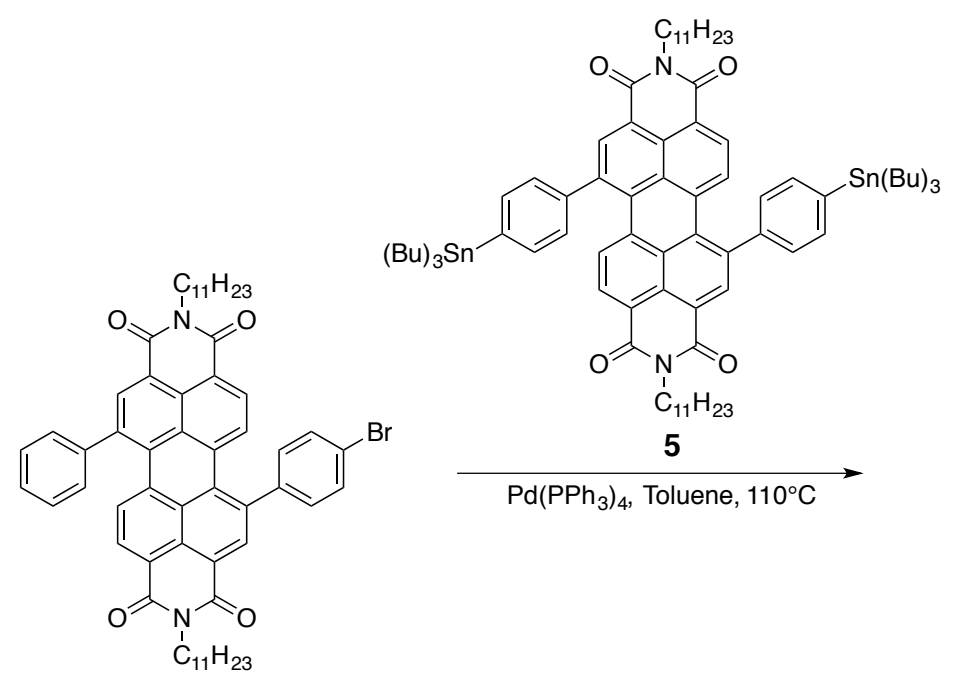

SI-2

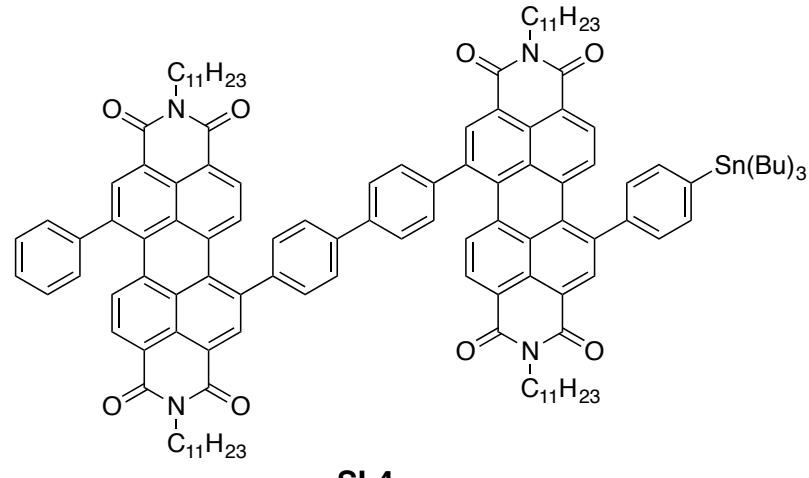

SI-4

Synthesis of SI-4. SI-2 ( $0.0750 \mathrm{~g}, 0.0810 \mathrm{mmol}, 1.00$ equiv) and 1,7-bis[4-(tributylstannyl)-phenyl]-PDI (0.463 g, $0.324 \mathrm{mmol}, 4.00$ equiv) were dissolved in toluene $(8.00 \mathrm{~mL})$ in a $20 \mathrm{~mL}$ scintillation vial equipped with a stir bar. The mixture was sparged with $\mathrm{N}_{2}$ for thirty minutes. While under $\mathrm{N}_{2}$, tetrakis(triphenylphosphine)palladium(0) $(0.00900 \mathrm{~g}, 0.00810 \mathrm{mmol}, 0.100$ equiv) was added. The mixture was further sparged for ten minutes before being placed in a $110^{\circ} \mathrm{C}$ oil bath and stirred overnight. The crude mixture was condensed and purified by column chromatography (40 g Redisep Rf Silica) using a gradient from $0 \%$ to $100 \% \mathrm{CH}_{2} \mathrm{Cl}_{2} /$ hexanes at $40 \mathrm{~mL} / \mathrm{min}$. Further purification by preparative HPLC (COSMOSIL Buckyprep 20 x $250 \mathrm{~mm}, 18.9 \mathrm{~mL} / \mathrm{min}, \quad 7: 93$ $\mathrm{CH}_{2} \mathrm{Cl}_{2}$ :hexanes) yielded SI-4 $\left(0.0270 \mathrm{~g}, 0.0140 \mathrm{mmol}, 17 \%\right.$ yield). ${ }^{1} \mathbf{H}$ NMR $\left(500 \mathrm{MHz}, \mathrm{CDCl}_{3}\right) \delta 8.67(\mathrm{br}, 4 \mathrm{H})$, $8.17(\mathrm{br}, 4 \mathrm{H}), 8.03(\mathrm{~d}, J=3.2 \mathrm{~Hz}, 1 \mathrm{H}), 8.01(\mathrm{~d}, J=3.2 \mathrm{~Hz}, 1 \mathrm{H}), 7.91(\mathrm{~d}, \mathrm{~J}=8.5 \mathrm{~Hz}, 1 \mathrm{H}), 7.87(\mathrm{~d}, \mathrm{~J}=7.6,4 \mathrm{H}), 7.85$ $(\mathrm{d}, \mathrm{J}=9.1 \mathrm{~Hz}, 1 \mathrm{H}), 7.74(\mathrm{~d}, \mathrm{~J}=2.0 \mathrm{~Hz}, 2 \mathrm{H}), 7.73(\mathrm{~d}, \mathrm{~J}=2.3 \mathrm{~Hz}, 2 \mathrm{H}), 7.61-7.59^{\star}(\mathrm{m}, 4 \mathrm{H}), 7.54-7.50^{\star}(\mathrm{m}, 5 \mathrm{H})$, $5.17(\mathrm{br}, 4 \mathrm{H}), 2.27-2.19(\mathrm{br} \mathrm{m}, 8 \mathrm{H}), 1.83(\mathrm{br}, 8 \mathrm{H}), 1.67-1.60^{\star}(\mathrm{m}, 6 \mathrm{H}), 1.44-1.35(\mathrm{~m}, 6 \mathrm{H}), 1.35-1.21$ (br m, $48 \mathrm{H}), 1.19-1.11^{*}(\mathrm{~m}, 6 \mathrm{H}), 0.95(\mathrm{t}, \mathrm{J}=7.3 \mathrm{~Hz}, 9 \mathrm{H}), 0.86-0.81(\mathrm{~m}, 24 \mathrm{H}) .{ }^{13} \mathrm{C} \mathrm{NMR}\left(100 \mathrm{MHz}, \mathrm{CDCl}_{3}\right) \delta 164.70$, $163.64,143.19,142.22,141.78,141.72,141.66,141.40,141.15,140.48,140.39,140.20,140.15,138.10,135.82$, 135.01, 134.82, 132.57, 130.28, 130.21, 130.03, 129.79, 129.35, 129.34, 129.28, 129.16, 129.07, 128.75, 128.64, 128.30, 127.97, 127.93, 122.90, 122.62, 122.21, 121.90, 54.68, 32.34, 31.78, 29.15*, 27.38*, 26.61, 22.58, 14.07, 13.75, 9.76*. IR $\left(\mathrm{cm}^{-1}\right)$ 2955, 2927, 2859, 1698, 1659, 1599, 1587, 1457, 1409, 1326, 1240, 1183, 814. HRMS (APCl+) calculated $m / z$ for $\left[\mathrm{C}_{128} \mathrm{H}_{148} \mathrm{~N}_{4} \mathrm{O}_{8} \mathrm{Sn}+\mathrm{Na}\right]^{+}$2012.0217, found 2012.0212.

Broadening (br) of peaks in the ${ }^{1} \mathrm{H}$ NMR spectrum is due to rotational isomers about the imide side chains. ${ }^{3,4}$ ${ }^{*}$ Tin satellite peaks visible. 
Multiple peaks for the same carbon in the ${ }^{13} \mathrm{C}$ NMR spectrum reflect rotational isomers about the imide side chains that have been seen previously. ${ }^{3,4}$ 


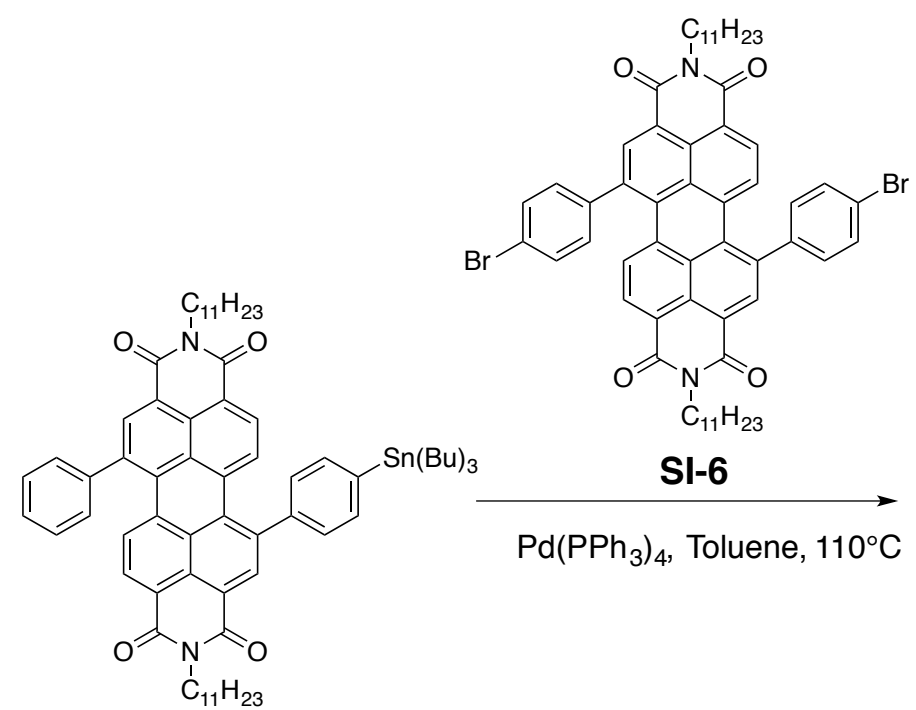

SI-3

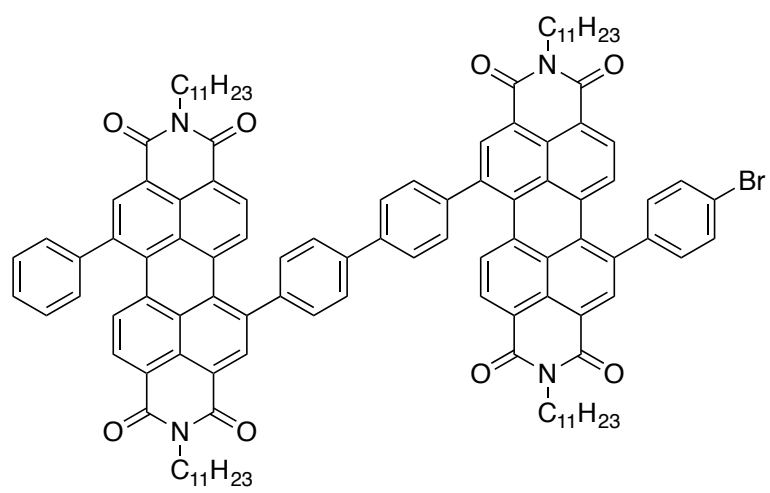

SI-5

Synthesis of SI-5. SI-3 (0.0550 g, $0.0480 \mathrm{mmol}, 1.00$ equiv) and $N, N^{\prime}$-di(6-undecyl)-1,7-di(4-bromophenyl)perylene-3,4:9,10-tetracarboxylic diimide (SI-6) $(0.194 \mathrm{~g}, 0.193 \mathrm{mmol}, 4.00$ equiv) were dissolved in toluene (6 $\mathrm{mL}$ ) in a $20 \mathrm{~mL}$ scintillation vial equipped with a stir bar. The mixture was sparged with $\mathrm{N}_{2}$ for thirty minutes. While under $\mathrm{N}_{2}$, tetrakis(triphenylphosphine)palladium(0) $(0.00600 \mathrm{~g}, 0.00480 \mathrm{mmol}, 0.100$ equiv) was added. The mixture was further sparged for ten minutes before being placed in a $110^{\circ} \mathrm{C}$ oil bath and stirred overnight. The crude mixture was condensed and purified by column chromatography ( $24 \mathrm{~g}$ Redisep Rf Silica) using a gradient from $0 \%$ to $100 \% \mathrm{CH}_{2} \mathrm{Cl}_{2} /$ hexanes at $40 \mathrm{~mL} / \mathrm{min}$. Further purification using preparative HPLC (Buckyprep, isocratic $15: 85 \mathrm{CH}_{2} \mathrm{Cl}_{2}:$ hexane) yielded $\mathbf{S I}-5\left(0.0150 \mathrm{~g}, 0.00800 \mathrm{mmol}, 18 \%\right.$ yield). ${ }^{1} \mathbf{H}$ NMR (500 MHz, $\left.\mathrm{CDCl}_{3}\right) \delta$ $8.71-8.58(\mathrm{br} \mathrm{m}, 4 \mathrm{H}), 8.24-8.12(\mathrm{br} m, 4 \mathrm{H}), 8.02(\mathrm{~d}, J=8.4 \mathrm{~Hz}, 2 \mathrm{H}), 7.87(\mathrm{~d}, J=7.9 \mathrm{~Hz}, 4 \mathrm{H}), 7.85(\mathrm{~d}, J=8.2$ $\mathrm{Hz}, 2 \mathrm{H}), 7.74-7.72(\mathrm{~m}, 4 \mathrm{H}), 7.67(\mathrm{~d}, J=8.0 \mathrm{~Hz}, 2 \mathrm{H}), 7.60(\mathrm{~d}, J=7.1 \mathrm{~Hz}, 2 \mathrm{H}), 7.54-7.48(\mathrm{~m}, 5 \mathrm{H}), 5.17(\mathrm{br}, 4 \mathrm{H})$, $2.23(\mathrm{br}, 8 \mathrm{H}), 1.83(\mathrm{br}, 8 \mathrm{H}), 1.26(\mathrm{br}, 48 \mathrm{H}), 0.86-0.81(\mathrm{br} \mathrm{m}, 24 \mathrm{H}) .{ }^{13} \mathrm{C}$ NMR $\left(100 \mathrm{MHz}, \mathrm{CDCl}_{3}\right) \delta 164.70,163.59$, 142.20, 141.75, 141.60, 141.16, 141.07, 140.65, 140.45, 140.24, 140.12, 139.64, 135.89, 135.47, 135.17, 134.81, $134.49,133.43,132.53,130.81,130.36,130.29,130.20,130.06,130.01,129.80,129.76,129.50,129.33,129.30$, 129.26, 129.07, 128.79, 128.75, 128.65, 128.04, 127.99, 127.97, 123.08, 122.99, 122.65, 122.32, 121.88, 54.70, 32.33, 31.78, 26.62, 22.59, 14.09. IR $\left(\mathrm{cm}^{-1}\right)$ 2954, 2924, 2858, 1697, 1657, 1598, 1587, 1457, 1408, 1324, 1239, 1183, 814. HRMS (APCl+) calculated $m / z$ for $\left[\mathrm{C}_{116} \mathrm{H}_{121} \mathrm{~N}_{4} \mathrm{O}_{8} \mathrm{Br}+\mathrm{Na}\right]^{+} 1799.8265$, found 1799.8259 .

Broadening (br) of peaks in the ${ }^{1} \mathrm{H}$ NMR spectrum is due to rotational isomers about the imide side chains. ${ }^{3,4}$ Multiple peaks for the same carbon in the ${ }^{13} \mathrm{C}$ NMR spectrum reflect rotational isomers about the imide side chains that have been seen previously. ${ }^{3,4}$ 


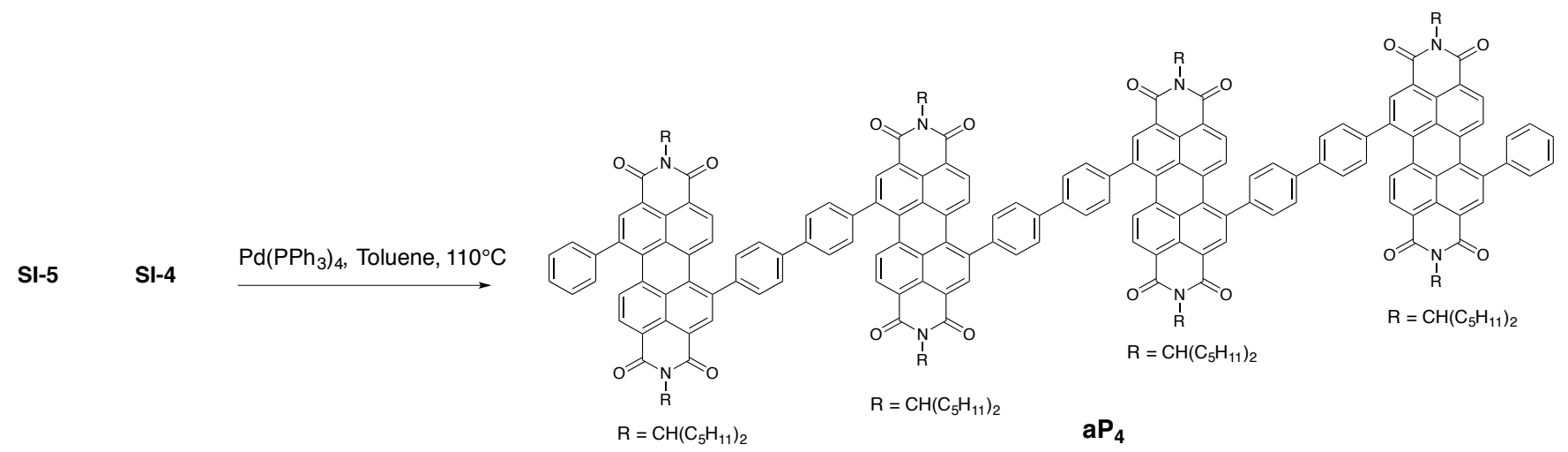

Synthesis of $a_{P_{4}}$ SI-4 $(0.0170 \mathrm{~g}, 0.00800 \mathrm{mmol}, 1.00$ equiv) and SI-5 (0.0150 g, $0.00800 \mathrm{mmol}, 1.00$ equiv) were dissolved in toluene $(2.0 \mathrm{~mL})$ in a $20 \mathrm{~mL}$ scintillation vial equipped with a stir bar. The mixture was sparged with $\mathrm{N}_{2}$ for thirty minutes. While under $\mathrm{N}_{2}$, tetrakis(triphenylphosphine)palladium(0) $(0.00600 \mathrm{~g}, 0.00480 \mathrm{mmol}$, 0.100 equiv) was added. The mixture was further sparged for ten minutes before being placed in a $110^{\circ} \mathrm{C}$ oil bath and stirred for eight hours. The crude mixture was filtered through Celite, concentrated and purified by preparative TLC using a mobile phase of $70: 30 \mathrm{CH}_{2} \mathrm{Cl}_{2}$ :hexanes. The product was washed with hexanes and precipitated from methanol to yield $\mathbf{a P}_{4}(0.00900 \mathrm{~g}, 0.00300 \mathrm{mmol}, 62 \%$ yield $) .{ }^{1} \mathrm{H} \mathbf{N M R}\left(500 \mathrm{MHz}, \mathrm{C}_{2} \mathrm{D}_{2} \mathrm{Cl}_{4}, 370 \mathrm{~K}\right) \delta 8.75(\mathrm{~s}, 4 \mathrm{H})$, $8.72(\mathrm{~s}, 2 \mathrm{H}), 8.67(\mathrm{~s}, 2 \mathrm{H}), 8.32-8.26(\mathrm{~m}, 6 \mathrm{H}), 8.19(\mathrm{~d}, \mathrm{~J}=8.2 \mathrm{~Hz}, 2 \mathrm{H}), 8.14(\mathrm{~d}, \mathrm{~J}=8.0 \mathrm{~Hz}, 2 \mathrm{H}), 8.14(\mathrm{~d}, \mathrm{~J}=8.2$ $\mathrm{Hz}, 2 \mathrm{H}), 8.12(\mathrm{~d}, J=8.3 \mathrm{~Hz}, 2 \mathrm{H}), 7.99-7.91(\mathrm{~m}, 14 \mathrm{H}), 7.84-7.78(\mathrm{~m}, 12 \mathrm{H}), 7.66(\mathrm{~d}, J=7.0 \mathrm{~Hz}, 4 \mathrm{H}), 7.62-7.56$ (m, 6H), $5.25-5.15(\mathrm{br} \mathrm{m}, 8 \mathrm{H}), 2.33-2.21(\mathrm{br} \mathrm{m}, 16 \mathrm{H}), 2.00-1.90(\mathrm{br} \mathrm{m}, 16 \mathrm{H}), 1.45-1.27$ (br m, $96 \mathrm{H}), 0.98-$ 0.88 (br m, 48H). ${ }^{13} \mathrm{C}$ NMR $\left(125 \mathrm{MHz}, \mathrm{C}_{2} \mathrm{D}_{2} \mathrm{Cl}_{4}, 370 \mathrm{~K}\right) \delta 163.81,142.26,141.79,140.98,140.40,140.30,140.27$, 135.11, 134.68, 134.64, 132.34, 132.31, 132.26, 130.04, 129.97, 129.52, 129.23, 129.13, 128.83, 128.63, 128.46, 127.96, 127.88, 122.77, $122.50,54.70,32.36,31.53,26.47,26.45,22.24,22.23,13.69$. IR $\left(\mathrm{cm}^{-1}\right) 2956,2924$ 2856, 1696, 1657, 1598, 1587, 1457, 1408, 1324, 1262, 1239, 1182, 1097, 1029, 861, 813, 740. HRMS (MALDI-) calculated $\mathrm{m} / \mathrm{z}$ for $\left[\mathrm{C}_{232} \mathrm{H}_{242} \mathrm{~N}_{8} \mathrm{O}_{16}\right]^{-} 3395.8369$, found 3395.8363 .

Broadening (br) of peaks in the ${ }^{1} \mathrm{H}$ NMR spectrum is due to rotational isomers about the imide side chains. ${ }^{3,4}$ Multiple peaks for the same carbon in the ${ }^{13} \mathrm{C}$ NMR spectrum reflect rotational isomers about the imide side chains that have been seen previously. ${ }^{3,4}$ 


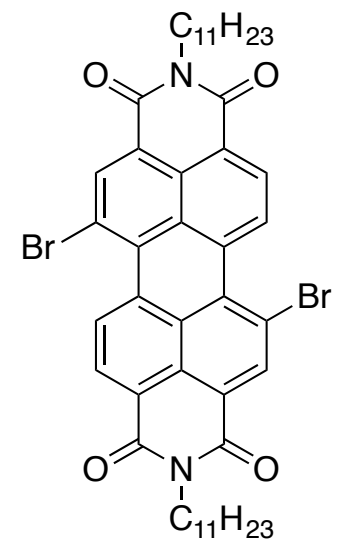

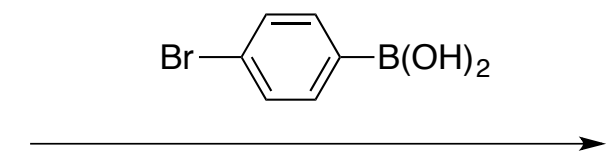

$\mathrm{Pd}\left(\mathrm{PPh}_{3}\right)_{4}, \mathrm{~K}_{2} \mathrm{CO}_{3}, \mathrm{EtOH}$, Toluene, r.t.

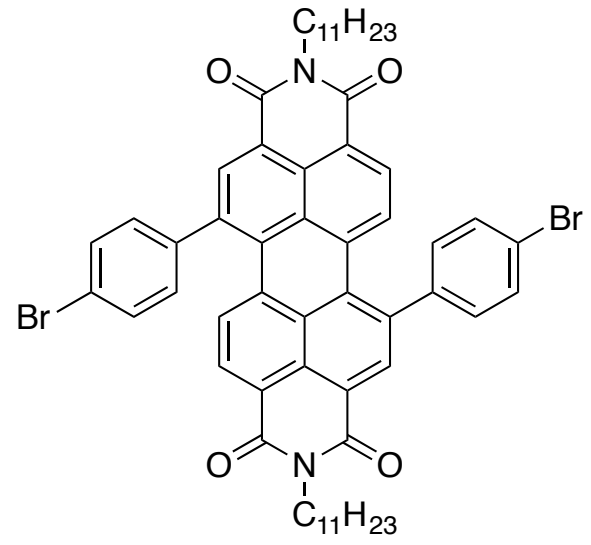

SI-6

\section{Synthesis of 1,7-N,N' -di(6-undecyl)-1,7-di(4-bromophenyl)- perylene-3,4:9,10-tetracarboxylic diimide (SI-}

6). The 1,6- and 1,7-regioisomers of $N, N^{\prime}$-di(6-undecyl)-dibromoperylene-3,4:9,10-tetracarboxylic diimide were separated using prep HPLC on a COSMOSIL Buckyprep 20 x 250 mm, $18.9 \mathrm{~mL} / \mathrm{min}$ and 12:88 CH2Cl2:hexanes. $N, N^{\prime}$-Di(6-undecyl)-1,7-dibromoperylene-3,4:9,10-tetracarboxylic diimide (0.200 g, $0.234 \mathrm{mmol}, 1.00$ equiv), 4bromophenylboronic acid $\left(0.141 \mathrm{~g}, 7.01 \mathrm{mmol}, 3.00\right.$ equiv), aqueous $\mathrm{K}_{2} \mathrm{CO}_{3}(2 \mathrm{M}, 2.00 \mathrm{~mL})$, EtOH $(0.400 \mathrm{~mL})$ and toluene $(6.00 \mathrm{~mL})$ were added to $20 \mathrm{~mL}$ scintillation vial equipped with a stir bar. The mixture was sparged with $\mathrm{N}_{2}$ for thirty minutes. While under $\mathrm{N}_{2}$, tetrakis(triphenylphosphine)palladium(0) $(0.0270 \mathrm{~g}, 0.0234 \mathrm{mmol}, 0.100$ equiv) was added. The mixture was further sparged for ten minutes and stirred overnight at room temperature. A small aliquot was taken 24 hours later and showed $\sim 10 \%$ conversion to product by ${ }^{1} \mathrm{H}$ NMR. Additional tetrakis(triphenylphosphine)palladium(0) $(0.108 \mathrm{~g}, 0.0936 \mathrm{mmol}, 0.400$ equiv) was added. The reaction was monitored for forty-eight hours and another 0.400 equiv of catalyst was added. In total, the reaction completed in 72 hours. The crude mixture was extracted with ethyl acetate and brine, concentrated and purified by column chromatography (40 g Redisep Rf Silica) using a gradient from $0 \%$ to $100 \% \mathrm{CH}_{2} \mathrm{Cl}_{2} /$ hexanes at $40 \mathrm{~mL} / \mathrm{min}$. Impure fractions were further purified by preparative TLC to yield a total $0.091 \mathrm{~g}(0.0905 \mathrm{mmol}, 39 \%)$ of SI-6. ${ }^{1} \mathbf{H}$ NMR $\left(500 \mathrm{MHz}, \mathrm{CDCl}_{3}\right) \delta 8.58(\mathrm{br}, 2 \mathrm{H}), 8.18(\mathrm{br}, 2 \mathrm{H}), 7.82(\mathrm{~d}, \mathrm{~J}=8.1 \mathrm{~Hz}, 2 \mathrm{H}), 7.65(\mathrm{~d}, \mathrm{~J}=8.3 \mathrm{~Hz}, 4 \mathrm{H}), 7.45(\mathrm{~d}, \mathrm{~J}$ $=8.4 \mathrm{~Hz}, 4 \mathrm{H}) .5 .16(\mathrm{br}, 2 \mathrm{H}), 2.28-2.16(\mathrm{~m}, 4 \mathrm{H}), 1.88-1.77(\mathrm{~m}, 4 \mathrm{H}), 1.38-1.18(\mathrm{br} \mathrm{m}, 24 \mathrm{H}) 0.81(\mathrm{br} t, \mathrm{~J}=6.9$ $\mathrm{Hz}, 12 \mathrm{H}) .{ }^{13} \mathrm{C}$ NMR $\left(125 \mathrm{MHz}, \mathrm{CDCl}_{3}\right) \delta 164.52,163.43,140.98,139.73,135.45,134.73,134.42,133.43,132.36$, $130.74,130.28,130.10,129.34,129.20,128.00,123.11,122.76,122.38,122.01,54.76,32.30,31.74,26.58$ 22.56, 14.04. IR $\left(\mathrm{cm}^{-1}\right)$ 2955, 2928, 2858, 1697, 1657, 1598, 1587, 1487, 1456, 1409, 1324, 1239, 1183, 1072, 1012, 814. HRMS (APCl+) calculated $m / z$ for $\left[\mathrm{C}_{58} \mathrm{H}_{60} \mathrm{~N}_{2} \mathrm{O}_{4} \mathrm{Br}_{2}+\mathrm{H}\right]^{+}$1007.2998, found 1007.2994. 
Broadening (br) of peaks in the ${ }^{1} \mathrm{H}$ NMR spectrum is due to rotational isomers about the imide side chains. ${ }^{3,4}$ Multiple peaks for the same carbon in the ${ }^{13} \mathrm{C}$ NMR spectrum reflect rotational isomers about the imide side chains that have been seen previously. ${ }^{3,4}$
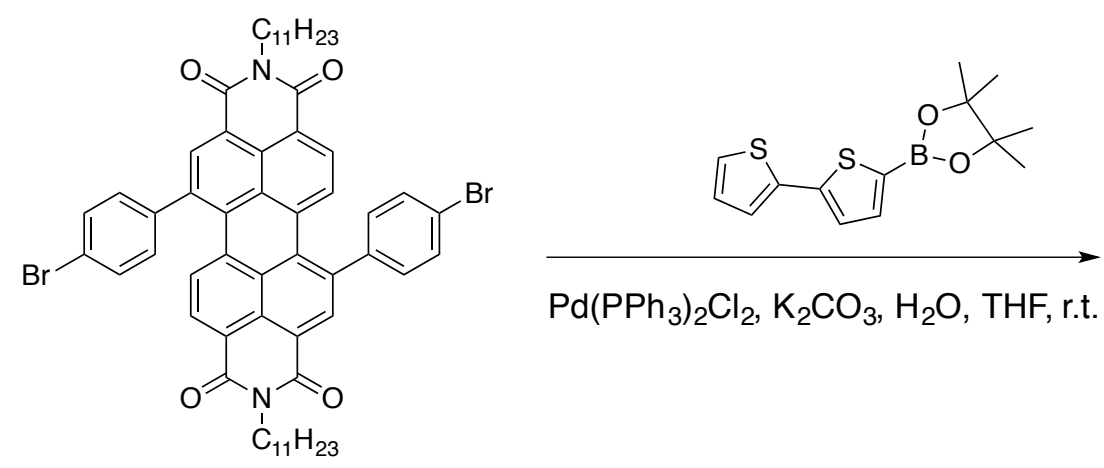

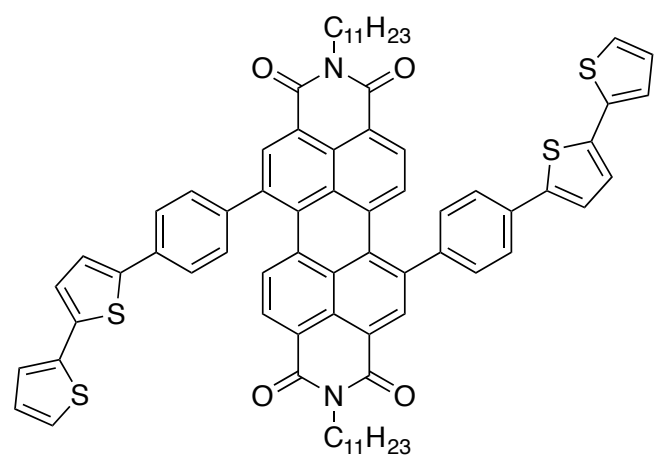

aBPB

Synthesis of aBPB. N,N'-Di(6-undecyl)-1,7-di(4-bromophenyl)-perylene-3,4:9,10-tetracarboxylic diimide $(0.100$ g, $0.0990 \mathrm{mmol}, 1.00$ equiv), 2,2'-bithiophene-5-boronic acid pinacol ester ( $1.74 \mathrm{~g}, 0.596 \mathrm{mmol}, 6.00$ equiv), $\mathrm{K}_{2} \mathrm{CO}_{3}\left(0.218 \mathrm{~g}, 1.58 \mathrm{mmol}, 16.0\right.$ equiv), $\mathrm{H}_{2} \mathrm{O}(1.00 \mathrm{~mL})$ and $\mathrm{THF}(3.00 \mathrm{~mL})$ were added to $20 \mathrm{~mL}$ scintillation vial equipped with a stir bar. The mixture was sparged with $\mathrm{N}_{2}$ for thirty minutes. While under $\mathrm{N}_{2}$, bis(triphenylphosphine)palladium chloride $(0.0110 \mathrm{~g}, 0.0150 \mathrm{mmol}, 0.150$ equiv) was added. The mixture was further sparged for ten minutes and stirred overnight at room temperature. The crude mixture was extracted with ethyl acetate and brine, concentrated and purified by column chromatography using a gradient from $0 \%$ to $100 \%$ $\mathrm{CH}_{2} \mathrm{Cl}_{2} /$ hexanes to yield aBPB $(0.112 \mathrm{~g}, 0.0950 \mathrm{mmol}, 94 \%) .{ }^{1} \mathrm{H}$ NMR $\left(500 \mathrm{MHz}, \mathrm{C}_{2} \mathrm{D}_{2} \mathrm{Cl}_{4}\right) \delta 8.64(\mathrm{br}, 2 \mathrm{H}), 8.17$ (br, 2H), $7.99(b r, 2 H), 7.76(d, J=7.9 \mathrm{~Hz}, 4 \mathrm{H}), 7.65(\mathrm{~d}, \mathrm{~J}=8.3 \mathrm{~Hz}, 4 \mathrm{H}), 7.40(\mathrm{~d}, \mathrm{~J}=3.8 \mathrm{~Hz}, 2 \mathrm{H}), 7.30$ (dd, J = 5.1, $1.1 \mathrm{~Hz}, 2 \mathrm{H}), 7.28(\mathrm{dd}, \mathrm{J}=3.6,1.1 \mathrm{~Hz}, 2 \mathrm{H}), 7.24(\mathrm{~d}, \mathrm{~J}=3.7 \mathrm{~Hz}, 2 \mathrm{H}), 7.09(\mathrm{dd}, \mathrm{J}=5.1,3.6 \mathrm{~Hz}, 2 \mathrm{H}), 5.12(\mathrm{br}, 2 \mathrm{H})$, $2.26-2.11$ (br m, 4H), $1.86(\mathrm{br}, 4 \mathrm{H}), 1.37-1.22$ (br m, 24H), $0.88-0.82$ (br m, 12H). ${ }^{13} \mathrm{C} \mathrm{NMR}(125 \mathrm{MHz}$, $\left.\mathrm{C}_{2} \mathrm{D}_{2} \mathrm{Cl}_{4}\right) \delta 164.47,164.37,163.41,163.30,141.70,140.97,140.11,137.25,136.99,135.48,134.77,134.55$, $134.08,132.26,130.00,129.67,129.24,129.09,128.00,127.78,126.91,124.80,124.77,124.63,123.91,122.83$, 122.42, 122.10, 121.74, 54.52, 32.16, 31.66, 26.53, 22.49, 14.09. IR $\left(\mathrm{cm}^{-1}\right) 2927,2857,1694,1654,1586,1497$, 1409, 1326, 1240, 1006, 950, 887, 838. HRMS (APCl+) calculated $m / z$ for $\left[\mathrm{C}_{74} \mathrm{H}_{70} \mathrm{~N}_{2} \mathrm{O}_{4} \mathrm{~S}_{4}+\mathrm{H}\right]^{+} 1179.4297$, found 1179.4301.

Broadening (br) of peaks in the ${ }^{1} \mathrm{H}$ NMR spectrum is due to rotational isomers about the imide side chains. ${ }^{3,4}$ 
Multiple peaks for the same carbon in the ${ }^{13} \mathrm{C}$ NMR spectrum reflect rotational isomers about the imide side chains that have been seen previously. ${ }^{3,4}$

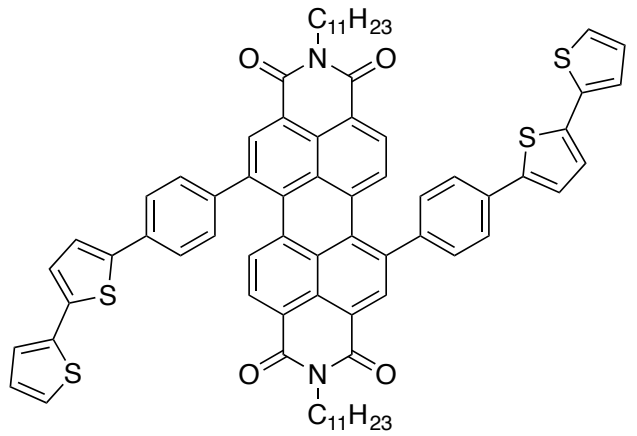

aBPB
NBS, toluene, $-20^{\circ} \mathrm{C}$ to r.t.

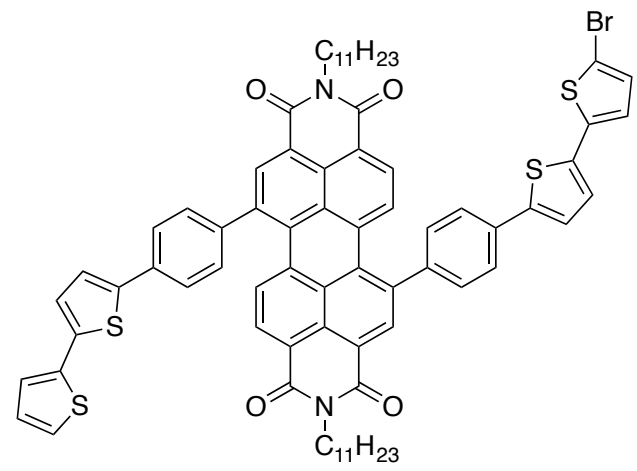

SI-7

Synthesis of SI-7. aBPB ( $0.0740 \mathrm{~g}, 0.0640 \mathrm{mmol}, 1.00$ equiv) was dissolved in toluene $(6.00 \mathrm{~mL})$ and sparged with $\mathrm{N}_{2}$ for fifteen minutes while at $-20^{\circ} \mathrm{C}$. $\mathrm{N}$-Bromosuccinimide $(0.0110 \mathrm{~g}, 0.0640 \mathrm{mmol}, 1.00$ equiv) was added and aluminum was placed over the reaction flask to protect from light. The reaction was stirred for twenty-four hours and allowed to warm to room temperature. The reaction mixture was concentrated and purified by column chromatography using a gradient from $0 \%$ to $100 \% \mathrm{CH}_{2} \mathrm{Cl}_{2} /$ hexanes to yield SI-7 $(0.00800 \mathrm{~g}, 0.00600 \mathrm{mmol}$, 10\%). ${ }^{1} \mathrm{H}$ NMR (500 MHz, $\left.\mathrm{CD}_{2} \mathrm{Cl}_{2}\right) \delta 8.62(\mathrm{br}, 2 \mathrm{H}), 8.15(\mathrm{br}, 2 \mathrm{H}), 8.00(\mathrm{~d}, \mathrm{~J}=6.9 \mathrm{~Hz}, 1 \mathrm{H}), 7.98(\mathrm{~d}, \mathrm{~J}=6.9 \mathrm{~Hz}, 1 \mathrm{H})$, $7.80-7.77(\mathrm{~m}, 4 \mathrm{H}), 7.65(\mathrm{~d}, \mathrm{~J}=8.1 \mathrm{~Hz}, 4 \mathrm{H}), 7.41(\mathrm{~d}, \mathrm{~J}=3.8 \mathrm{~Hz}, 1 \mathrm{H}), 7.39(\mathrm{~d}, \mathrm{~J}=3.8 \mathrm{~Hz}, 1 \mathrm{H}), 7.31(\mathrm{~d}, \mathrm{~J}=4.7 \mathrm{~Hz}$, 1H), $7.29(\mathrm{~d}, \mathrm{~J}=3.5 \mathrm{~Hz}, 1 \mathrm{H}), 7.25(\mathrm{~d}, \mathrm{~J}=3.7 \mathrm{~Hz}, 1 \mathrm{H}), 7.19(\mathrm{~d}, \mathrm{~J}=3.8 \mathrm{~Hz}, 1 \mathrm{H}), 7.09(\mathrm{dd}, \mathrm{J}=5.1,3.6 \mathrm{~Hz}, 1 \mathrm{H}), 7.06$ $(\mathrm{d}, \mathrm{J}=3.8 \mathrm{~Hz}, 1 \mathrm{H}), 7.03(\mathrm{~d}, \mathrm{~J}=3.8 \mathrm{~Hz}, 1 \mathrm{H}), 5.12(\mathrm{br}, 2 \mathrm{H}), 2.24-2.12(\mathrm{br} \mathrm{m}, 4 \mathrm{H}), 1.86(\mathrm{br}, 4 \mathrm{H}), 1.33-1.24(\mathrm{br} \mathrm{m}$, $24 \mathrm{H}), 0.89-0.83(\mathrm{br} \mathrm{m}, 12 \mathrm{H}) .{ }^{13} \mathrm{C} \mathrm{NMR}^{\star}\left(100 \mathrm{MHz}, \mathrm{C}_{2} \mathrm{D}_{2} \mathrm{Cl}_{4}\right) \delta 142.25,141.70,141.17,140.13,138.53,137.27$, 136.99, 136.10, 134.92, 134.58, 134.10, 133.88, 132.30, 130.84, 130.02, 129.69, 129.09, 128.00, 127.79, 126.96, 125.05, 124.79, 124.66, 123.96, 123.91, 111.12, 54.55, 32.16, 31.65, 26.53, 22.48, 14.08. IR (cm $\left.{ }^{-1}\right) 2954,2926$, $2857,1697,1656,1597,1586,1457,1409,1326,1241,1185,838,813,796$. HRMS (ESI+) calculated $\mathrm{m} / \mathrm{z}$ for $\left[\mathrm{C}_{74} \mathrm{H}_{69} \mathrm{~N}_{2} \mathrm{O}_{4} \mathrm{~S}_{4} \mathrm{Br}+\mathrm{H}\right]^{+}$1257.3402, found 1257.3392.

${ }^{*}$ Partial spectrum reported due to limited solubility.

Broadening (br) of peaks in the ${ }^{1} \mathrm{H}$ NMR spectrum is due to rotational isomers about the imide side chains. ${ }^{3,4}$ Multiple peaks for the same carbon in the ${ }^{13} \mathrm{C}$ NMR spectrum reflect rotational isomers about the imide side chains that have been seen previously. ${ }^{3,4}$ 


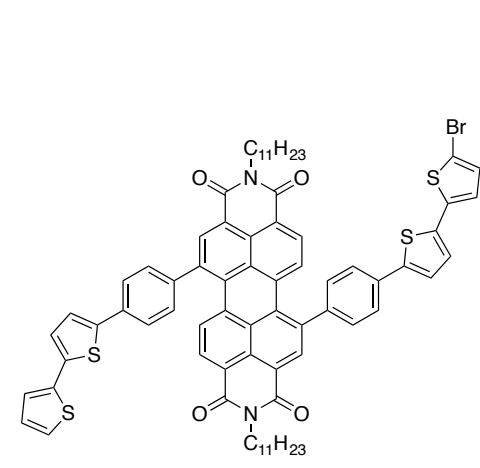

SI-7

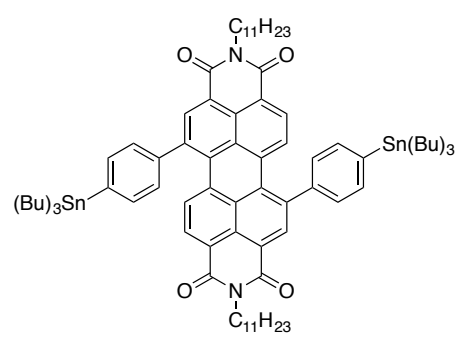

1. Toluene, $\mathrm{Pd}\left(\mathrm{PPh}_{3}\right)_{4}, 110^{\circ} \mathrm{C}$

2. $\mathrm{HCl} 2 \mathrm{M}, \mathrm{DCM}$

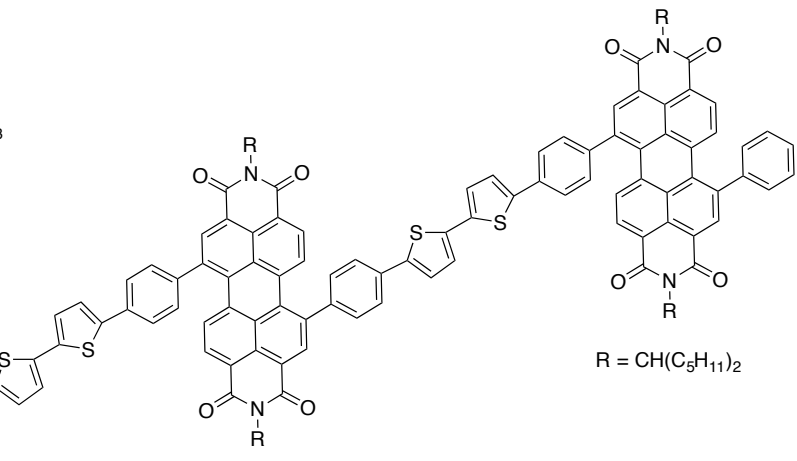

$\mathrm{R}=\mathrm{CH}\left(\mathrm{C}_{5} \mathrm{H}_{11}\right)_{2} \quad$ aPBPB

Synthesis of aPBPB. SI-7 (0.0230 g, $0.0180 \mathrm{mmol}, 1.00$ equiv) and 1,7-bis[4-(tributylstannyl)-phenyl]-PDI (0.105

$\mathrm{g}, 0.0780 \mathrm{mmol}, 4.00$ equiv) were dissolved in toluene $(6.00 \mathrm{~mL})$ in a $20 \mathrm{~mL}$ scintillation vial equipped with a stir bar. The mixture was sparged with $\mathrm{N}_{2}$ for thirty minutes. While under $\mathrm{N}_{2}$, tetrakis(triphenylphosphine)palladium(0) $(0.00200 \mathrm{~g}, 0.00200 \mathrm{mmol}, 0.100$ equiv) was added. The mixture was further sparged for ten minutes before being placed in a $107^{\circ} \mathrm{C}$ oil bath and stirred overnight. The crude mixture was concentrated and purified by preparative TLC using a mobile phase of $50: 50 \mathrm{CH}_{2} \mathrm{Cl}_{2}$ :hexanes. The product was passed through a small silica plug to remove residual impurities. The product was then dissolved in $\mathrm{CH}_{2} \mathrm{Cl}_{2}(2.0 \mathrm{~mL})$ and $\mathrm{HCl}(2.0 \mathrm{~mL})$ and stirred at room temperature for two days. The crude mixture was extracted with water and $\mathrm{CH}_{2} \mathrm{Cl}_{2}$, concentrated and purified by column chromatography (4 $\mathrm{g}$ Redisep $\mathrm{Rf}$ Silica) using a gradient from $0 \%$ to $100 \%$ $\mathrm{CH}_{2} \mathrm{Cl}_{2} /$ hexanes. The product was precipitated from $\mathrm{CH}_{2} \mathrm{Cl}_{2}$ and methanol to yield aPBPB as a purple solid (0.0050 g, $0.0020 \mathrm{mmol}, 14 \%) .{ }^{1} \mathrm{H}$ NMR $\left(400 \mathrm{MHz}, \mathrm{C}_{2} \mathrm{D}_{2} \mathrm{Cl}_{4}\right) \delta 8.62(\mathrm{br}, 4 \mathrm{H}), 8.17(\mathrm{br}, 4 \mathrm{H}), 8.03-7.98(\mathrm{~m}, 3 \mathrm{H})$, $7.84(\mathrm{~d}, \mathrm{~J}=8.4 \mathrm{~Hz}, 1 \mathrm{H}), 7.83-7.77(\mathrm{~m}, 6 \mathrm{H}), 7.70-7.63(\mathrm{~m}, 6 \mathrm{H}), 7.61(\mathrm{br} \mathrm{d}, \mathrm{J}=6.3 \mathrm{~Hz}, 2 \mathrm{H}), 7.58-7.51(\mathrm{~m}, 3 \mathrm{H})$, $7.45(\mathrm{br} \mathrm{d}, \mathrm{J}=3.1 \mathrm{~Hz}, 2 \mathrm{H}), 7.41(\mathrm{~d}, \mathrm{~J}=3.8 \mathrm{~Hz}, 1 \mathrm{H}), 7.32(\mathrm{~d}, \mathrm{~J}=3.9 \mathrm{~Hz}, 2 \mathrm{H}), 7.30-7.27(\mathrm{~m}, 2 \mathrm{H}), 7.25(\mathrm{~d}, \mathrm{~J}=3.7$ $\mathrm{Hz}, 1 \mathrm{H}), 7.11-7.06(\mathrm{~m}, 1 \mathrm{H}), 5.16(\mathrm{br}, 4 \mathrm{H}), 2.31-2.13(\mathrm{br} \mathrm{m}, 8 \mathrm{H}), 1.89-1.76(\mathrm{br} \mathrm{m}, 8 \mathrm{H}), 1.27(\mathrm{br}, 48 \mathrm{H}), 0.84(\mathrm{br}$ $\mathrm{t}, \mathrm{J}=6.6 \mathrm{~Hz}, 24 \mathrm{H}) .{ }^{13} \mathrm{C}$ NMR $\left(100 \mathrm{MHz}, \mathrm{C}_{2} \mathrm{D}_{2} \mathrm{Cl}_{4}\right) \delta 165.13,164.00,142.97,142.87,142.53,142.18,142.14$, $142.03,141.56,140.82,140.79,140.76,137.89,137.71,137.67,137.66,135.90,135.31,134.72,134.65,134.62$, $133.09,130.79,130.63,130.47,130.43,129.89,129.81,129.66,129.07,128.56,128.53,128.49,127.51,127.47$, $125.52,125.34,125.30,125.23,125.08,124.45,123.60,123.26,122.88,122.52,54.99,54.48,54.40,32.84$, 32.34, 27.14, 23.16, 14.38. IR $\left(\mathrm{cm}^{-1}\right)$ 2954, 2925, 2854, 1697, 1659, 1597, 1587, 1459, 1409, 1326, 1265, 1248, 1240, 814, 740. HRMS (ESI+) calculated $m / z$ for $\left[\mathrm{C}_{132} \mathrm{H}_{130} \mathrm{~N}_{4} \mathrm{O}_{8} \mathrm{~S}_{4}+\mathrm{H}\right]^{+} 2027.8850$, found 2027.8820 .

Broadening (br) of peaks in the ${ }^{1} \mathrm{H}$ NMR spectrum is due to rotational isomers about the imide side chains. ${ }^{3,4}$ 
Multiple peaks for the same carbon in the ${ }^{13} \mathrm{C}$ NMR spectrum reflect rotational isomers about the imide side chains that have been seen previously. ${ }^{3,4}$ 

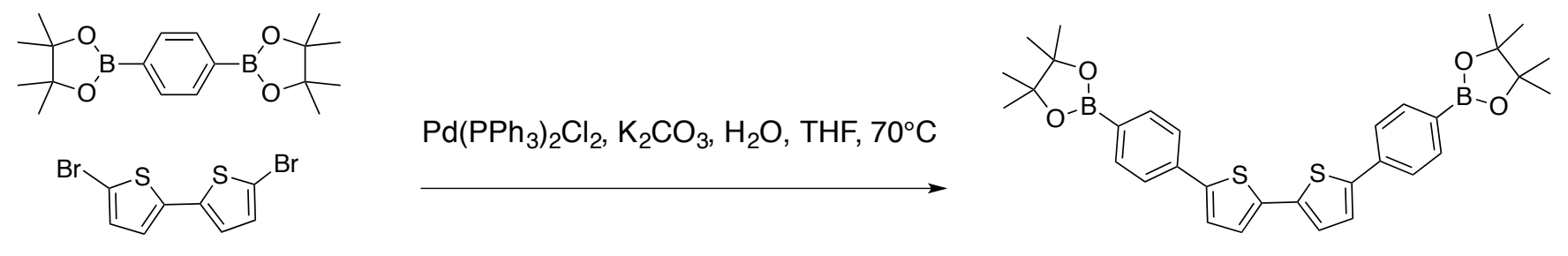

SI-8

Synthesis of SI-8: 1,4-Benzenediboronic acid bis(pinacol) ester ( $0.815 \mathrm{~g}, 2.47 \mathrm{mmol}, 4.00$ equiv), 5,5'-dibromo2,2'-bithiophene (0.200 g, $0.617 \mathrm{mmol}, 1.00$ equiv) and $\mathrm{K}_{2} \mathrm{CO}_{3}(2.12 \mathrm{~g}, 15.0 \mathrm{mmol}, 25.00$ equiv) were dissolved in THF $(21.0 \mathrm{~mL})$ and $\mathrm{H}_{2} \mathrm{O}(6.00 \mathrm{ml})$ in a $100 \mathrm{~mL}$ round bottom flask equipped with a stir bar. The mixture was sparged with $\mathrm{N}_{2}$ for thirty minutes. While under $\mathrm{N}_{2}$, bis(triphenylphosphine)palladium chloride $(0.0430 \mathrm{~g}, 0.0620$ mmol, 0.100 equiv) was added. The mixture was further sparged for thirty minutes before being placed in a $70^{\circ} \mathrm{C}$ oil bath and stirred overnight. The crude mixture was extracted with brine and ethyl acetate. The organic layer was collected, concentrated and purified by column chromatography using a gradient of $0-100 \%$ of hexanes/DCM. The final product was a pale yellow solid $(0.030 \mathrm{~g}, 0.0526,9 \%) .{ }^{1} \mathbf{H}$ NMR $\left(400 \mathrm{MHz}, \mathrm{CD}_{2} \mathrm{Cl}_{2}\right) \delta$ $7.80(\mathrm{~d}, \mathrm{~J}=8.2 \mathrm{~Hz}, 2 \mathrm{H}), 7.64(\mathrm{~d}, \mathrm{~J}=8.2 \mathrm{~Hz}, 2 \mathrm{H}), 7.36(\mathrm{~d}, \mathrm{~J}=3.8 \mathrm{~Hz}, 1 \mathrm{H}), 7.24(\mathrm{~d}, \mathrm{~J}=3.8 \mathrm{~Hz}, 1 \mathrm{H}), 1.36(\mathrm{~s}, 24 \mathrm{H})$. IR $\left(\mathrm{cm}^{-1}\right)$ 2973, 2934, 2857, 1605, 1399, 1362, 1145, 1093, 963, 859, 806. HRMS (ESI+) calculated $\mathrm{m} / \mathrm{z}$ for $\left[\mathrm{C}_{32} \mathrm{H}_{36} \mathrm{~B}_{2} \mathrm{O}_{4} \mathrm{~S}_{2}\right]^{+} 570.2241$, found 570.2252 . 


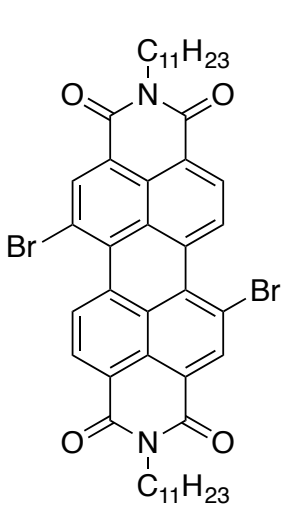<smiles>CC1(C)O[Te]C(C)(C)C1(C)C</smiles>

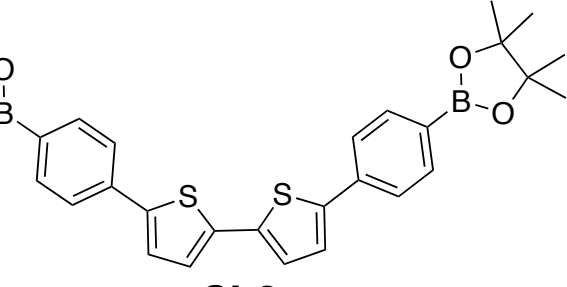

SI-8

1. $\mathrm{Pd}\left(\mathrm{PPh}_{3}\right)_{4}, \mathrm{Na}_{2} \mathrm{CO}_{3}(\mathrm{aq}), \mathrm{THF}, 82^{\circ} \mathrm{C}$

2.<smiles>OB(O)c1ccccc1</smiles>

3.

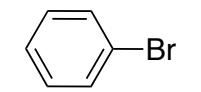

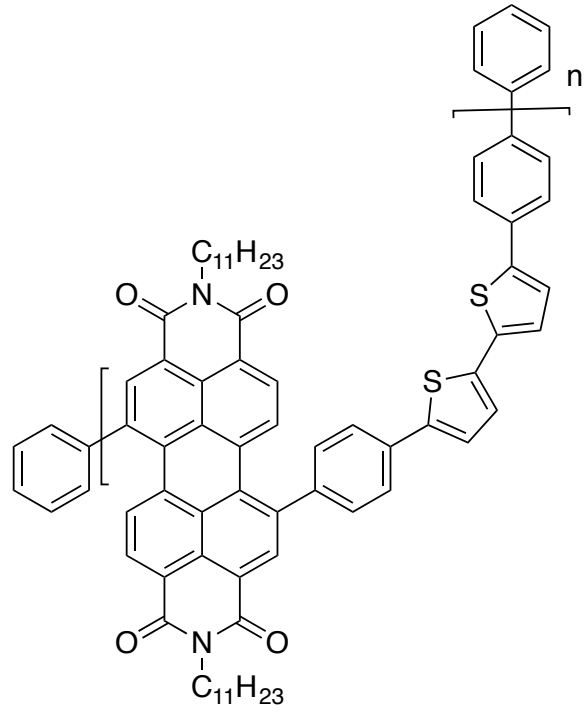

$\mathrm{aPB}_{\mathrm{n}}$

Synthesis of $a(P B)_{n} . \quad N, N^{\prime}$-Di(6-undecyl)-1,7-dibromoperylene-3,4:9,10-tetracarboxylic diimide (0.0420 g, 0.0490 mmol, 1.03 equiv), SI-8 (0.027 g, $0.0474 \mathrm{mmol}, 1.00$ equiv), aqueous $\mathrm{Na}_{2} \mathrm{CO}_{3}(2 \mathrm{M}, 2.20 \mathrm{~mL}$ ) and THF (4.00 mL) were added to a $20 \mathrm{~mL}$ scintillation vial equipped with a stir bar. The mixture was sparged with $\mathrm{N}_{2}$ for thirty minutes. While under $\mathrm{N}_{2}$, tetrakis(triphenylphosphine)palladium(0) $(0.002 \mathrm{~g}, 0.002 \mathrm{mmol}, 0.0400$ equiv) was added. The mixture was further sparged for ten minutes and stirred for 48 hours at $82{ }^{\circ} \mathrm{C}$. Then phenylboronic acid $\left(0.0170 \mathrm{~g}, 0.142 \mathrm{mmol}, 3.30\right.$ equiv) was added to the reaction and allowed to stir for three hours at $82{ }^{\circ} \mathrm{C}$, followed by bromobenzene $(0.200 \mathrm{~mL}, 1.90 \mathrm{mmol}, 40$ equiv). The reaction was left stirring overnight. The crude mixture was extracted with ethyl acetate and brine and concentrated. Solids were crashed out with methanol and further purified using soxhlet extraction using methanol, followed by hexanes. The final product was recovered using chloroform. The reaction yielded $0.040 \mathrm{~g}, 82 \%$ yield*. ${ }^{1} \mathrm{H} \mathrm{NMR}^{\star}\left(500 \mathrm{MHz}, \mathrm{C}_{2} \mathrm{D}_{2} \mathrm{Cl}_{4}\right) \delta 8.71(\mathrm{~s}, 2 \mathrm{H}), 8.27(\mathrm{~d}$, $\mathrm{J}=8.0 \mathrm{~Hz}, 2 \mathrm{H}), 8.10(\mathrm{~d}, \mathrm{~J}=8.0 \mathrm{~Hz}, 2 \mathrm{H}), 7.86(\mathrm{~d}, \mathrm{~J}=7.5 \mathrm{~Hz}, 4 \mathrm{H}), 7.71(\mathrm{~d}, \mathrm{~J}=8.0 \mathrm{~Hz}, 4 \mathrm{H}), 7.47(\mathrm{~d}, \mathrm{~J}=3.0 \mathrm{~Hz}$, 2H), $7.37(\mathrm{~d}, \mathrm{~J}=3.4 \mathrm{~Hz}, 2 \mathrm{H}), 5.26-5.16(\mathrm{~m}, 2 \mathrm{H}), 2.28(\mathrm{br}, 4 \mathrm{H}), 1.99(\mathrm{br}, 4 \mathrm{H}), 1.43(\mathrm{br}, 24 \mathrm{H})^{\star \star}, 0.95(\mathrm{br}, 12 \mathrm{H})$. GPC: $\mathrm{Mn}=6,388 ; \mathrm{Mw}=30,238$ and $\mathrm{PDI}=4.73 ;$ solvent $=$ chloroform; $\lambda=440 \mathrm{~nm}$. HRMS (MALDI) shows oligomers with repeating units of $1012 \mathrm{~m} / \mathrm{z}$ up to the eight-mer.

${ }^{*}$ Polymer yields do not incorporate phenyl caps.

${ }^{* *}$ The broad peak at $1.43 \mathrm{ppm}$ indicates water in the sample and prevents integration of the overlapping alkyl protons. 


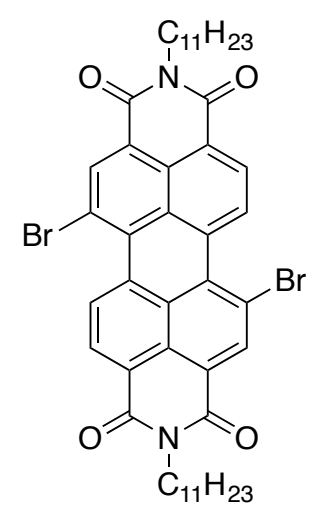

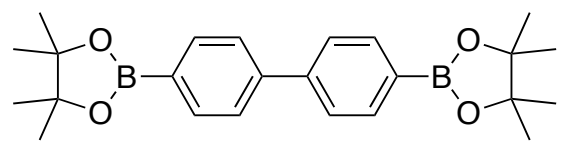

1. $\mathrm{Pd}\left(\mathrm{PPh}_{3}\right)_{4}, \mathrm{Na}_{2} \mathrm{CO}_{3}(\mathrm{aq}), \mathrm{THF}, 82^{\circ} \mathrm{C}$

2.<smiles>OB(O)c1ccccc1</smiles>

3.<smiles>Brc1ccccc1</smiles>

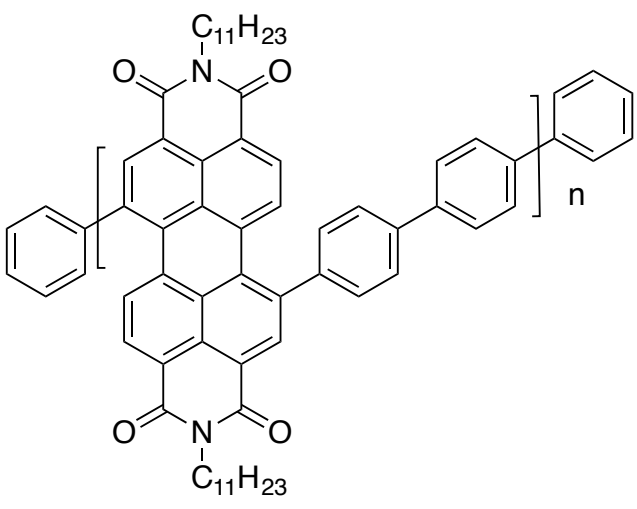

$\mathrm{aP}_{\mathrm{n}}$

Synthesis of $a P_{n} . N, N^{\prime}$-Di(6-undecyl)-1,7-dibromoperylene-3,4:9,10-tetracarboxylic diimide (0.200 g, 0.234 mmol, 1.00 equiv), 4,4' -biphenyldiboronic acid bis(pinacol) ester ( $0.0950 \mathrm{~g}, 0.234 \mathrm{mmol}, 1.00$ equiv), aqueous $\mathrm{Na}_{2} \mathrm{CO}_{3}(2 \mathrm{M}, 11.0 \mathrm{~mL})$ and THF $(19.0 \mathrm{~mL})$ were added to $100 \mathrm{~mL}$ two-neck, round bottom flask equipped with a stir bar. The mixture was sparged with $\mathrm{N}_{2}$ for thirty minutes. While under $\mathrm{N}_{2}$, tetrakis(triphenylphosphine)palladium(0) $(0.0110 \mathrm{~g}, 0.009 \mathrm{mmol}, 0.0400$ equiv) was added. The mixture was further sparged for ten minutes and stirred for 48 hours at $78{ }^{\circ} \mathrm{C}$. Then, commercially available phenylboronic acid $\left(0.0940 \mathrm{~g}, 0.767 \mathrm{mmol}, 3.30\right.$ equiv) was added to the reaction and allowed to stir for two hours at $78{ }^{\circ} \mathrm{C}$, followed by bromobenzene $(1.0 \mathrm{ml}, 9.55 \mathrm{mmol}, 41.0$ equiv). The reaction was left stirring overnight. The crude mixture was extracted with ethyl acetate and brine and concentrated. Solids were crashed out with methanol and further purified using soxhlet extraction using methanol, followed by hexanes. The final product was recovered using chloroform. The reaction yielded $0.181 \mathrm{~g}$ for a $91 \%$ yield ${ }^{*}{ }^{1} \mathrm{H}_{\mathrm{NMR}}{ }^{\star}\left(500 \mathrm{MHz}, \mathrm{C}_{2} \mathrm{D}_{2} \mathrm{Cl}_{4}\right) \delta 8.77(\mathrm{~s}, 2 \mathrm{H}), 8.33(\mathrm{~d}, \mathrm{~J}$ $=8.5 \mathrm{~Hz}, 2 \mathrm{H}), 8.18(\mathrm{~d}, \mathrm{~J}=8.3 \mathrm{~Hz}, 2 \mathrm{H}), 7.99(\mathrm{~d}, \mathrm{~J}=8.1 \mathrm{~Hz}, 4 \mathrm{H}), 7.84(\mathrm{~d}, \mathrm{~J}=7.8 \mathrm{~Hz}, 4 \mathrm{H}), 5.27-5.20(\mathrm{~m}, 2 \mathrm{H}), 2.31$ (br, 4H), $1.99(\mathrm{br}, 4 \mathrm{H}), 1.42(\mathrm{br}, 24 \mathrm{H})^{\star \star}, 0.95(\mathrm{br}, 12 \mathrm{H})$. GPC: $\mathrm{M}_{\mathrm{n}}=16,950 ; \mathrm{M}_{\mathrm{w}}=61,169$ and PDI = 3.61; solvent = THF; $\lambda=500 \mathrm{~nm}$. HRMS (MALDI) shows oligomers with repeating units of $849 \mathrm{~m} / \mathrm{z}$ up to the nine-mer.

* Polymer yields do not incorporate phenyl caps.

${ }^{* *}$ The broad peak at $1.43 \mathrm{ppm}$ indicates water in the sample and prevents integration of the overlapping alkyl protons. 


\section{IV. ${ }^{1} \mathrm{H}$ NMR and ${ }^{13} \mathrm{C}$ NMR Spectra}

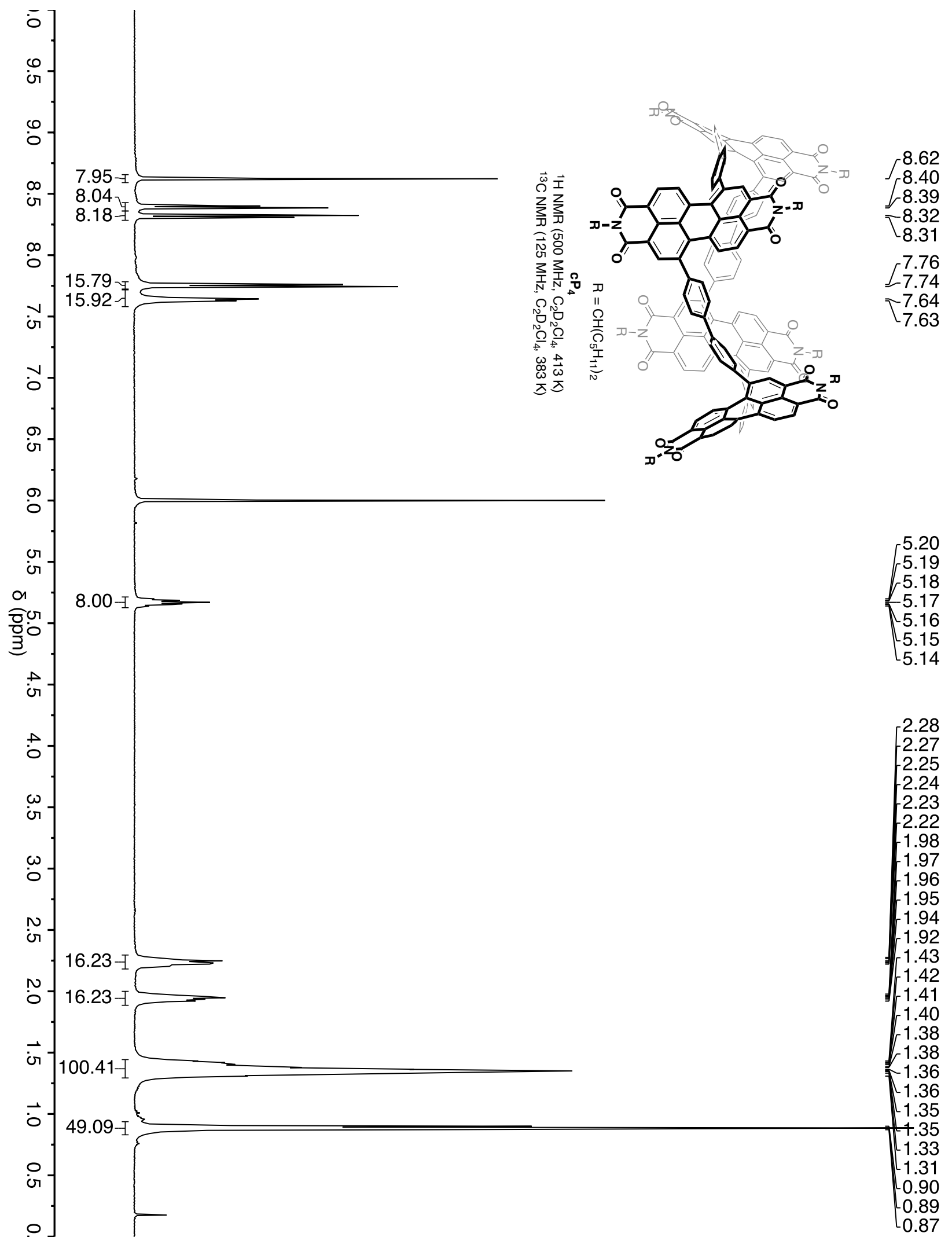




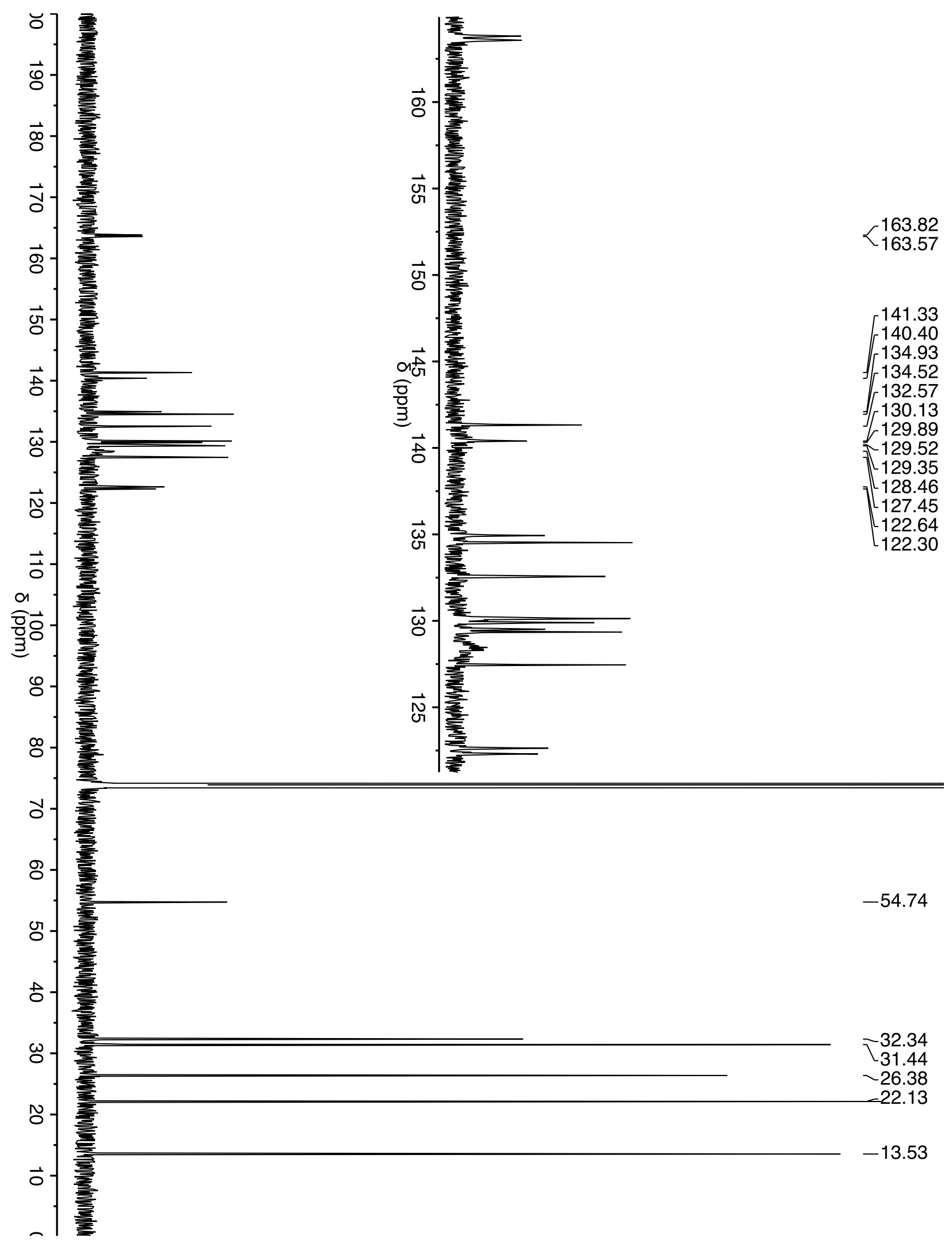




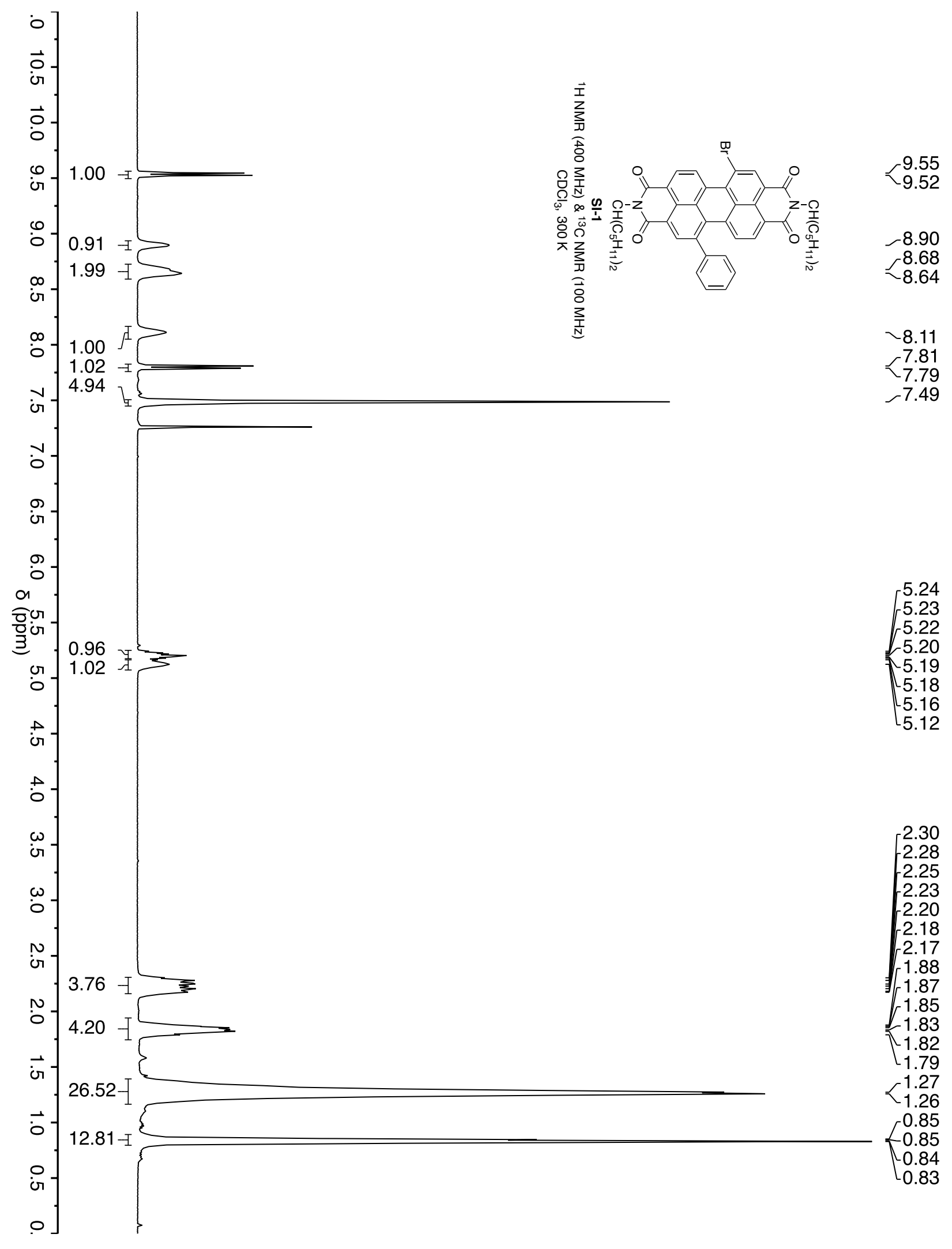




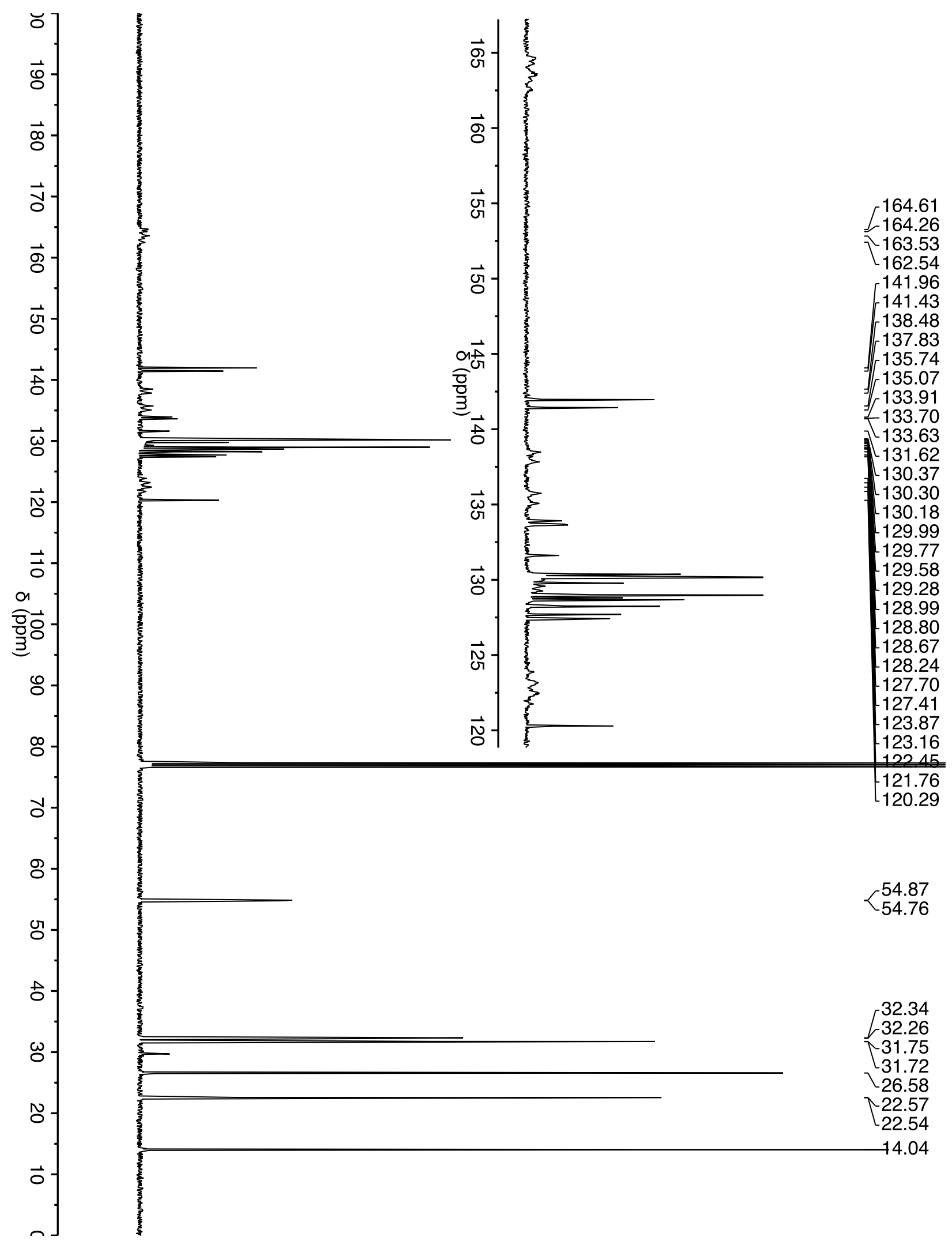




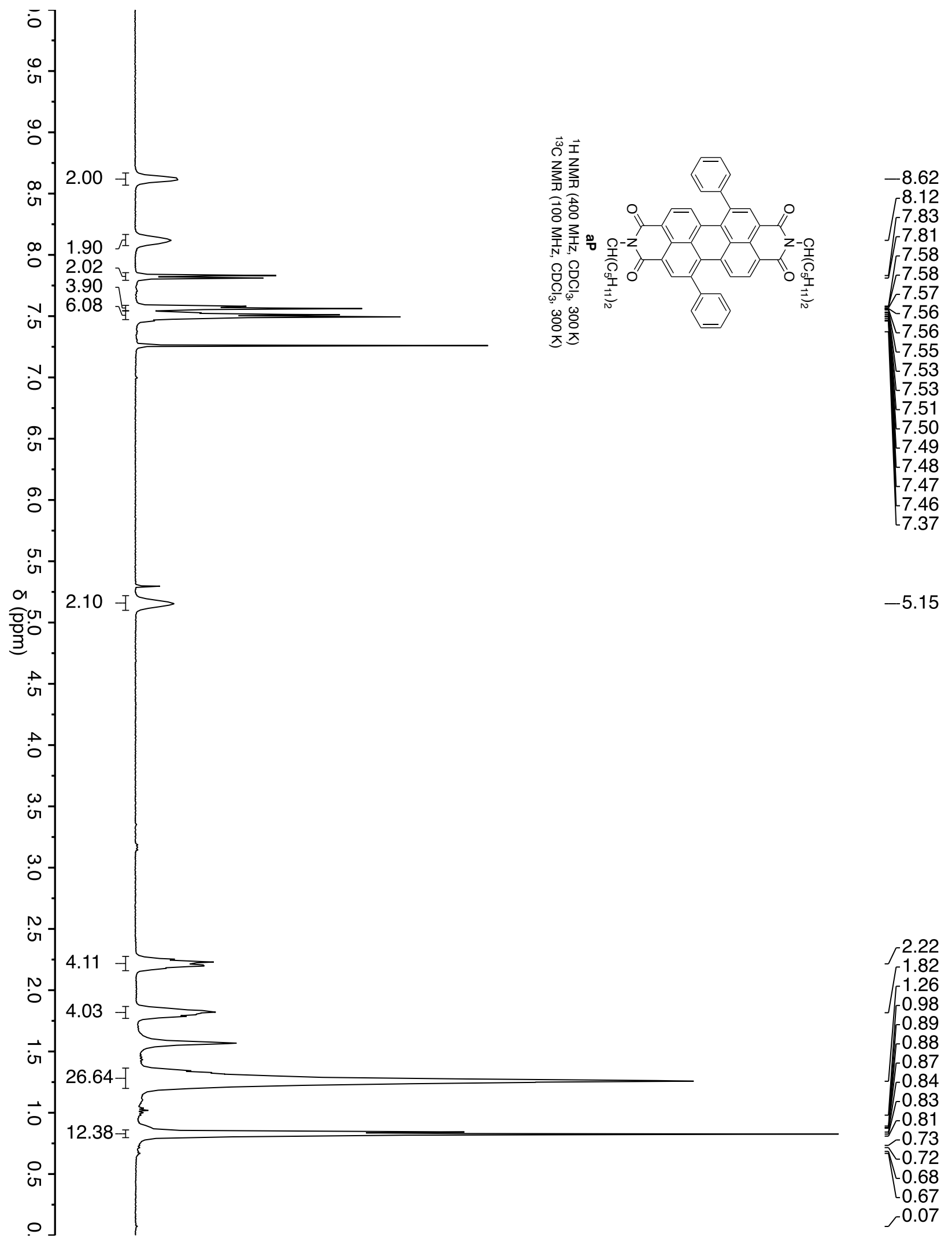




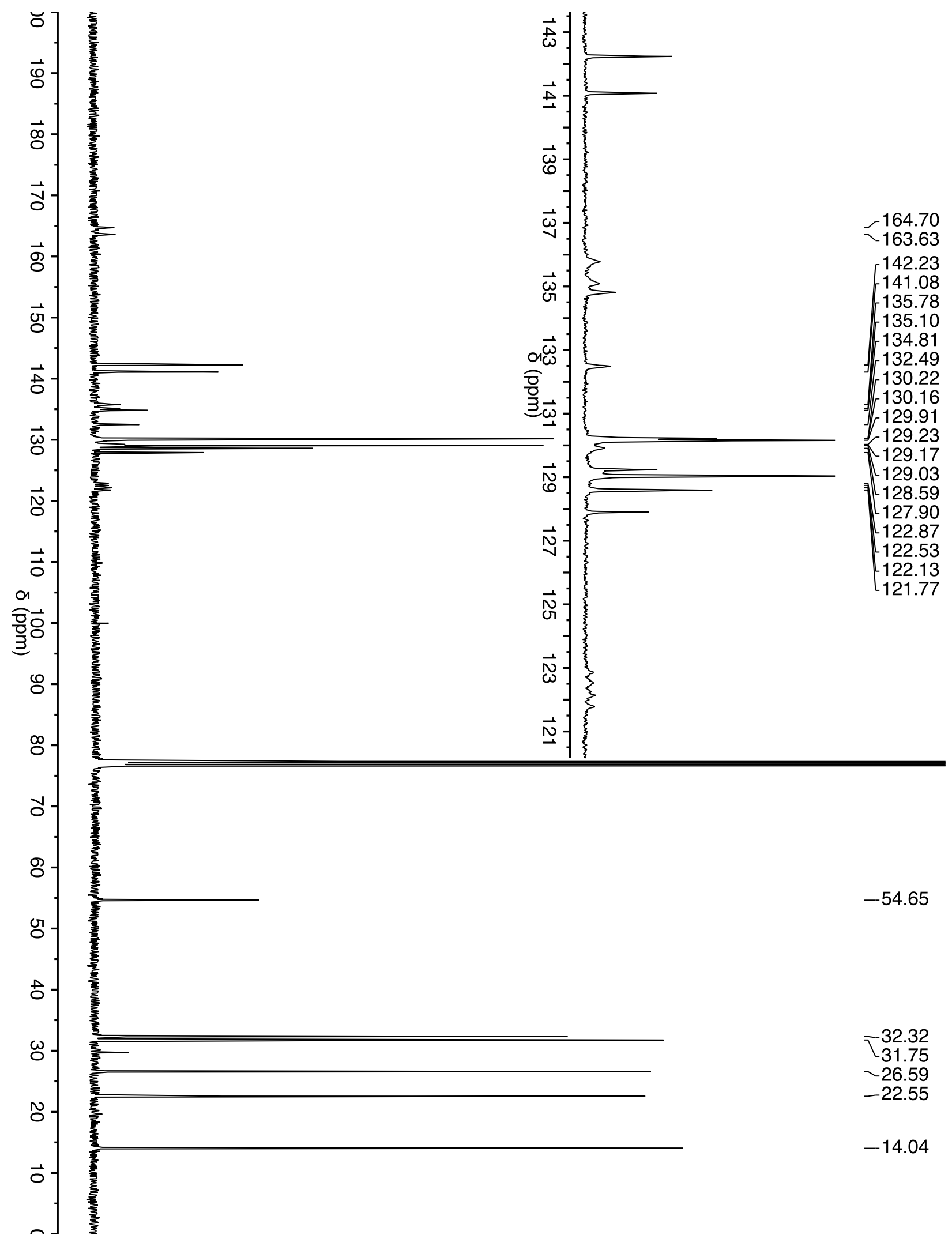




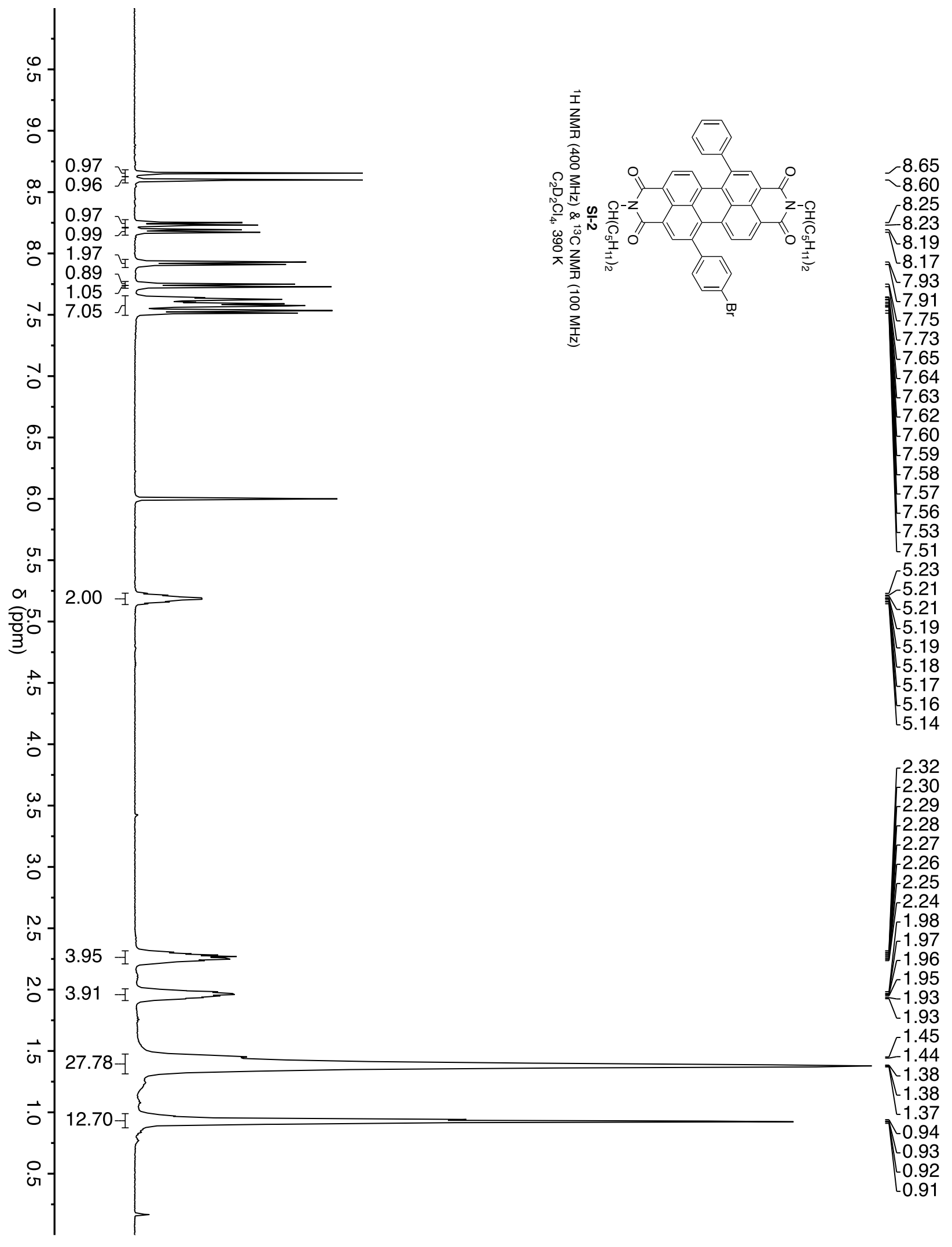




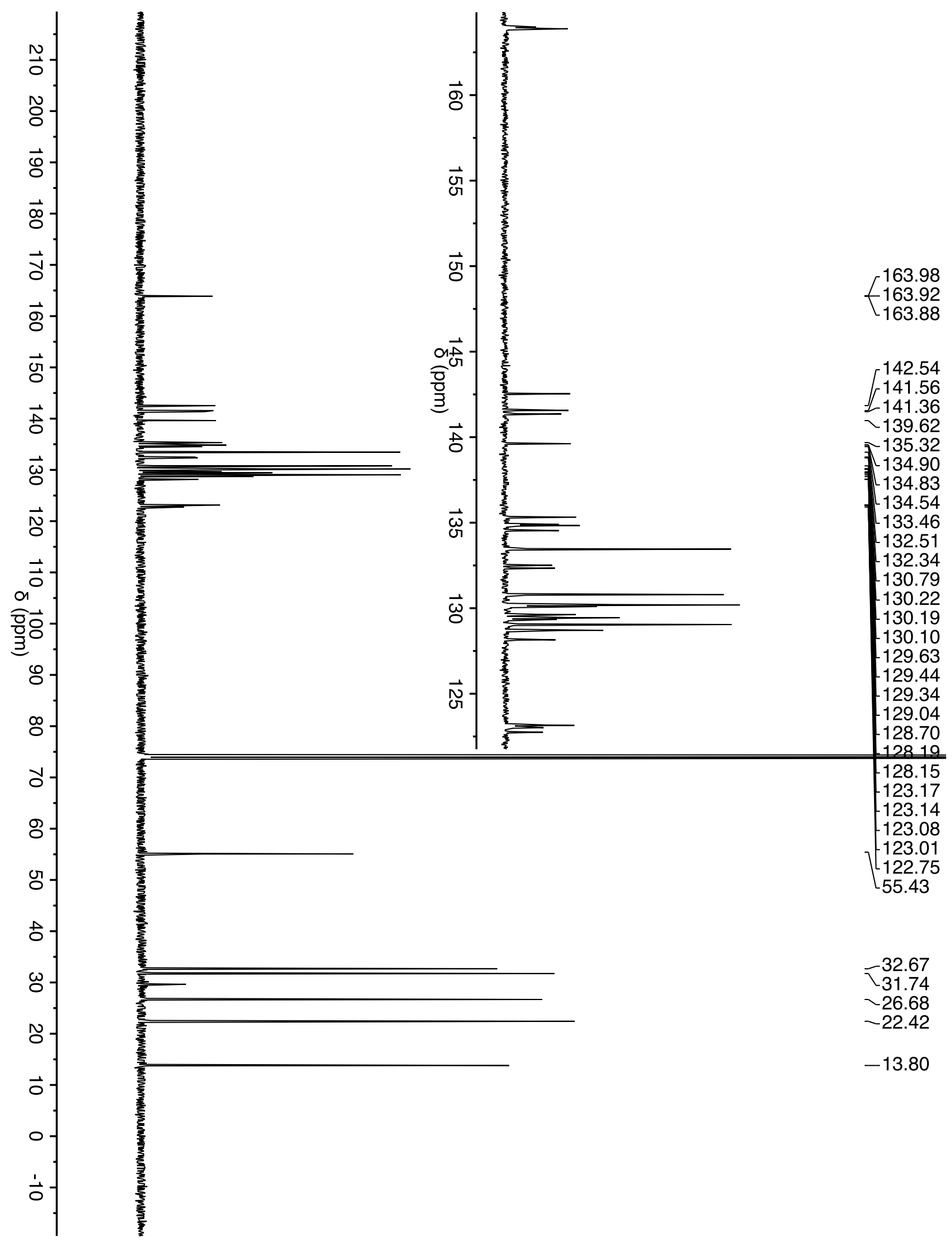




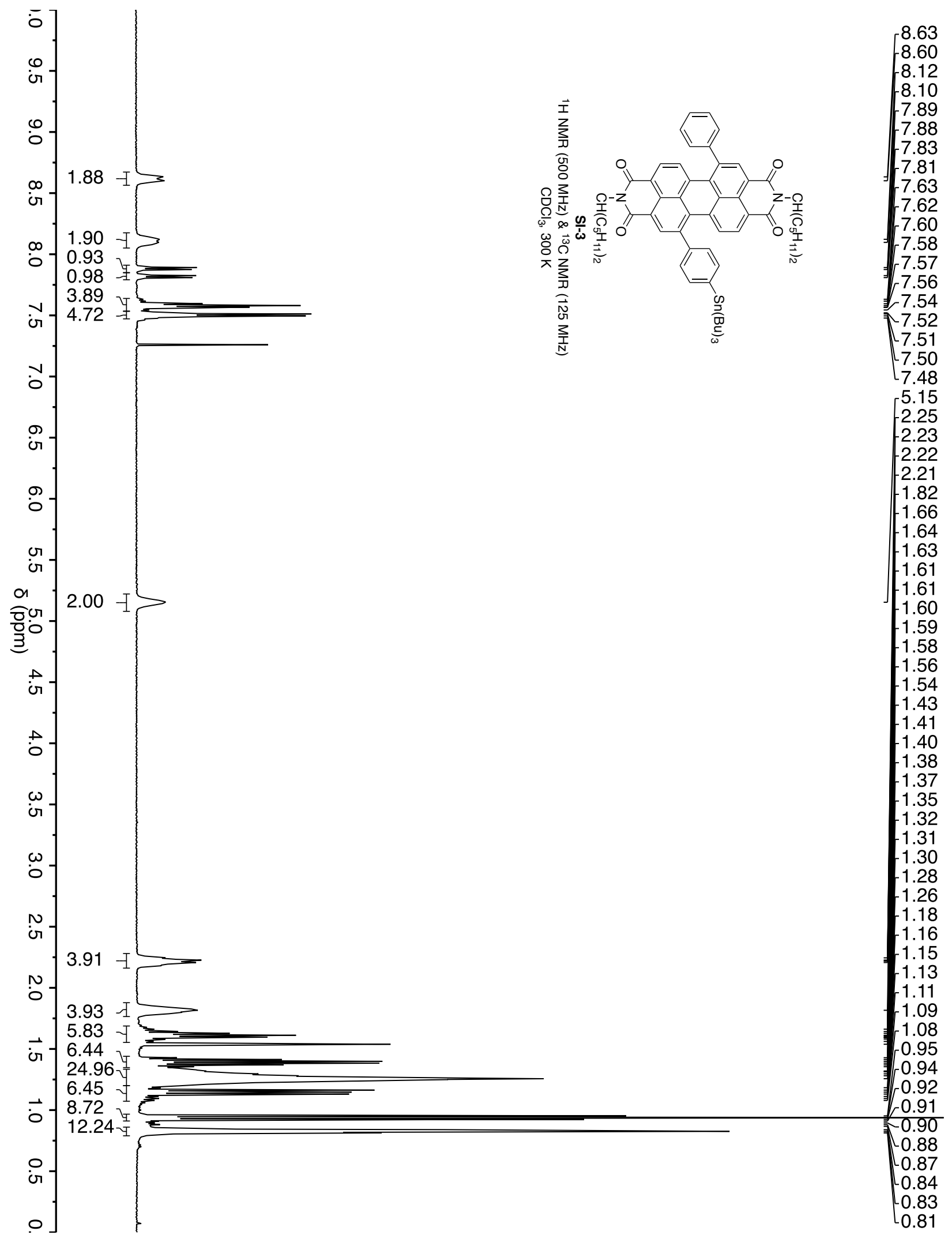




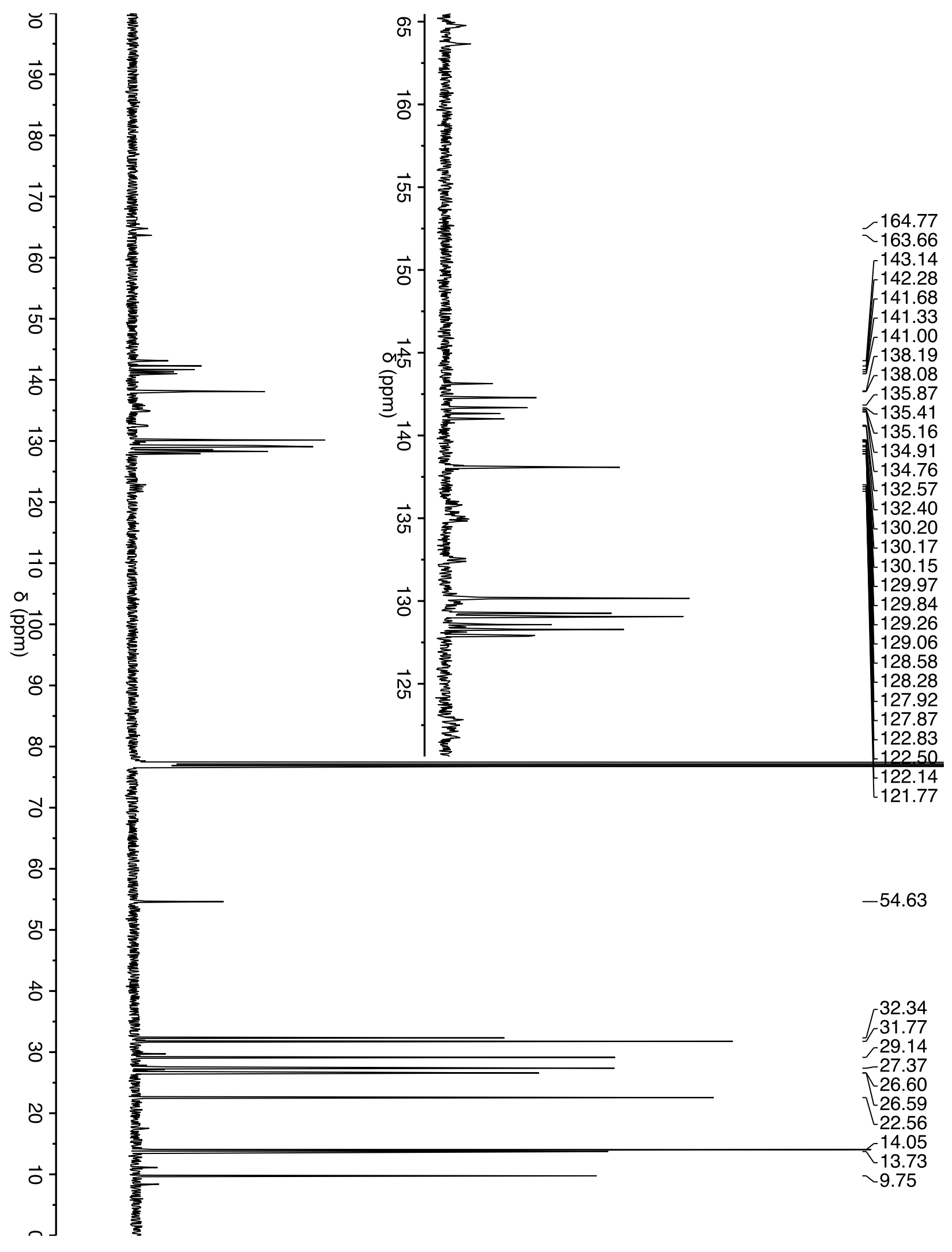




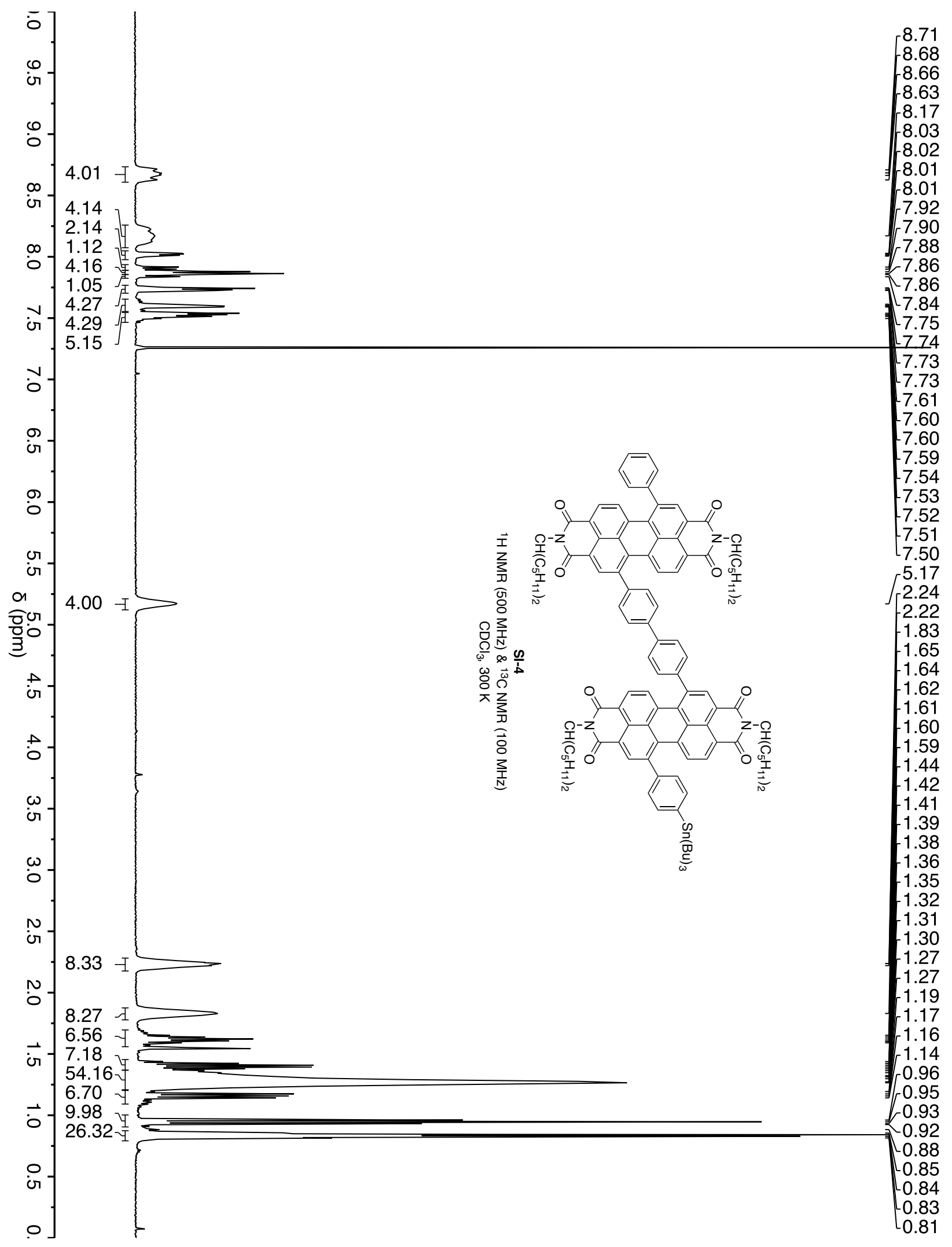




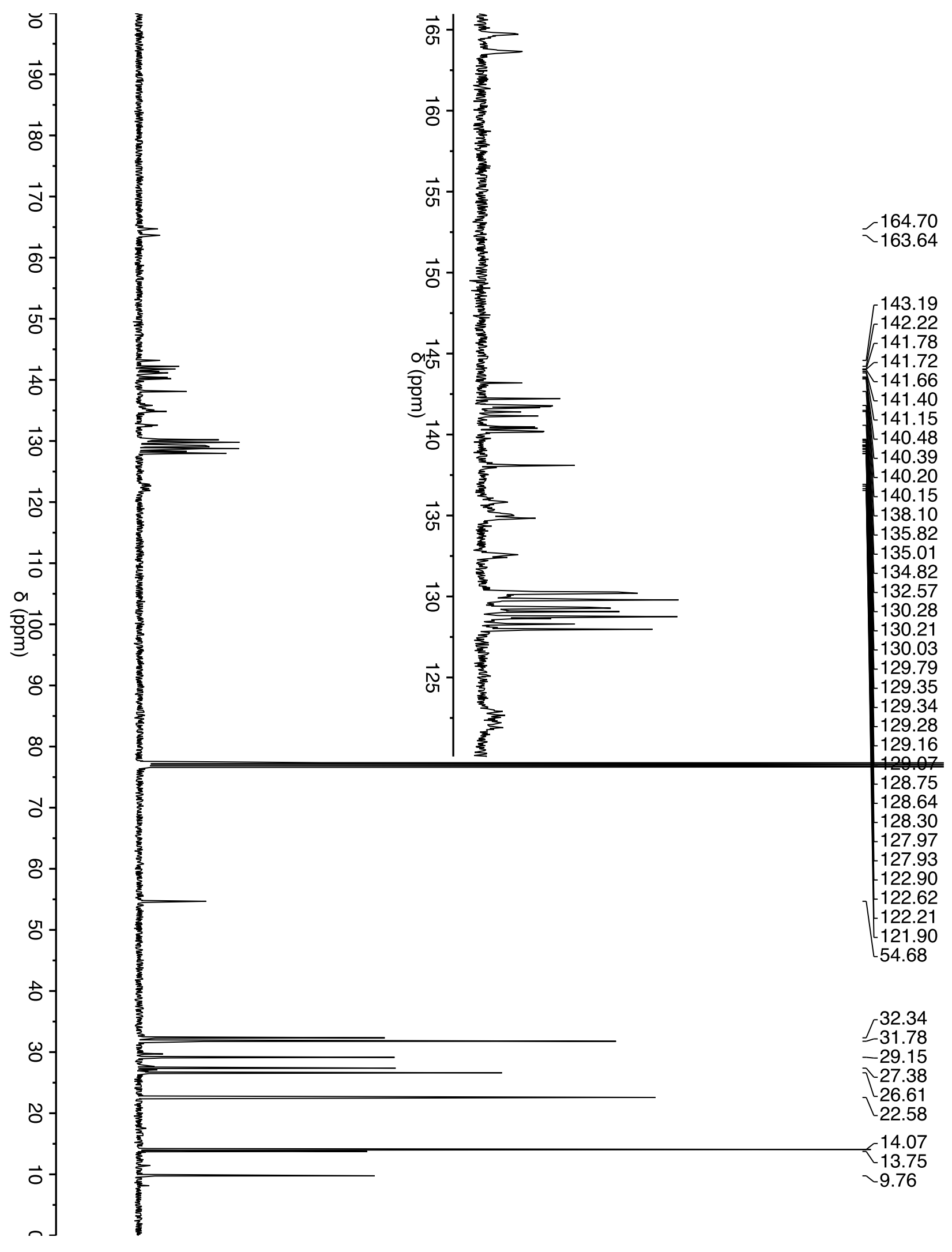




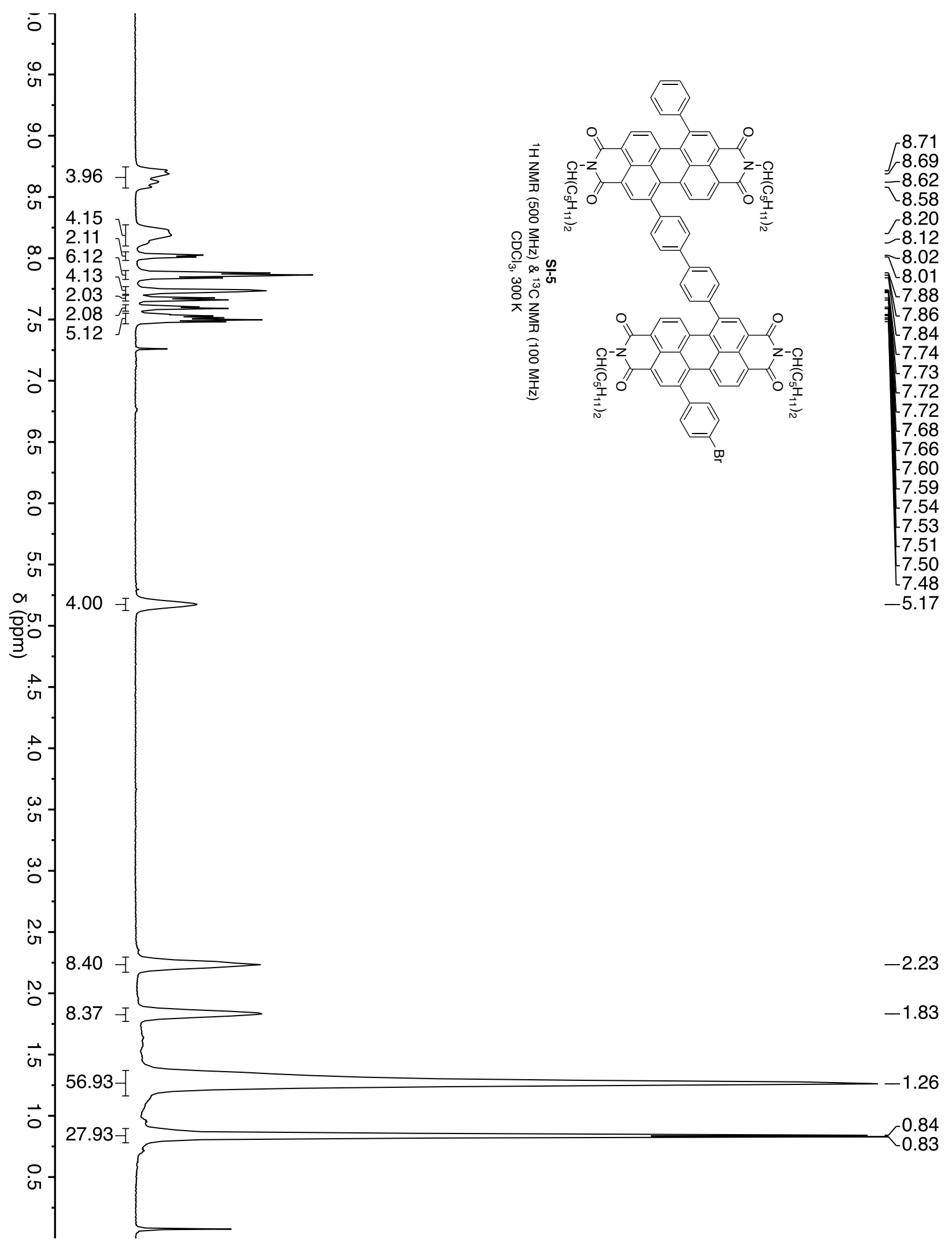




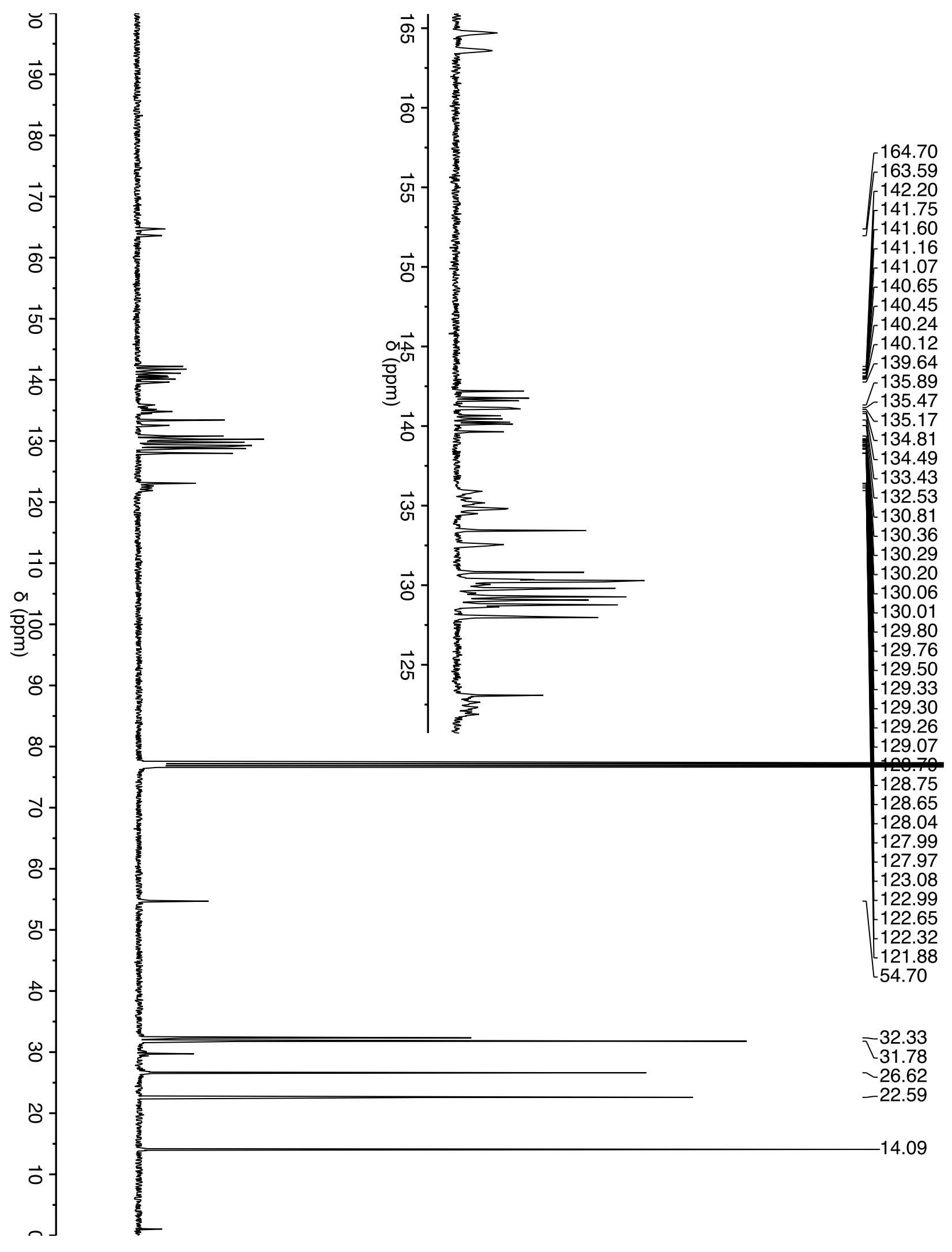




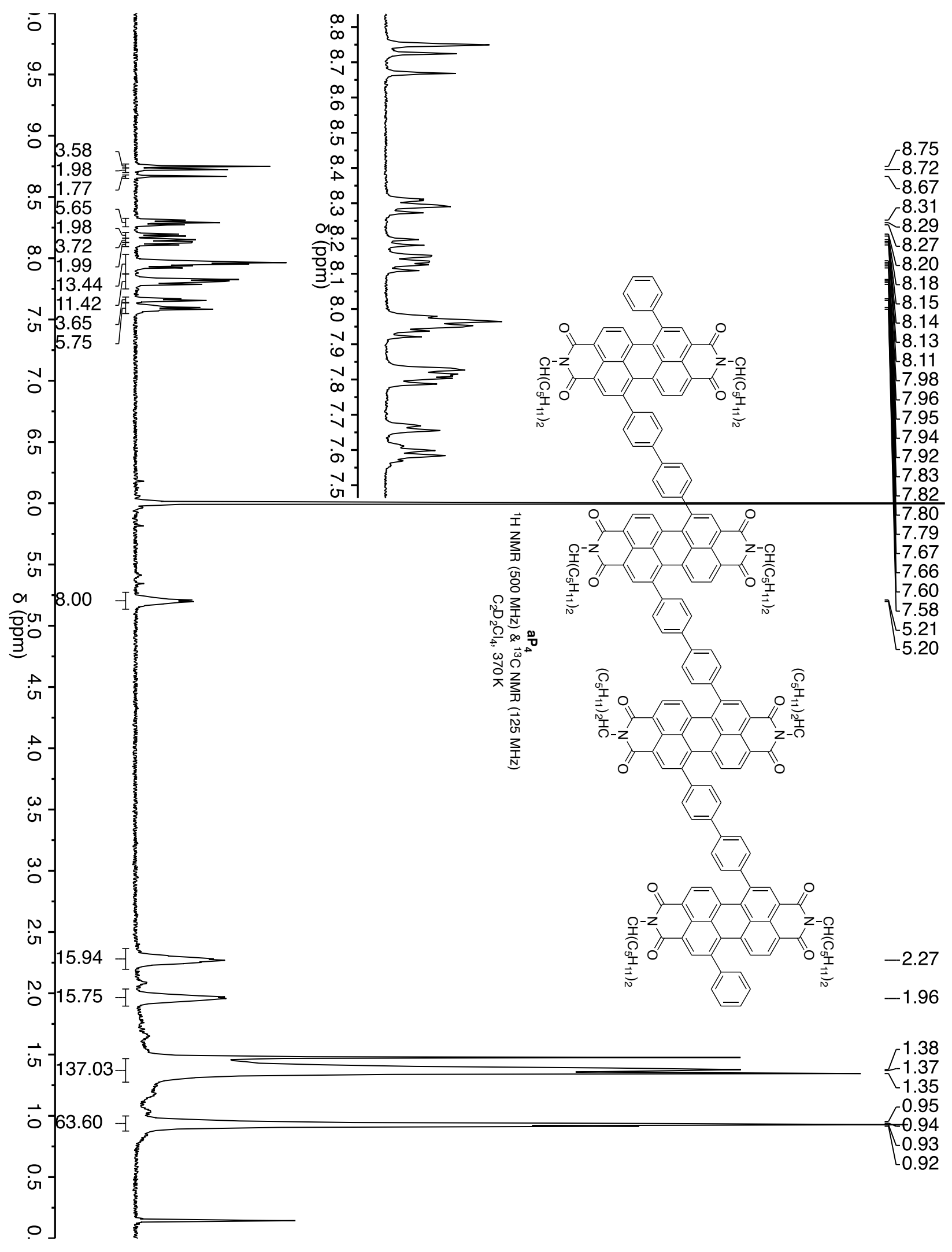




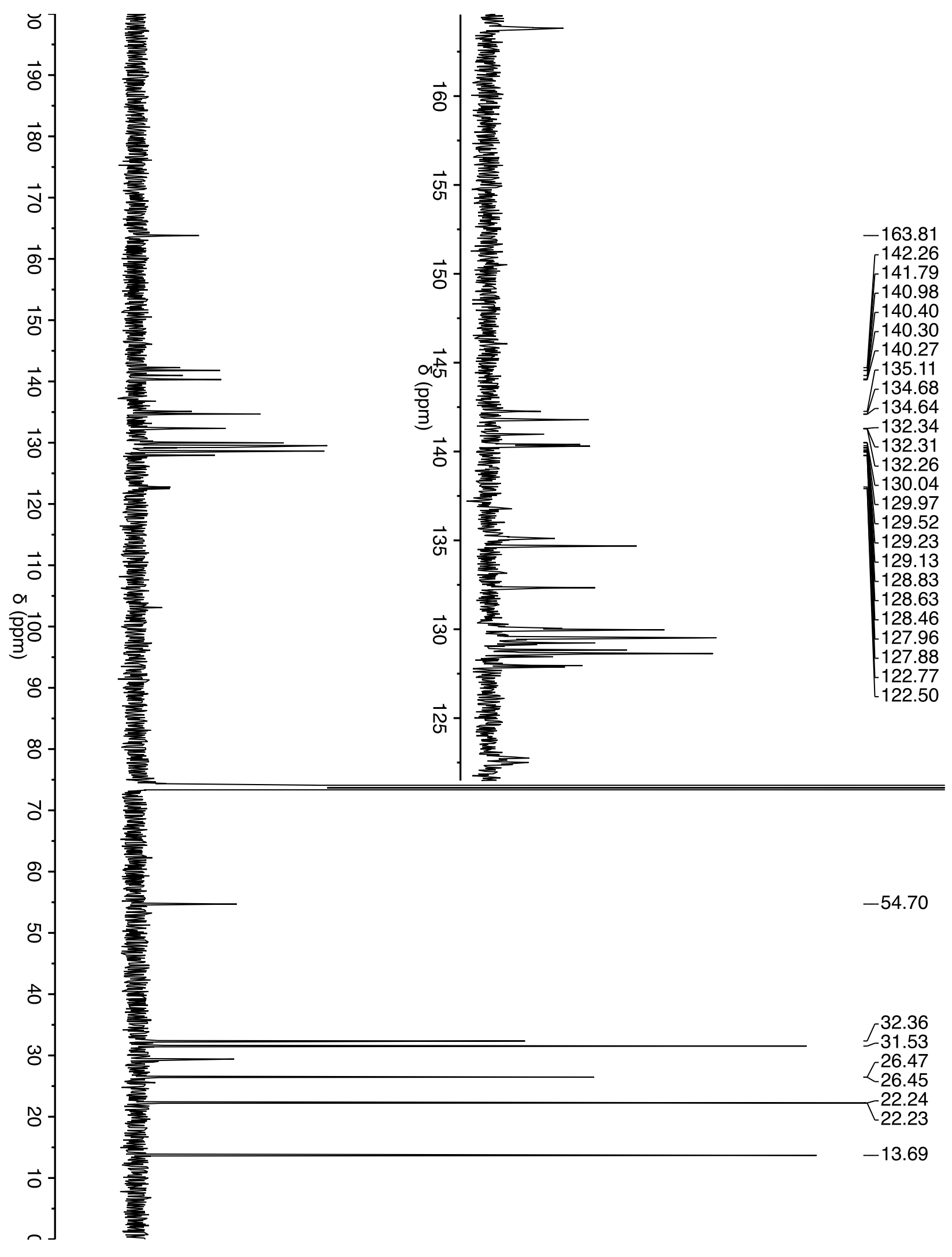




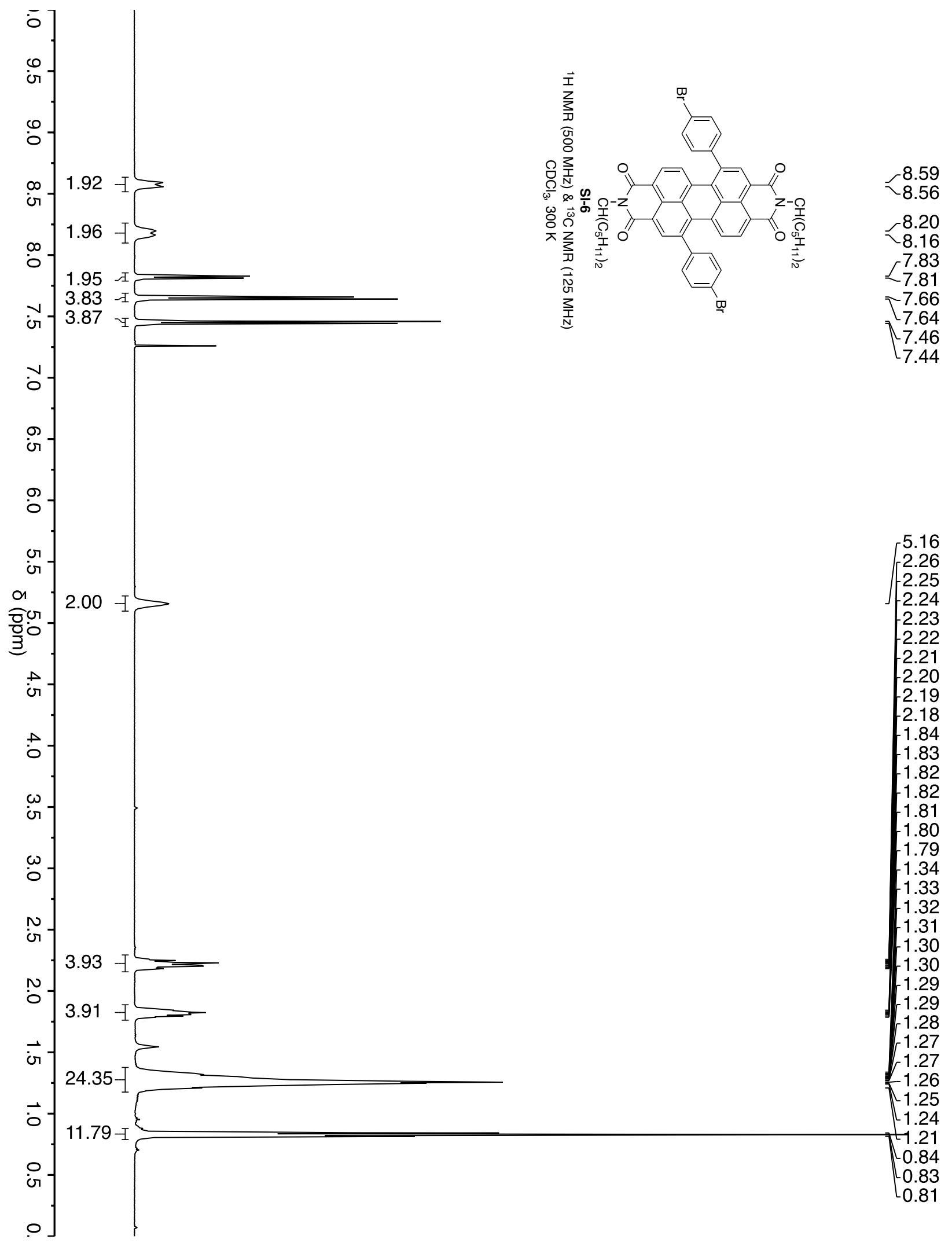




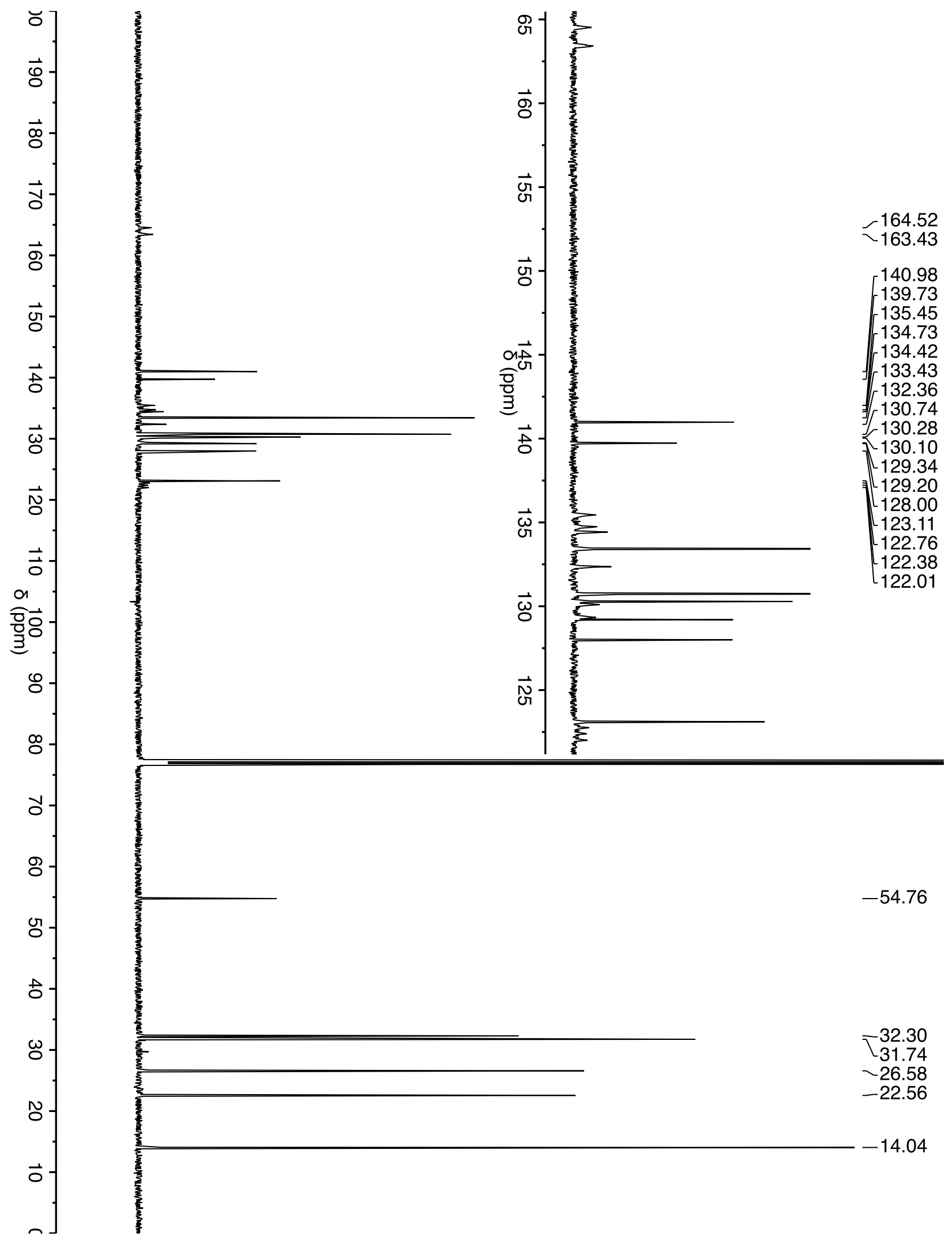




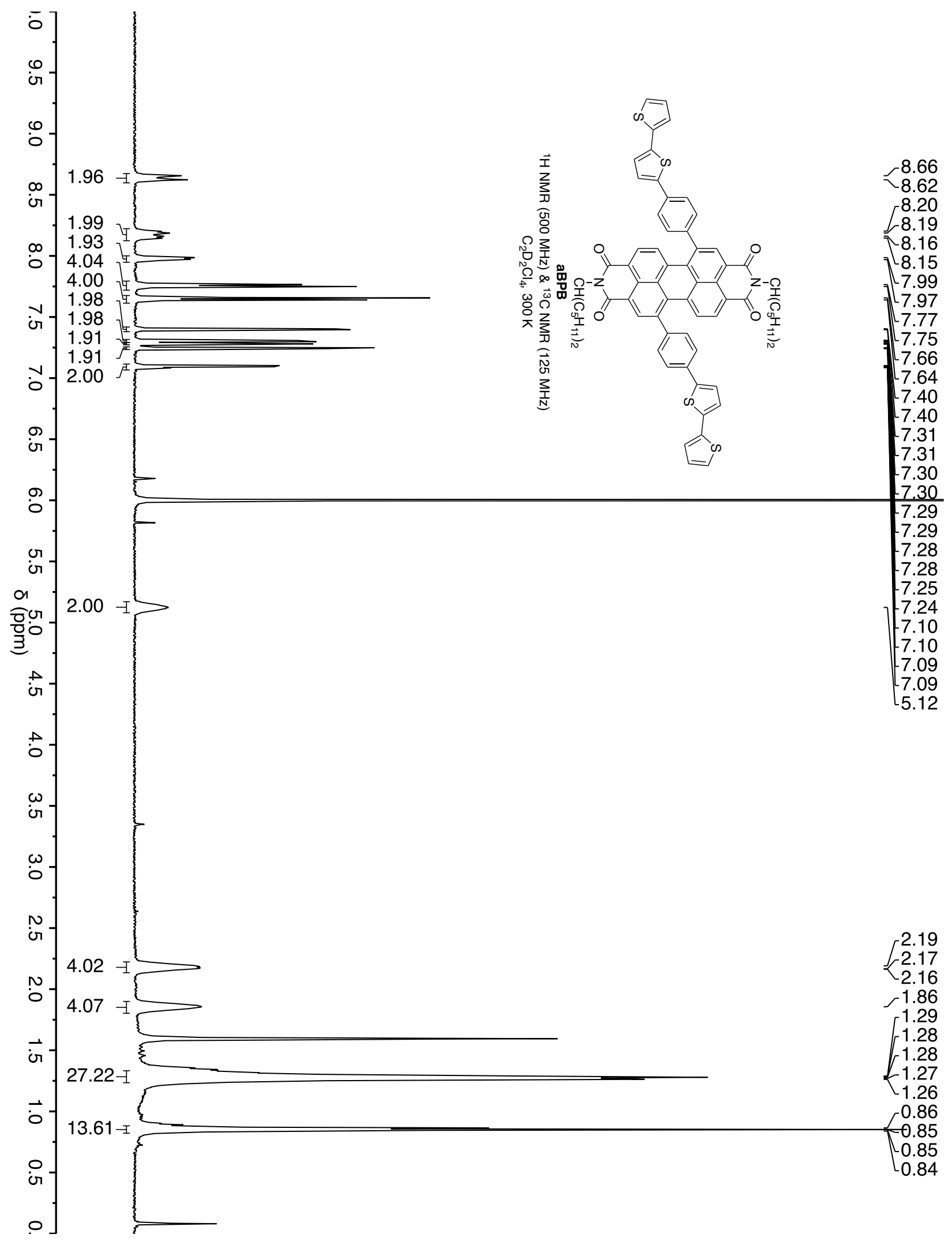




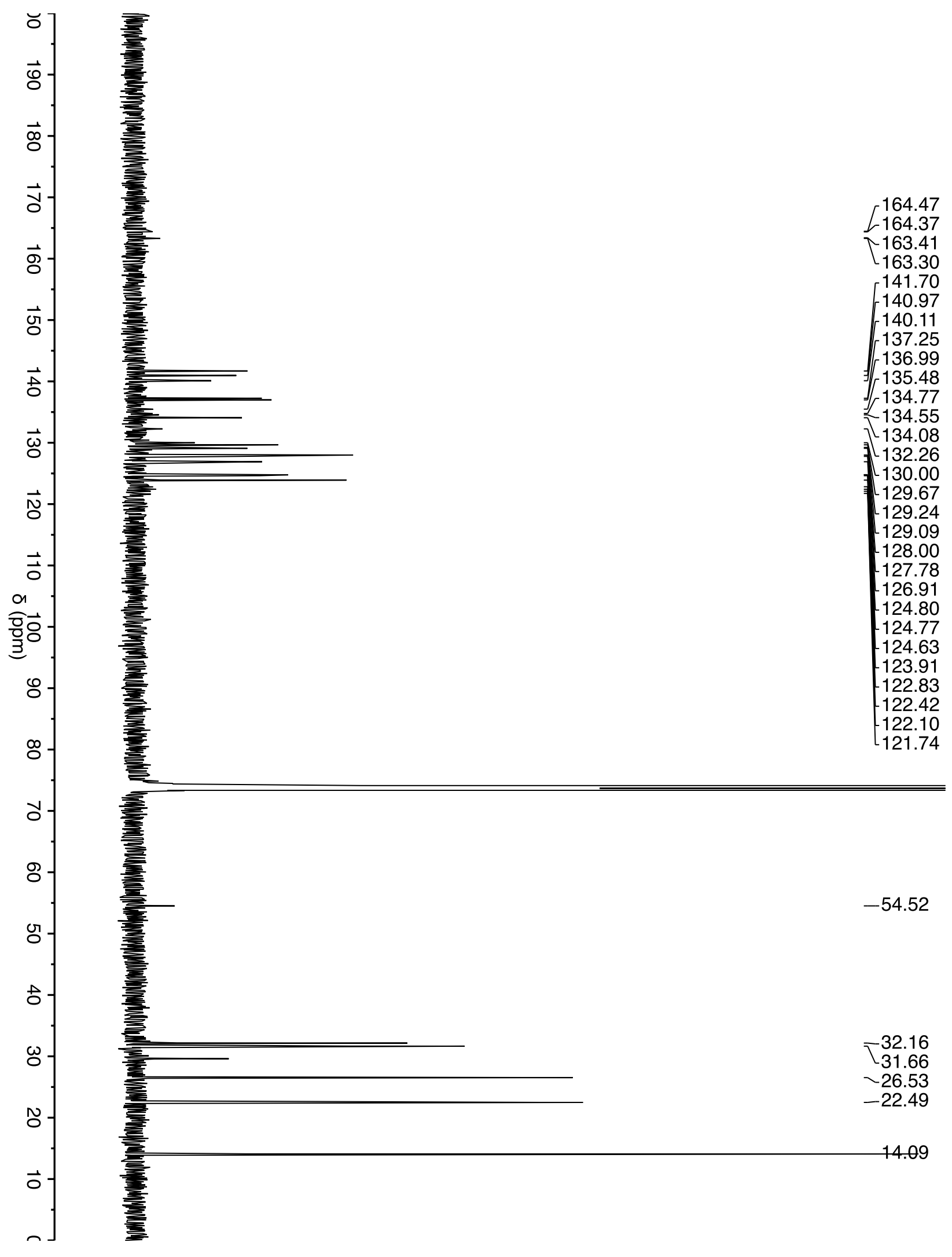




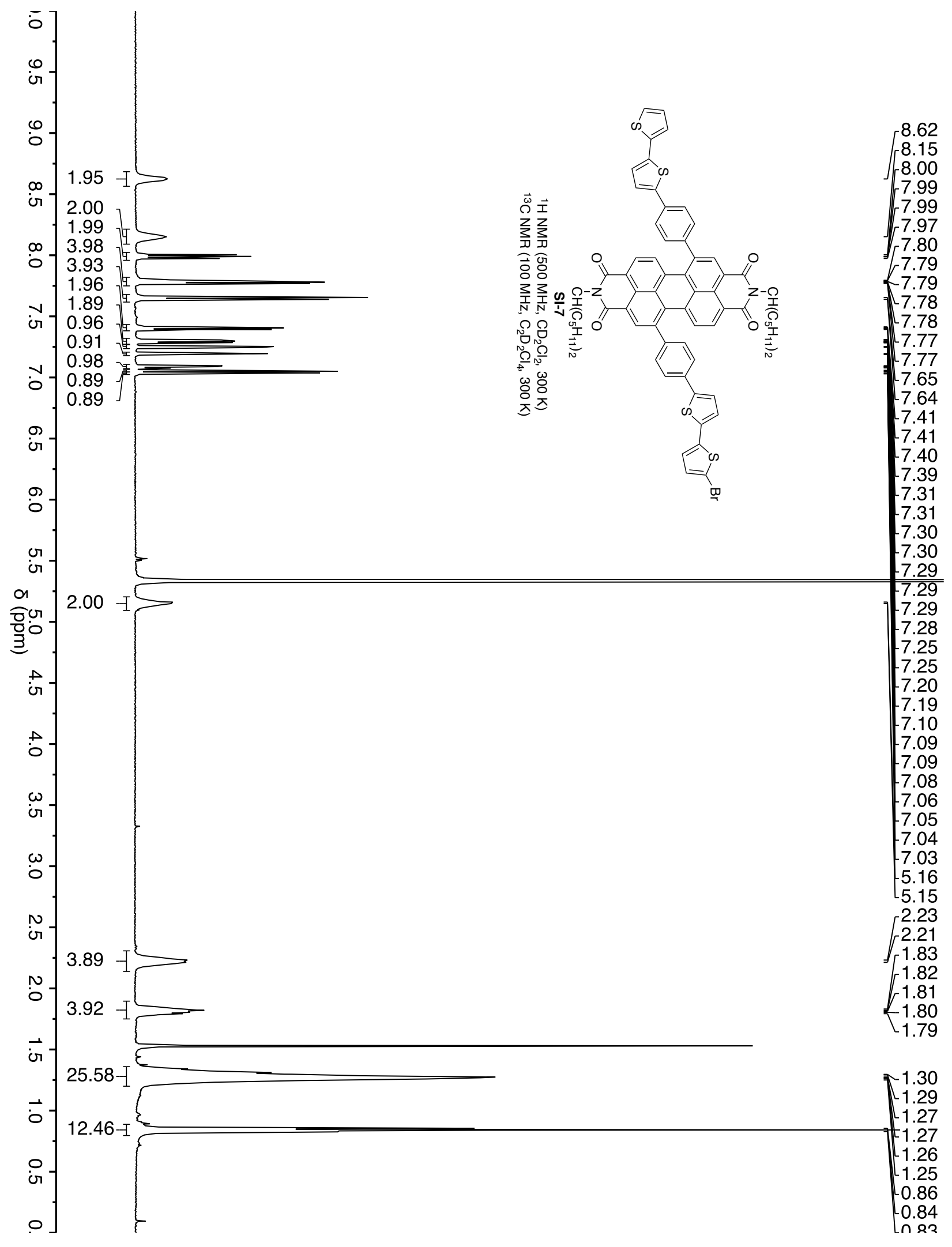




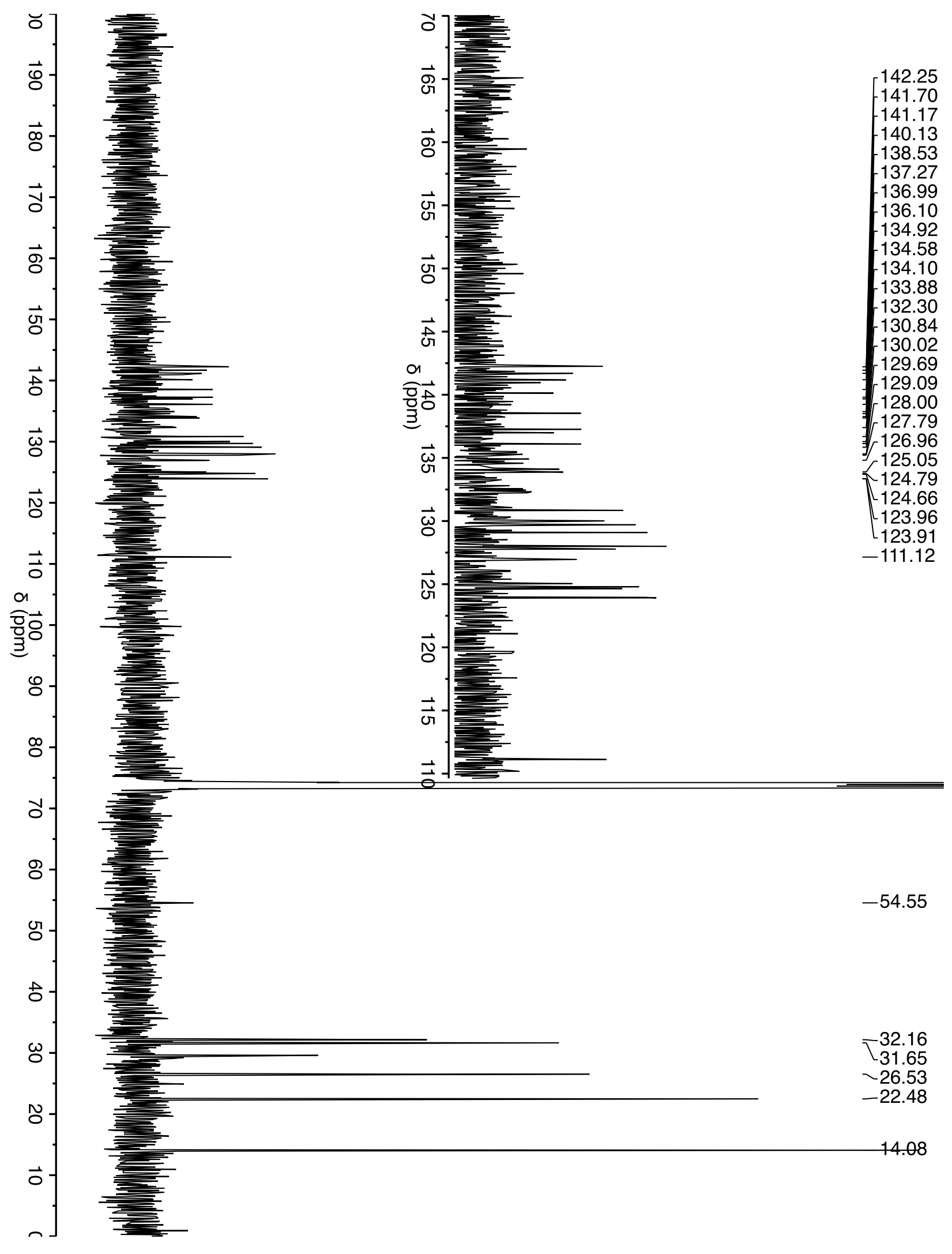




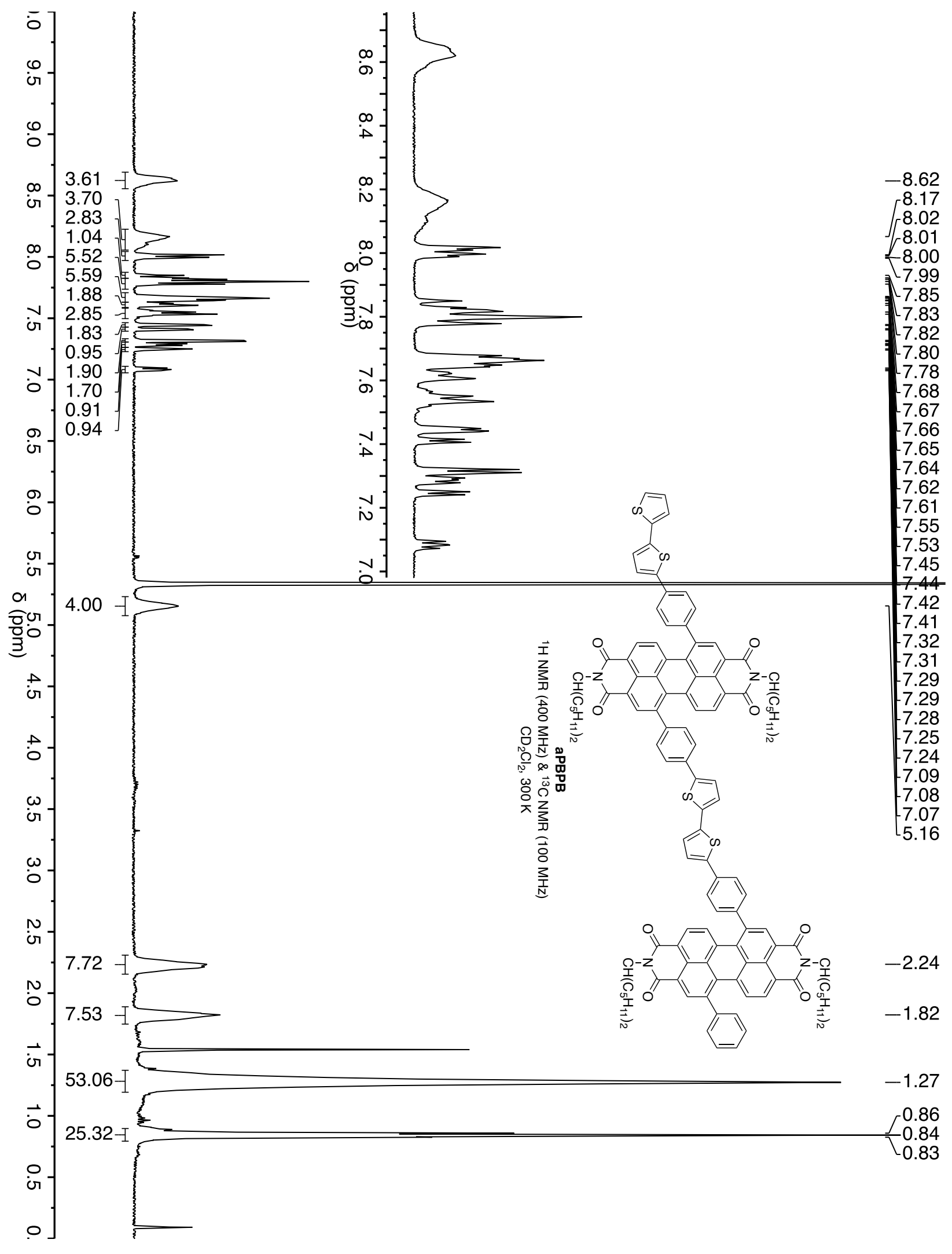




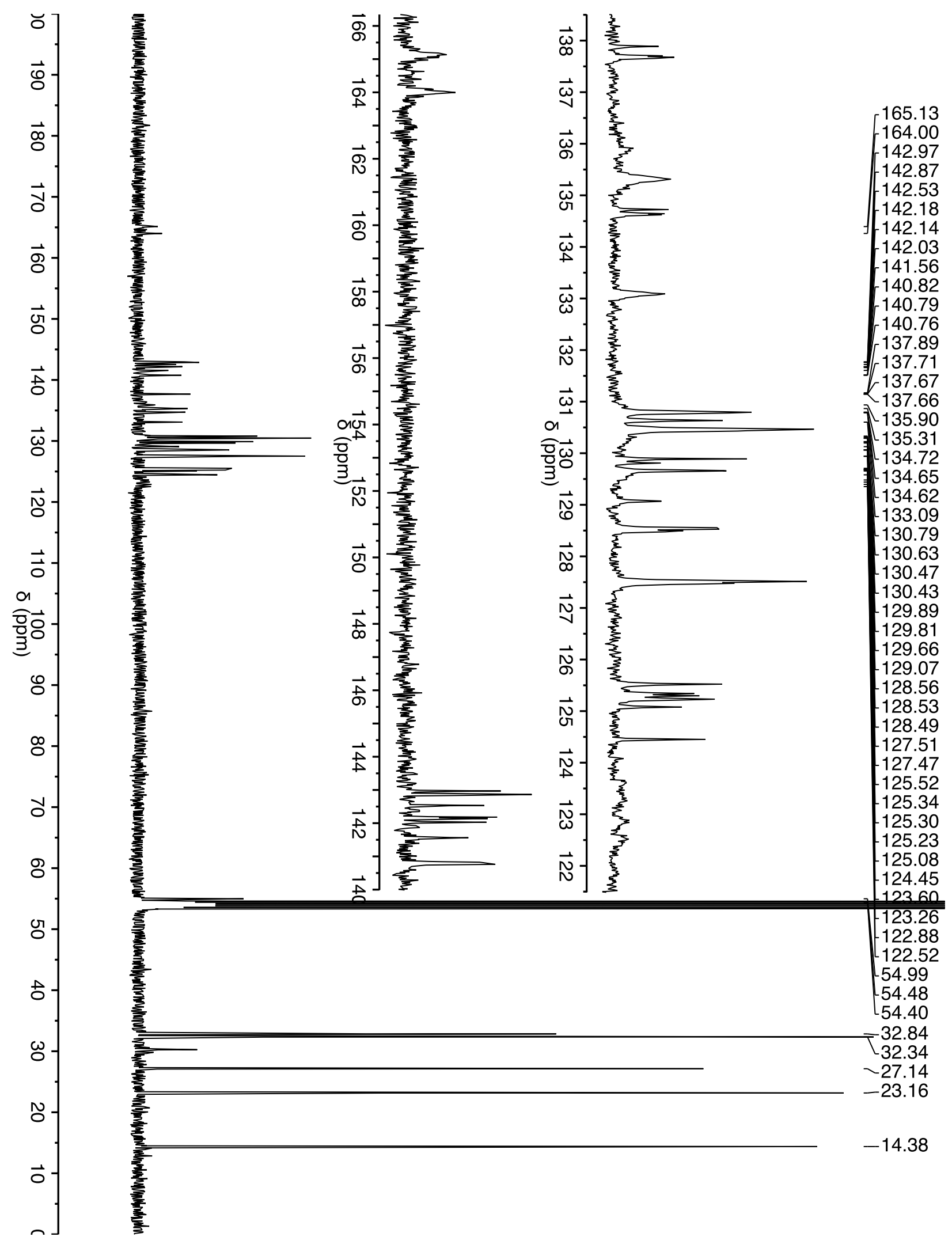




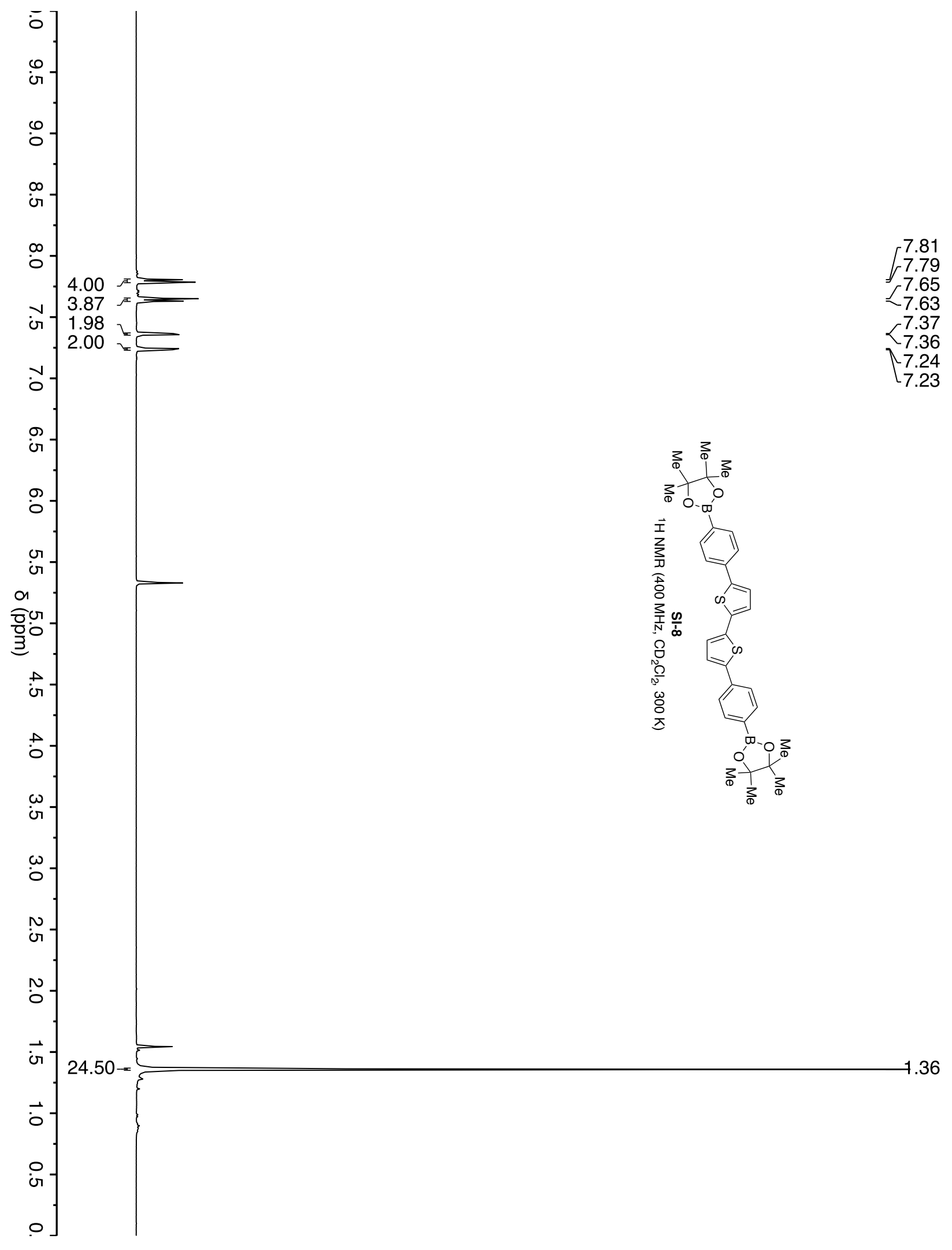




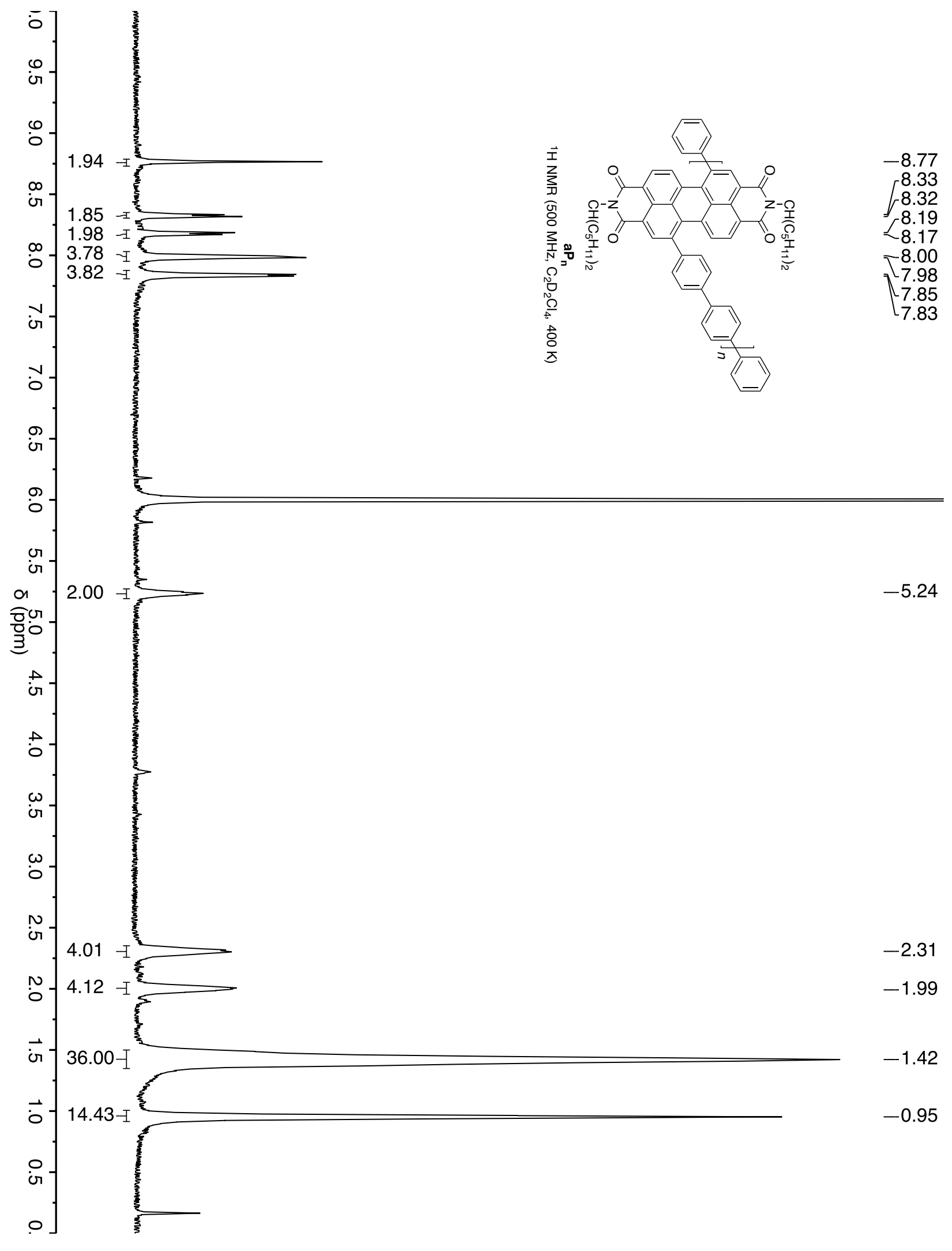




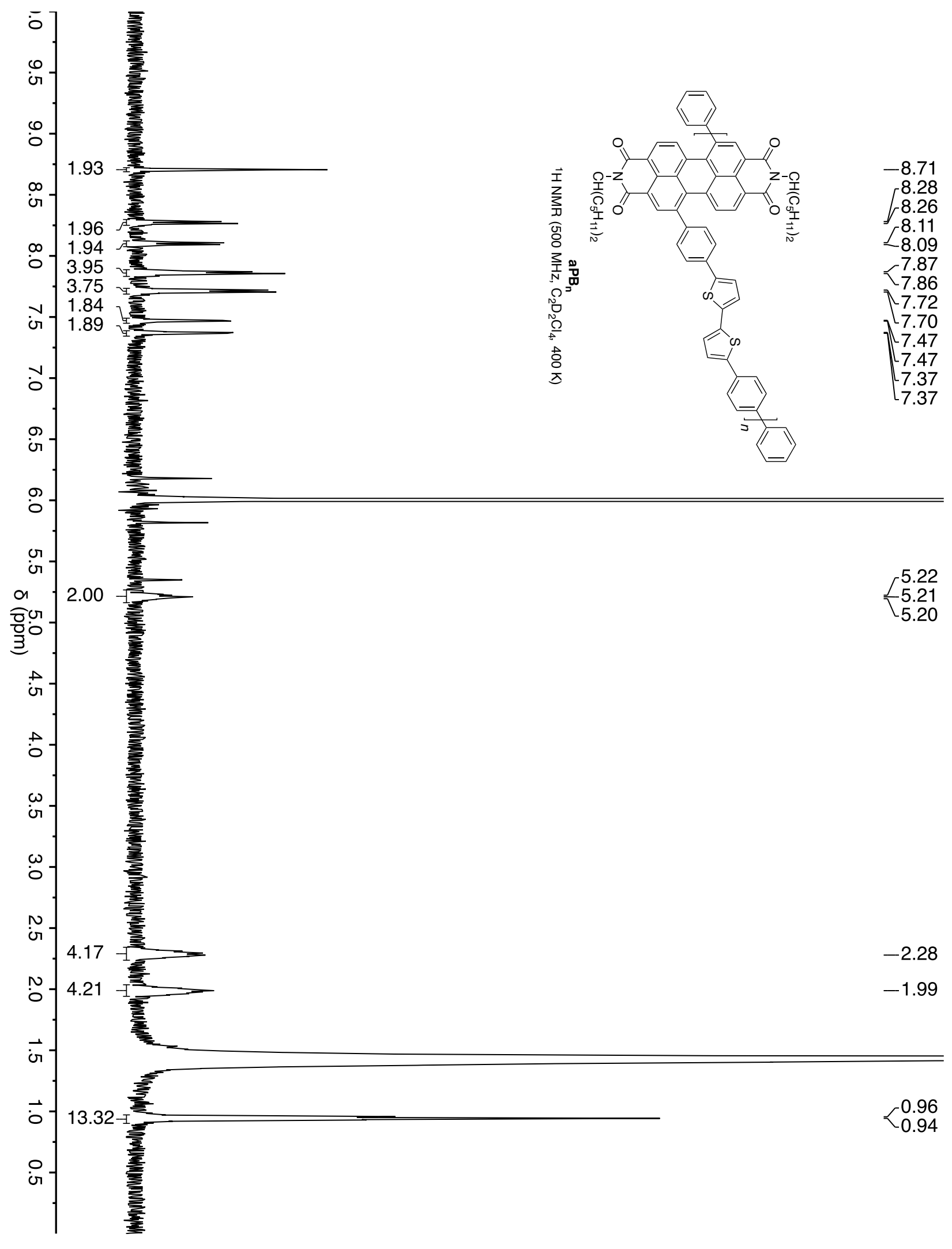




\section{Density Functional Theory (DFT) calculations}

All quantum chemical calculations were performed using Jaguar, version 8.2, Schrodinger, Inc., New York, NY, 2013. (See A. D. Bochevarov, E. Harder, T. F. Hughes, J. R. Greenwood, D. A. Braden, D. M. Philipp, D. Rinaldo, M. D. Halls, J. Zhang, R. A. Friesner, "Jaguar: A High Performance Quantum Chemistry Software Program with Strengths in Life and Materials Sciences", Int. J. Quantum Chem., 2013, 113(18), 2110-2142). All geometries were optimized using the B3LYP functional and the $6-31 G^{* *}$ basis set. In the following pages, we include $\mathbf{C P}_{4}$ optimized geometry and total energy for the (SSSS)- stereoisomer. cPBPB's optimized structure was previously reported. ${ }^{3}$ 


\section{Optimized Geometries for $\mathbf{C P}_{4}$}

Compound $(S, S, S, S)-\mathbf{c} \mathbf{P}_{4}$

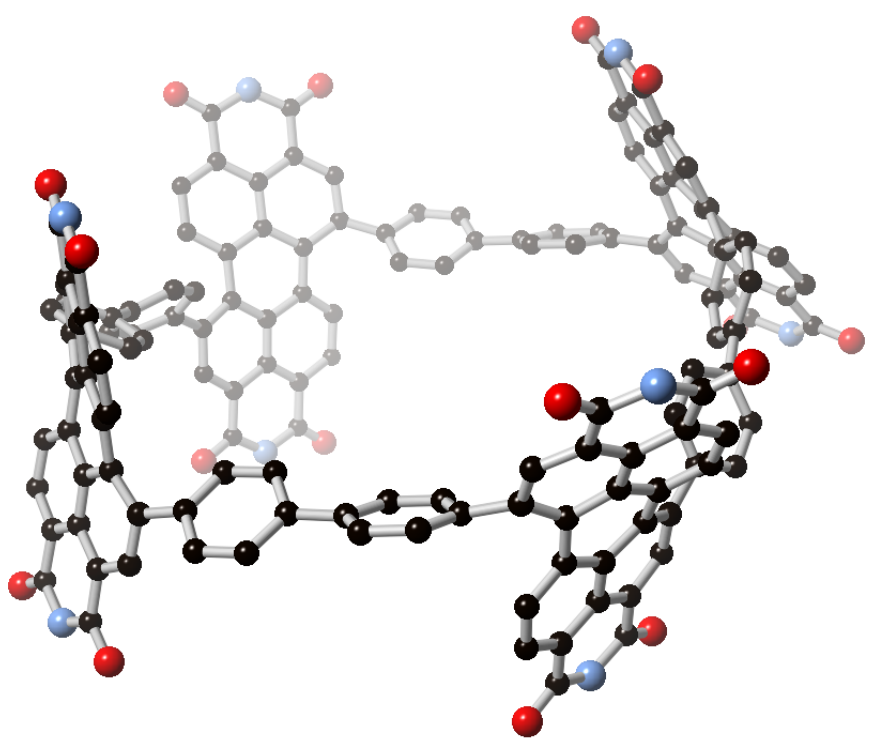

Energy: $\mathbf{- 7 4 8 2 . 6 5 9 9}$ hartrees

\begin{tabular}{cc} 
atom & $x$ \\
H1 & 2.7686998882 \\
H2 & 4.9018944861 \\
H3 & 6.1896179135 \\
H4 & 4.1036255702 \\
H5 & -4.1267948287 \\
H6 & -1.8086546635 \\
C7 & -7.8877905588 \\
C8 & -7.6422905106 \\
C9 & -6.4034143827 \\
C10 & -5.8527544683 \\
C11 & -8.6132930500 \\
C12 & -7.1767480054 \\
C13 & -5.3995969668 \\
C14 & -8.8964423203 \\
C15 & -4.9061980964 \\
C16 & -7.0865353078 \\
C17 & -3.8936187621 \\
C18 & -7.2256547637 \\
C19 & -8.3934935770 \\
C20 & -4.0890114143 \\
N21 & -8.3884566640 \\
C22 & -5.6127783605 \\
C23 & -5.1580912900 \\
& \\
\hline
\end{tabular}

angstroms

$y \quad z$

$\begin{array}{ll}-8.0253694187 & 0.2598638329\end{array}$

$-8.3719335166-3.4567220523$

$-6.3555320877 \quad-2.9019171059$

$-6.0581716250 \quad 0.8376641613$

$-8.7330185987 \quad 0.6211550990$

$-9.5129992441 \quad 0.5698928093$

$5.6704461128 \quad-2.2642246602$

$6.5665918956-1.1289473997$

$7.2811837858 \quad-1.0568099399$

$6.6097084927-3.3689976368$

$6.8026594881-0.1504728318$

$8.3270631966 \quad 1.0415704911$

$7.1495806406 \quad-2.0751084625$

$4.6832334176 \quad-2.2936085167$

$8.7357571025 \quad 0.2228803614$

$5.8794230699 \quad-3.4312359044$

$8.4337121737-0.6603627793$

$5.0540110217 \quad-7.1620989744$

$7.6814633973 \quad 0.9141335908$

$7.6107024795 \quad-1.7953240831$

$4.2684877970 \quad-7.1513004255$

$6.3529808081 \quad-5.7900909539$

$6.8421900170 \quad-4.5597806135$ 


\begin{tabular}{|c|c|c|c|}
\hline C24 & -6.7654166766 & 5.5870987661 & -5.8574554291 \\
\hline C25 & -9.1303548244 & 3.9310849129 & -6.0071151995 \\
\hline C26 & -6.1681314961 & 8.1191930415 & 0.0727540123 \\
\hline $\mathrm{C} 27$ & -6.9427836061 & 9.2383062637 & 2.1871155751 \\
\hline $\mathrm{C} 28$ & 2.0104939098 & -11.8044279149 & 2.1819287283 \\
\hline C29 & 3.3894107671 & -11.7703048668 & 2.4938307328 \\
\hline C30 & 2.2738047768 & -9.2102591502 & -3.4701063814 \\
\hline C31 & -0.1943654187 & 6.1537691785 & -2.9565893602 \\
\hline C32 & -2.8226666175 & 7.1583501082 & -2.4456489108 \\
\hline C33 & -1.3214644574 & 5.3075712330 & -2.944 \\
\hline C34 & 3.5426107429 & -7.6953058776 & -0.4 \\
\hline C35 & -7.5008334227 & 5.3265292046 & -4.6 \\
\hline C36 & -8.6506033055 & 4.5024681682 & 5566 \\
\hline C37 & -0.8231366284 & -11.2379866790 & -3.602 \\
\hline C38 & -5.4660033824 & 10.7447485794 & 3.403 \\
\hline O39 & -3.53 & 791101 & \\
\hline C40 & -9.2847845340 & 4.1541821255 & -3.547 \\
\hline N41 & 2103867 & 658209 & 3702 \\
\hline C42 & 99977171 & -11.1276493217 & -5.0 \\
\hline $\mathrm{H} 43$ & -5.0694852716 & 6.5557 & -6.7066 \\
\hline C44 & 5665929 & & \\
\hline 045 & -10.1167263629 & 3.2094087169 & -6.0750336247 \\
\hline C46 & 5403841 & 360142 & 5289 \\
\hline $\mathrm{H} 47$ & -7.5118232541 & 3.7761883050 & 12277 \\
\hline O48 & 1147478 & 5.2753422008 & 12092 \\
\hline C49 & 342089 & -9.7255244356 & \\
\hline C50 & 2.4813932651 & -10.7705404949 & -0.0061 \\
\hline C51 & -8.8267133894 & 3.7493163960 & -8.450 \\
\hline C52 & -10.2684675889 & 1.9801629376 & 54467 \\
\hline C53 & 6657661 & -12.0149520758 & 47865 \\
\hline C54 & -11.1950365114 & 2.5939173780 & 84124 \\
\hline C55 & 3.8353982097 & -10.7583571769 & 890808 \\
\hline C56 & 0.3614889412 & -10.6412206443 & -3.1156095029 \\
\hline C57 & 1.5268397336 & -12.7609942119 & 4.4575 \\
\hline C58 & -8.5509443482 & 3.4624678721 & -0.1418 \\
\hline C59 & 4.2870710637 & -11.2677706082 & 80306 \\
\hline C60 & -1.6441426852 & -11.9404290339 & -2.7359572895 \\
\hline C61 & -0.4344057992 & 7.5290221815 & -2.8193610315 \\
\hline C62 & 5.4548153879 & -6.7303679579 & -2.1948460403 \\
\hline C63 & -10.7873396999 & 3.5629654752 & -1.0189396791 \\
\hline C64 & -1.7157248162 & 8.0173149012 & -2.5722263869 \\
\hline C65 & -0.1733412517 & -11.4261754999 & -0.8529945438 \\
\hline C66 & -8.9508203818 & 2.4726933764 & 0.7463582068 \\
\hline C67 & 2.6880363826 & -9.3422944372 & -2.1223442459 \\
\hline C68 & 1.1836335288 & -9.8817234561 & -3.9803221392 \\
\hline 069 & -2.1802377138 & -11.6722439507 & -5.5045881911 \\
\hline 070 & -7.7912758779 & 9.4716218528 & 3.0378328365 \\
\hline
\end{tabular}




\begin{tabular}{|c|c|c|c|}
\hline N71 & -5.6817892669 & 9.8473349729 & 2.2643801251 \\
\hline 072 & 0.7570973395 & -13.1598778654 & 5.3221484211 \\
\hline C73 & -2.5761291814 & -10.1546114584 & 0.9902936311 \\
\hline C74 & 5.2352107022 & -6.0427584058 & -0.9940933369 \\
\hline C75 & 3.8845457419 & -12.2780282170 & 3.7968422392 \\
\hline C76 & -4.5557481755 & -11.7571568859 & 2.0942465241 \\
\hline N77 & 2.9106603904 & -12.7658881753 & 4.6857405036 \\
\hline C78 & -3.2336569911 & -12.2071193332 & 2.0534546556 \\
\hline O79 & 1.5264969409 & -9.0841706711 & -6.1952154559 \\
\hline C80 & 3.7048693699 & -8.3497791896 & -1.65 \\
\hline C81 & -4.9085173555 & -10.4898170835 & 1.60 \\
\hline C82 & 3.3523670611 & -13.2840198525 & 5.98 \\
\hline C83 & -2.5980886449 & 5.7915590760 & -2.68 \\
\hline O84 & 5.0724995334 & -12.2852889487 & 16249616 \\
\hline C85 & 398772 & -11.4120226544 & 1.50 \\
\hline C86 & -3.885 & -9.7062271828 & 1.03 \\
\hline C87 & 4.2992322141 & -6.5786356807 & -0.08 \\
\hline C88 & 4.7144337122 & -7.8699 & -2.5 \\
\hline C89 & 7318084 & -11.3659 & 87553 \\
\hline C90 & -0.7665402986 & -11.7499502823 & 619 \\
\hline H91 & -9.1610344353 & 7.8649731337 & \\
\hline H92 & -10.0824085750 & 3.4218 & -3.600 \\
\hline H93 & -2.9066883116 & 8.8230 & 46067 \\
\hline H94 & -1.8454565540 & 9.08468 & 18911 \\
\hline C95 & 0.1652334756 & -11.4990 & 586 \\
\hline C96 & -0.28023 & -12.174 & \\
\hline C97 & 0.7384194343 & -10.7831617404 & 367017 \\
\hline H98 & -8.2196015303 & 2.04182 & 98763 \\
\hline C99 & 1.0712995344 & -12.2645536937 & 83187 \\
\hline $\mathrm{H} 100$ & -1.1913040644 & 4.2423 & 41066 \\
\hline C101 & & -10.2555 & 494500 \\
\hline $\mathrm{H} 102$ & -3.4229804053 & 5.0909170503 & -2.6166732197 \\
\hline $\mathrm{H} 103$ & -0.9758942729 & -12.4119827973 & 486575 \\
\hline $\mathrm{H} 104$ & 4.5594919194 & -10.3525553803 & 3921830 \\
\hline $\mathrm{H} 105$ & -12.2265976953 & 2.2527390308 & 148107 \\
\hline $\mathrm{H} 106$ & -2.5364333678 & -12.4129981720 & 3990276 \\
\hline $\mathrm{H} 107$ & -11.5143507344 & 3.9616511647 & -1.7213195691 \\
\hline $\mathrm{H} 108$ & 0.3982599553 & 8.2266149145 & -2.8349571999 \\
\hline $\mathrm{H} 109$ & 5.3428661999 & -11.2665513780 & 1.8148493158 \\
\hline $\mathrm{H} 110$ & 2.8021353369 & -8.5375778636 & -4.1348350274 \\
\hline $\mathrm{H} 111$ & -2.0002332994 & -12.5454429804 & -0.7139780219 \\
\hline $\mathrm{H} 112$ & -2.9929018341 & -13.1848322976 & 2.4625099763 \\
\hline $\mathrm{H} 113$ & -5.3141969915 & -12.3872614159 & 2.5506041295 \\
\hline C114 & -0.6845222468 & -10.2217987474 & -7.2640753236 \\
\hline $\mathrm{H} 115$ & -9.7403692272 & 3.1832612435 & -8.2868090667 \\
\hline & -9.0021167831 & 4.5788240933 & -9.1386927546 \\
\hline $\mathrm{H} 117$ & -8.0508784226 & 3.1097866927 & -8.8776006294 \\
\hline
\end{tabular}




\begin{tabular}{|c|c|c|c|}
\hline $\mathrm{H} 118$ & -4.4989755360 & 11.2223091929 & 3.2677135043 \\
\hline $\mathrm{H} 119$ & -6.2676370532 & 11.4837827712 & 3.4405850136 \\
\hline $\mathrm{H} 120$ & -5.4782867644 & 10.1782301765 & 4.3379913209 \\
\hline $\mathrm{H} 121$ & -0.3946818508 & -9.2278179922 & -7.6003934030 \\
\hline 122 & 4.4310918453 & -13.4102252549 & 5.9403340059 \\
\hline $\mathrm{H} 123$ & 3.0919207863 & -12.5838727156 & 6.7827135872 \\
\hline $\mathrm{H} 124$ & 2.8509474260 & -14.2317980916 & 6.1815609732 \\
\hline & -1.7549391264 & -10.3832028158 & -7.36 \\
\hline $\mathrm{H} 126$ & -9.5668433162 & 6.2953578402 & -0.2179045045 \\
\hline 1127 & -4.2445393488 & 7.4224429637 & $-4.53583 C$ \\
\hline $\mathrm{H} 128$ & -0.1484398136 & -10.9653147601 & -7.862 \\
\hline $\mathrm{H} 129$ & -7.7710608563 & -6.8867708001 & 2.0971 \\
\hline & -9.5762866529 & -10.6967515158 & 1.2606 \\
\hline & 3264093 & -11.7540390345 & 1.2 \\
\hline 32 & -5.5672058056 & -7.9480551455 & 2.16 \\
\hline & 943641 & -0.3232 & 0.5 \\
\hline & 408753 & -2.433 & \\
\hline & 435200 & -5.080 & 5.4 \\
\hline & 68355 & -6.143 & 6.2 \\
\hline 137 & -10.7554025581 & -8.2984 & 3286 \\
\hline & 347477 & -7.956 & \\
\hline & -12.98 & & \\
\hline 40 & -13.3495597782 & -7.0367 & -2.1 \\
\hline & 306300 & -5.77 & -1 . \\
\hline C142 & 3912432 & 029483 & -1.6 \\
\hline C143 & -10.2928358637 & 4862 & 3.5 \\
\hline & 329633 & -3.7 & \\
\hline C145 & -9.8716892715 & -7.63261 & $4.3 \xi$ \\
\hline C146 & 720429 & $-6.271<$ & 226 \\
\hline & 130256 & -3.5021 & 155 \\
\hline C148 & -9.6315153349 & -7.4104 & 5.7 \\
\hline & 844653 & $-4.15 s$ & \\
\hline C150 & -7.4415010004 & -10.6889931697 & 08991 \\
\hline C151 & -11.6898820047 & -4.616093 & 2.0 \\
\hline & 320951 & -7.9697 & 860 \\
\hline C153 & -11.7460594876 & -7.5062801198 & 50133 \\
\hline & -14.4921946360 & -5.0517682920 & -2.2 \\
\hline 0155 & -10.1240048208 & -2.3804859488 & 252139 \\
\hline C156 & -9.9907013331 & -1.5784454075 & 1.95 \\
\hline C157 & -6.2803282270 & -9.9298827756 & 75873 \\
\hline C158 & -9.4969971867 & -5.9156058533 & 7.7150622452 \\
\hline & -11.6020994427 & 0.6254506915 & 806225 \\
\hline N160 & -9.6589421250 & -4.6075411447 & 8.1933202728 \\
\hline C161 & -11.7858315182 & -0.5648528092 & 3.1913319649 \\
\hline 0162 & -12.1269657480 & -8.9633400807 & -2.2330651346 \\
\hline C163 & -8.8489354043 & -8.7030694841 & 1.6591921864 \\
\hline C164 & -10.5763924038 & 0.7467667466 & 1.5320432214 \\
\hline
\end{tabular}




\begin{tabular}{|c|c|c|c|}
\hline C165 & -9.3739070550 & -4.4008465543 & 9.6165017392 \\
\hline 0166 & -9.1392557835 & -6.8072086304 & 8.4736310430 \\
\hline C167 & -10.9819492252 & -1.6872651089 & 2.9432492240 \\
\hline C168 & -9.7812216435 & -0.3845001293 & 1.2811229114 \\
\hline C169 & -6.4411069192 & -8.5560926113 & 1.9549555045 \\
\hline C170 & -8.7005074139 & -10.0861048403 & 1.4630854458 \\
\hline C171 & -10.5298563712 & -5.3093852366 & 4.0791533269 \\
\hline & -10.9732482917 & -2.9220058214 & 3.7864260145 \\
\hline C173 & -11.0458724126 & -4.2386095284 & 3.2797084482 \\
\hline C174 & 8560353 & -2.7 & 5.149 \\
\hline C175 & -11.4509985901 & -5.9181921131 & 1.459364 \\
\hline C176 & -10.3373654048 & -3.7758882495 & 5.986490 \\
\hline & -10.57 & -6.85 & 2.10 \\
\hline $\mathrm{H} 178$ & -10.64 & -1.72 & 5.55 \\
\hline $\mathrm{H} 17$ & -9.726 & -8.62 & 3.985 \\
\hline $\mathrm{H} 180$ & -13.95 & 3202 & -0.30 \\
\hline $\mathrm{H} 181$ & 06470 & $-8.2180 \varepsilon$ & 6.391 \\
\hline & 59127 & -9.17 & -0.401 \\
\hline & -12.8 & -2.80 & \\
\hline & 44255 & $-0.614 c$ & 3.956 \\
\hline H185 & -12.23 & 485 & 2.700 \\
\hline C186 & -14.01 & $-7.452 c$ & -3.4286 \\
\hline & 0585 & -7.26 & -4.291300790 \\
\hline & -8.32 & -4.61 & 9.8233767768 \\
\hline H189 & -9.60463 & -3.3648 & 9.851 \\
\hline H190 & -9.98 & -5.0818 & 10.214 \\
\hline & $-14.926 C$ & -6.8746 & -3.529 \\
\hline H192 & -14.21 & -8.52 & -3.376 \\
\hline & 2.7692 & 2.739 & -1.963 \\
\hline H194 & 4.3824697618 & 6.1541 & -4.0123909599 \\
\hline H195 & 2.16412 & 7.1972 & -4.0294 \\
\hline & 9790 & 3.8041 & -1.9177 \\
\hline H197 & 4.8622995173 & -3.871652 & -2.49721 \\
\hline & 5.2575644365 & -1.5274955406 & -1.9049 \\
\hline & 5.4585591546 & 1.9512 & 1.5530300386 \\
\hline C200 & 5.0288835747 & 3.18321 & $2.097 C$ \\
\hline C201 & 41225 & 3.5869848206 & -4.4451 \\
\hline C202 & 2.6481898931 & 3.7229634873 & -2.4043063402 \\
\hline C203 & 8.0917664566 & 0.8627903440 & -4.24583 \\
\hline N204 & 8.1772762329 & 1.8826037310 & -6.4815245122 \\
\hline C205 & 8.6897269164 & 0.9181472508 & -5.6007387100 \\
\hline C206 & 7.1758208657 & 2.8171032603 & -6.1690853097 \\
\hline C207 & 5.4171629821 & 2.9322631942 & -0.7014573327 \\
\hline C208 & 7.9229098594 & -0.1806097741 & -2.0778045705 \\
\hline C209 & 4.9976538220 & 4.1335640405 & -0.1230073742 \\
\hline $\mathrm{C} 210$ & 7.0902479598 & 1.7881938346 & -3.8700739687 \\
\hline $\mathrm{C} 211$ & 5.3559919434 & 0.9137423231 & 3.8424435805 \\
\hline
\end{tabular}




\begin{tabular}{|c|c|c|c|}
\hline C212 & 4.8249376561 & 4.2671839143 & 1.2596997035 \\
\hline C213 & 8.5219610279 & -0.0928224229 & -3.3393866942 \\
\hline C214 & 2.2866276015 & 6.2270171268 & -3.5569368504 \\
\hline C215 & 6.9160445454 & 0.7009237633 & -1.6745205034 \\
\hline C216 & 5.0304452308 & 3.6022574617 & -3.1444250382 \\
\hline $\mathrm{C} 217$ & 6.6223511850 & 2.7495769704 & -4.7957847075 \\
\hline O218 & 9.5860147969 & 0.1680615020 & -5.9639750935 \\
\hline O219 & 5.4417802442 & -0.0478392949 & 4.5949825747 \\
\hline C220 & 5.6362091405 & -2.3066202661 & -1.2541405593 \\
\hline C221 & 1.1755202459 & 5.5766668574 & -2.9942193716 \\
\hline C222 & 4.8069484451 & 3.3279320100 & 3.55620864 \\
\hline C223 & 6.4743293277 & -4.3410429277 & 0.4 \\
\hline N224 & 5.0139177175 & 2.1787400125 & 4.3390 \\
\hline C225 & 6.7329450351 & -3.0087260577 & 0.7635 \\
\hline 0226 & 6.7878450064 & 3.6346682573 & -6.992 \\
\hline C227 & 3.7552863181 & 4.3598583661 & -2.988 \\
\hline C228 & 5.7766096308 & -4.6789813574 & -0.722 \\
\hline C229 & 4.8029953841 & 2.2830305754 & 5.786 \\
\hline 0230 & 4.4676350141 & 4.3859270164 & 4.0679 \\
\hline C231 & 6.2725379855 & -1.9584690635 & $-0.0<$ \\
\hline C232 & 5.4092254132 & -3.6352505372 & \\
\hline C233 & 1.3970526051 & 4.3188008867 & -2.4020 \\
\hline C234 & 3.5479818652 & 5.6286738083 & -3.55 \\
\hline C235 & 5.7268152557 & 1.8289903366 & 0.1588 \\
\hline C236 & 6.2283771176 & -0.5516973618 & 0.4497 \\
\hline C237 & 6.2778275008 & 0.6103557408 & \\
\hline C238 & 5.9227934943 & -0.4000269658 & 1.8237 \\
\hline C239 & 6.5404860006 & 1.7658772089 & -2.55665 \\
\hline C240 & 5.6123427053 & 0.8197408773 & 2.3846822578 \\
\hline C241 & 5.6155221957 & 2.7827049290 & -2.1515074449 \\
\hline $\mathrm{H} 242$ & 5.9021556403 & -1.2667642159 & 2.4734711948 \\
\hline H243 & 4.8008688348 & 4.9878328942 & -0.7579233070 \\
\hline $\mathrm{H} 244$ & 9.3096461214 & -0.7765475833 & -3.6360772706 \\
\hline $\mathrm{H} 245$ & 4.5145253372 & 5.2102923009 & 1.6958587534 \\
\hline $\mathrm{H} 246$ & 5.1707825429 & 4.2317850114 & -5.2131687926 \\
\hline $\mathrm{H} 247$ & 8.2468523447 & -0.9580224583 & -1.3992601000 \\
\hline H248 & 7.2723784567 & -2.7848685080 & 1.6790119805 \\
\hline H249 & 6.7961386380 & -5.1252612749 & 1.1226769586 \\
\hline C250 & 8.7658267217 & 1.9070118874 & -7.8240982402 \\
\hline $\mathrm{H} 251$ & 8.2041883334 & 2.6245171726 & -8.4170064432 \\
\hline H252 & 4.8805138004 & 3.3321878423 & 6.0604367850 \\
\hline H253 & 3.8123675878 & 1.9076999855 & 6.0600590512 \\
\hline $\mathrm{H} 254$ & 5.5546994044 & 1.6809141304 & 6.2951699058 \\
\hline H255 & 8.7126343048 & 0.9093776097 & -8.2630326940 \\
\hline H256 & 9.8169567350 & 2.2008135132 & -7.7690262555 \\
\hline
\end{tabular}




\section{References}

${ }^{1}$ You, J. B.; Dou, L. T.; Yoshimura, K.; Kato, T.; Ohya, K.; Moriarty, T.; Emery, K.; Chen, C. C.; Gao, J.; Li, G.; Yang, Y. Nat. Commun. 2013, 4, 10.

2 Sun, Y.; Seo, J. H.; Takacs, C. J.; Seifter, J.; Heeger, A. J. Advanced Materials 2011, 23, 1679.

${ }^{3}$ Ball, M.; Fowler, B.; Li, P.; Joyce, L. A.; Li, F.; Liu, T.; Paley, D.; Zhong, Y.; Li, H.; Xiao, S.; Ng, F.; Steigerwald, M. L.; Nuckolls, C. J. Am. Chem. Soc. 2015, 137, 9982.

${ }^{4}$ Rajasingh, P.; Cohen, R.; Shirman, E.; Shimon, L. J. W.; Rybtchinski, B. J. Org. Chem. 2007, 72, 5973. 